\title{
Isotopic Labeling Experiments Solve the Hedycaryol Problem
}

Houchao Xu, ${ }^{\dagger}$ Nathalie D. Lackus, ${ }^{\S}$ Tobias G. Köllner,§ and Jeroen S. Dickschat*,†

†Kekulé Institute for Organic Chemistry and Biochemistry, University of Bonn, Gerhard-DomagkStraße 1, 53121 Bonn, Germany

\$ax Planck Institute for Chemical Ecology, Hans-Knöll-Strasse 8, 07745 Jena, Germany

Email: dickschat@uni-bonn.de

\section{Table of contents}

Site-directed mutagenesis $\quad 2$

Protein expression and enzymatic preparation of hedycaryol 3

$\begin{array}{ll}\text { Spectroscopic methods } & 4\end{array}$

GC/MS analysis of enzymatic products $\quad 5$

$\begin{array}{lr}\text { Spectroscopic data for } \mathbf{1} \text { and } \mathbf{2} & 6\end{array}$

$\begin{array}{ll}\text { NMR data of } 2 & 7\end{array}$

$\begin{array}{lr}\text { NMR spectra of } 2 & 8\end{array}$

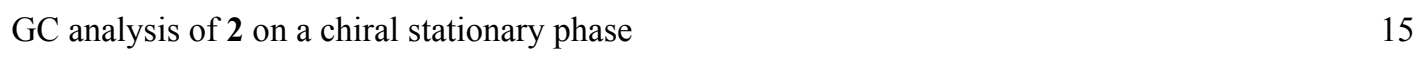

$\begin{array}{ll}\text { NMR spectra of } \mathbf{1} & 16\end{array}$

$\begin{array}{lr}\text { Tabulated overview of labeling experiments } & 18\end{array}$

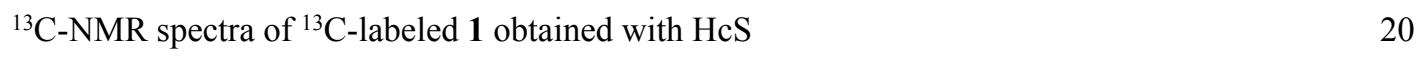

${ }^{13} \mathrm{C},{ }^{13} \mathrm{C}$-COSY NMR of $\left({ }^{13} \mathrm{C}_{15}\right)$-1 obtained with HcS 23

NMR data of the three conformers of $\mathbf{1} 26$

$\begin{array}{ll}\text { Stereoselective deuteration experiments for } \mathbf{1} & 29\end{array}$

${ }^{13} \mathrm{C}$-NMR spectra of ${ }^{13} \mathrm{C}$-labeled 1 obtained with PtTPS5-C403A 38

${ }^{13} \mathrm{C},{ }^{13} \mathrm{C}$-COSY NMR of $\left({ }^{13} \mathrm{C}_{15}\right)$-1 obtained with PtTPS5-C403A

$\begin{array}{ll}\text { Cope rearrangement of } 1 & 44\end{array}$

${ }^{13} \mathrm{C}$-NMR spectra of ${ }^{13} \mathrm{C}$-labeled $\mathbf{2}$ obtained by Cope rearrangement of $\mathbf{1} 45$

Stereoselective deuteration experiments for 1

$\begin{array}{ll}\text { References } & 51\end{array}$ 


\section{Site-directed mutagenesis}

For site-directed mutagenesis, the QuickChange II site-directed mutagenesis kit (Agilent) was used according to the manufacturer's instruction. The PCR-based mutagenesis protocol was performed with the PtTPS5 cDNA cloned into the expression vector pET100/D-TOPO (Thermo Fisher Scientific) using primers containing the desired mutations (Table S1).

Table S1. Primers used for site-directed mutagenesis.

\begin{tabular}{|c|c|}
\hline name & sequence $^{[a]}$ \\
\hline C403L-PtTPS5-fwd & GTGGTGGTGTGTATACTTCTctTTATCCTATGGCCGCAGTGGC \\
\hline C403L-PtTPS5-rev & GCCACTGCGGCCATAGGATAAagAGAAGTATACACACCACCAC \\
\hline C403S-PtTPS5-fwd & GTGGTGGTGTGTATACTTCTaGTTATCCTATGGCCGCAGTGGC \\
\hline C403S-PtTPS5-rev & GCCACTGCGGCCATAGGATAACtAGAAGTATACACACCACCAC \\
\hline W251F-PtTPS5-fwd & AGCTGAGGATTATCTCTAGGTttTGGATAGACTTGGACTTTGC \\
\hline W251F-PtTPS5-rev & GCAAAGTCCAAGTCTATCCAaaACCTAGAGATAATCCTCAGCT \\
\hline R288M PtTPS5-fwd & AGCCACAATTTGTACTTGCAAtGAGGTTCATAACAAAAGTACT \\
\hline R288M PtTPS5-rev & AGTACTTTTGTTATGAACCTCaTTGCAAGTACAAATTGTGGCT \\
\hline R265M-PtTPS5-fwd & CTACAAAGCTACCCTTTGCTatgGACAGGGTGATTGAGTGCTT \\
\hline R265M-PtTPS5-rev & AAGCACTCAATCACCCTGTCcatAGCAAAGGGTAGCTTTGTAG \\
\hline E379Q-PtTPS5-fwd & AAGGGCCTACCTTATTCAAGCCAGATGGTTCAACC \\
\hline E379Q-PtTPS5-rev & GGTTGAACCATCTGGCTTgAATAAGGTAGGCCCTT \\
\hline E379M-PtTPS5-fwd & AAGCAAGGGCCTACCTTATTatgGCCAGATGGTTCAACCAAGA \\
\hline E379M-PtTPS5-rev & TCTTGGTTGAACCATCTGGCcatAATAAGGTAGGCCCTTGCTT \\
\hline R442M-PtTPS5-fwd & СTCATCTGATATCGGTAtGCTCATGGATGACATTA \\
\hline R442M-PtTPS5-rev & TAATGTCATCCATGAGCaTACCGATATCAGATGAG \\
\hline Y521F-PtTPS5-fwd & TATCATAGACGTTGTATttAAGGATTATGATGGCT \\
\hline Y521F-PtTPS5-rev & AGCCATCATAATCCTTaаATACAACGTCTATGATA \\
\hline C403A-PtTPS5-fwd & GTGGTGGTGTGTATACTTCTgccTATCCTATGGCCGCAGTGGC \\
\hline C403A-PtTPS5-rev & GCCACTGCGGCCATAGGATAggcAGAAGTATACACACCACCAC \\
\hline C403Y-PtTPS5-fwd & TGGTGTGTATACTTCTTaTTATCCTATGGCCGCAG \\
\hline C403Y-PtTPS5-rev & CTGCGGCCATAGGATAAtAAGAAGTATACACACCA \\
\hline Y $404 \mathrm{~F}-\mathrm{PtTPS} 5-\mathrm{fwd}$ & TGTGTATACTTCTTGTT七TCCTATGGCCGCAGTGG \\
\hline Y404F-PtTPS5-rev & CCACTGCGGCCATAGGAaAACAAGAAGTATACACA \\
\hline Y $404 \mathrm{~A}-\mathrm{PtTPS} 5-\mathrm{fwd}$ & GTGGTGTGTATACTTCTTGTgcaCCTATGGCCGCAGTGGCATG \\
\hline Y404A-PtTPS5-rev & CATGCCACTGCGGCCATAGGtgcACAAGAAGTATACACACCAC \\
\hline
\end{tabular}

[a] Nucleotides deviating from original sequence are shown in small bold letters. 


\section{Protein expression and purification}

The expression strain Escherichia coli BL21 (DE3) was transformed with the plasmid constructs by electroporation. The cells were plated on LB agar containing ampicillin (100 mg mL-1, PtTPS5-C403A) or kanamycin (50 mg mL-1, HcS), and incubated at 37 ${ }^{\circ} \mathrm{C}$ overnight. A single colony was selected from the plate and inoculated in $10 \mathrm{~mL}$ of liquid LB medium at $37^{\circ} \mathrm{C}$ overnight. The fresh cultures were sequentially inoculated using $20 \mathrm{~mL} \mathrm{~L}^{-1}$ of precultures, followed by culturing at $37{ }^{\circ} \mathrm{C}$ with shaking in LB medium until an $\mathrm{OD}_{600}=0.4-0.6$ was reached. The cultures were cooled to $18{ }^{\circ} \mathrm{C}$ and protein expression was induced by addition of IPTG (400 mM in water, $1 \mathrm{~mL} \mathrm{~L}^{-1}$ ). The expression cultures were shaken at $18{ }^{\circ} \mathrm{C}$ overnight and then centrifuged at $14.610 \times \mathrm{g}\left(4{ }^{\circ} \mathrm{C}\right)$ for $2 \mathrm{~min}$. The supernatant was discarded and the cell pellet was resuspended in binding buffer $\left(10 \mathrm{~mL} \mathrm{~L}^{-1}\right.$ culture; $20 \mathrm{mM} \mathrm{Na}_{2} \mathrm{HPO}_{4}, 500 \mathrm{mM} \mathrm{NaCl}, 20$ $\mathrm{mM}$ imidazole, $1 \mathrm{mM} \mathrm{MgCl}, \mathrm{pH}=7.4,4{ }^{\circ} \mathrm{C}$ ). The resulting suspension was subjected to ultra-sonication for cell lysis. The cell debris was removed by centrifugation $(14,610$ $\mathrm{x} \mathrm{g}, 15 \mathrm{~min}, 4{ }^{\circ} \mathrm{C}$ ) and the supernatant was loaded onto a $\mathrm{Ni}^{2+}$-NTA affinity chromatography column (Super Ni-NTA, Generon, Slough, UK). The column was washed with binding buffer $\left(2 \times 10 \mathrm{~mL} \mathrm{~L}^{-1}\right.$ culture $)$, and the desired His-tagged protein was eluted using elution buffer ( $10 \mathrm{~mL} \mathrm{~L}^{-1}$ culture, $20 \mathrm{mM} \mathrm{Na} \mathrm{HPO}_{4}, 500 \mathrm{mM} \mathrm{NaCl}, 500$ $\mathrm{mM}$ imidazole, $1 \mathrm{mM} \mathrm{MgCl}_{2}, \mathrm{pH}=7.4,4^{\circ} \mathrm{C}$ ). Fractions containing protein were pooled, analysed by Bradford assay to determine the protein concentration (PtTPS5-C403A: $0.63 \mathrm{mg} \mathrm{mL}^{-1}$, HcS: $2.2 \mathrm{mg} \mathrm{mL}^{-1}$ ) and by SDS-PAGE (Figure S1).

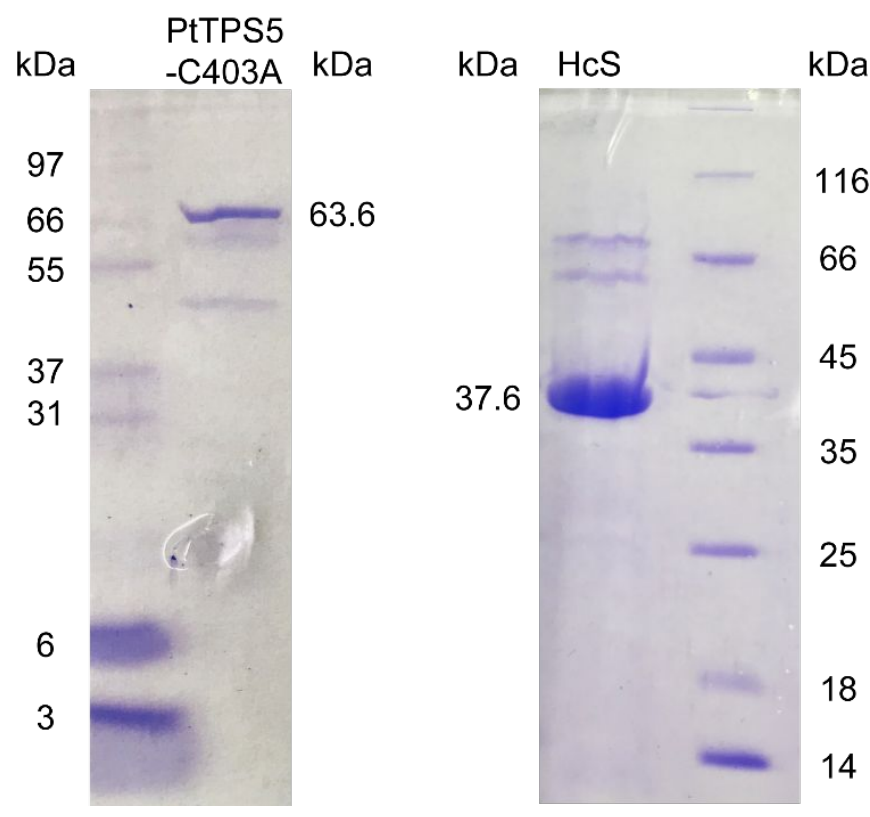

Figure S1. SDS-PAGE of purified PtTPS5-C403A and HcS.

\section{Preparative scale incubation for isolation of hedycaryol}

For the preparative scale incubation, $\mathrm{FPP}(80 \mathrm{mg})$ was dissolved in $\mathrm{NH}_{4} \mathrm{HCO}_{3}$ solution $(40 \mathrm{~mL}, 25 \mathrm{mM})$, followed by addition of incubation buffer $(200 \mathrm{~mL}, 50 \mathrm{mM}$ Tris, $10 \mathrm{mM}$ $\mathrm{MgCl}_{2}, 20$ vol-\% glycerol, $\left.\mathrm{pH} 8.2\right)$ and protein elution fraction ( $\left.80 \mathrm{~mL}\right)$. The enzymatic reaction mixture was shaken at $30{ }^{\circ} \mathrm{C}$ overnight and then extracted with pentane $(3 \mathrm{x}$ $200 \mathrm{~mL}$ ). The organic layers were dried with $\mathrm{MgSO}_{4}$ and concentrated under reduced pressure. The crude product was dissolved in $\mathrm{C}_{6} \mathrm{D}_{6}(0.5 \mathrm{~mL})$ and analyzed by NMR spectrometer directly. 


\section{NMR spectroscopy}

NMR spectra were recorded at $298 \mathrm{~K}$ on a Bruker (Billerica, MA, USA) Avance I (500 $\mathrm{MHz})$, Avance III HD Prodigy $(500 \mathrm{MHz})$ or Avance III HD Cryo $(700 \mathrm{MHz}) \mathrm{NMR}$ spectrometer. Spectra were measured in $\mathrm{C}_{6} \mathrm{D}_{6}$ and referenced against solvent signals $\left({ }^{1} \mathrm{H}-\mathrm{NMR}\right.$, residual proton signal: $\left.\delta=7.16 \mathrm{ppm} ;{ }^{13} \mathrm{C}-\mathrm{NMR}: \delta=128.06 \mathrm{ppm}\right) \cdot{ }^{[1]}$

\section{GC/MS}

GC/MS analyses were carried out on a 7890B/5977A series gas chromatography/mass selective detector (Agilent, Santa Clara, CA, USA). The GC was equipped with an HP5-MS fused silica capillary column $(30 \mathrm{~m}, 0.25 \mathrm{~mm}$ i. d., 0.50 $\mu \mathrm{m}$ film; Agilent) and operated using the settings 1) inlet pressure: $77.1 \mathrm{kPa}$, He at $23.3 \mathrm{~mL} \mathrm{~min}^{-1}, 2$ ) injection volume: $1 \mu \mathrm{L}, 3$ ) temperature program: $5 \mathrm{~min}$ at $50{ }^{\circ} \mathrm{C}$ then increasing 5 or $10^{\circ} \mathrm{C} \mathrm{min}-1$ to $\left.320^{\circ} \mathrm{C}, 4\right) 60 \mathrm{~s}$ valve time, and 5) carrier gas: He at 1.2 $\mathrm{mL} \mathrm{min}^{-1}$. The MS was operated with settings 1) source: $\left.230^{\circ} \mathrm{C}, 2\right)$ transfer line: 250 ${ }^{\circ} \mathrm{C}$, 3) quadrupole: $150{ }^{\circ} \mathrm{C}$ and 4) electron energy: $70 \mathrm{eV}$.

\section{Chiral GC}

GC with a homochiral stationary phase was carried out on an Agilent 7820A GC system equipped with an FID detector and an Agilent Cyclosil-B capillary column (30 $\mathrm{m}, 0.25 \mathrm{~mm}$ inner diameter, $0.25 \mu \mathrm{m}$ film). The GC was programmed as follows: starting from $80{ }^{\circ} \mathrm{C}$ for $5 \mathrm{~min}$, increasing with $2{ }^{\circ} \mathrm{C} \mathrm{min}-1$ to $220^{\circ} \mathrm{C}$, while holding this temperature for $5 \mathrm{~min}$. Inlet temperature: $250^{\circ} \mathrm{C}$, injection volume: $1 \mu \mathrm{L}$, carrier gas: $\mathrm{H}_{2}\left(2.3 \mathrm{~mL} \mathrm{~min}^{-1}\right)$.

\section{Optical rotation}

Optical rotations were recorded on a Modular Compact Polarimeter MCP 100 (Anton Paar, Graz, Austria). The temperature setting was $25^{\circ} \mathrm{C}$; the wavelength of the light used was $589 \mathrm{~nm}$ (sodium $D$ line); the path-length was $10 \mathrm{~cm}$, the compound concentrations $c$ are given in $\mathrm{g} 100 \mathrm{~mL}^{-1}$. 
A)

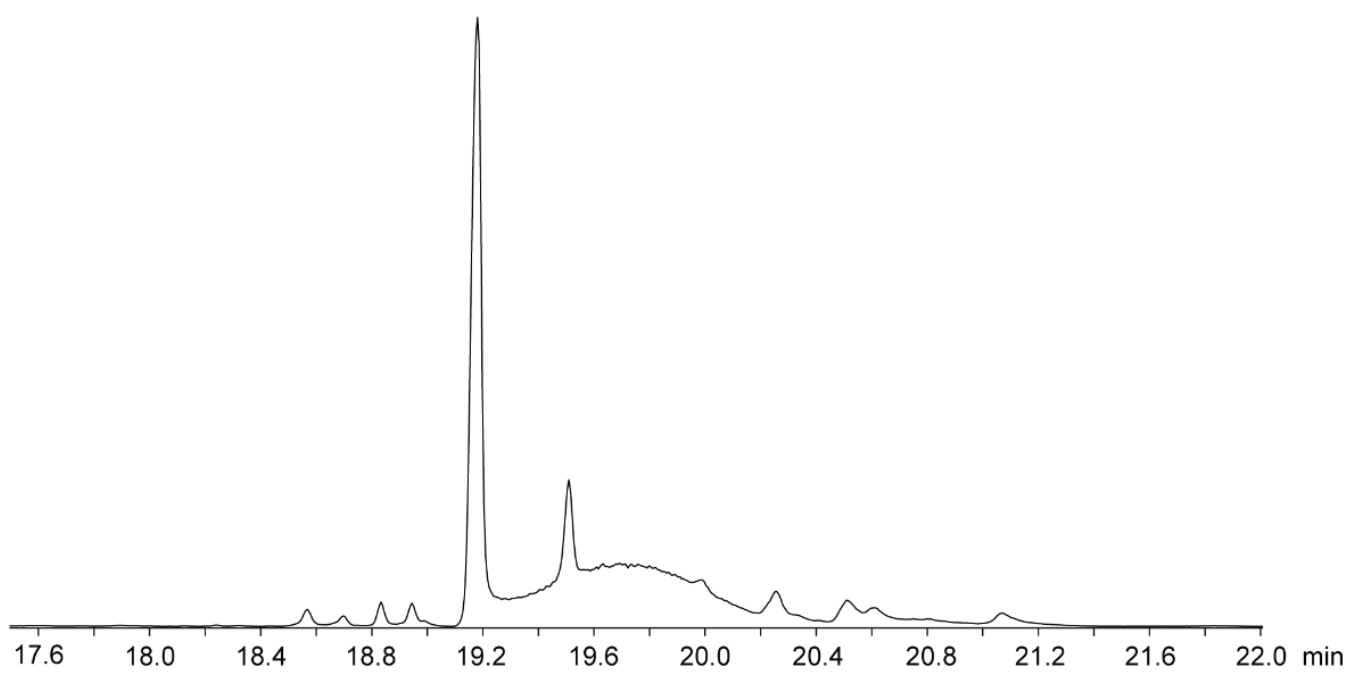

B)

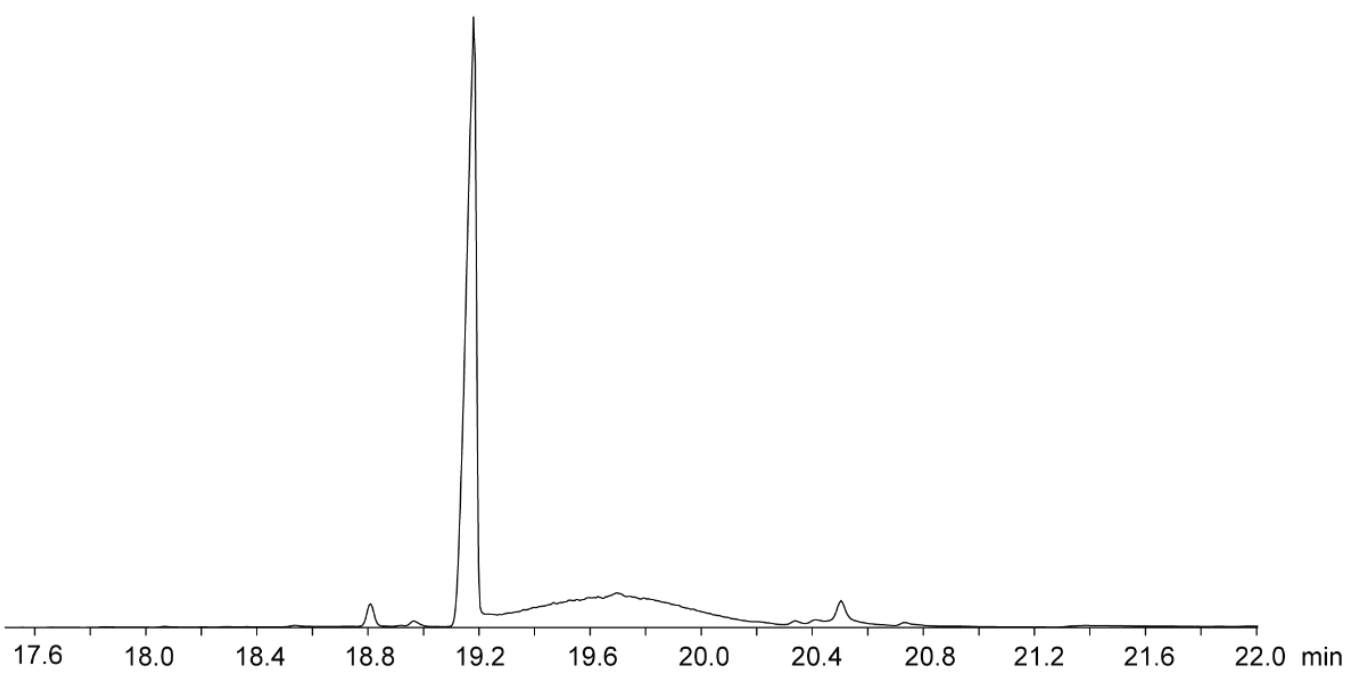

C)

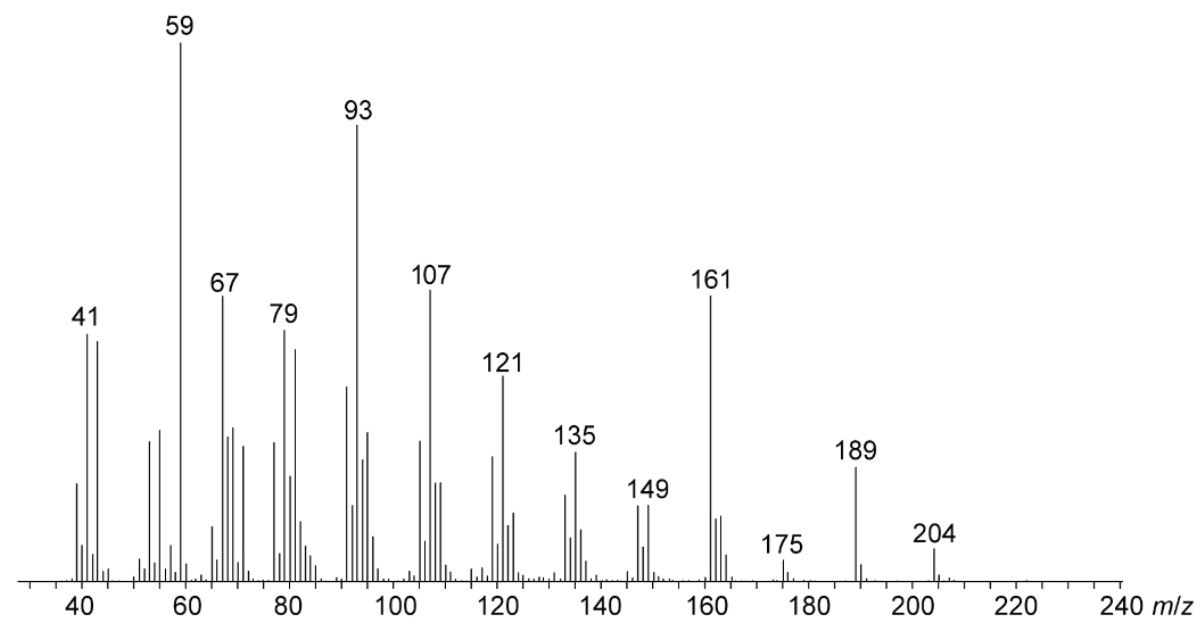

Figure S2. GC/MS analysis of extracts from enzyme incubations. Total ion chromatogram of products obtained from FPP with A) HcS and B) PtTPS5-C403A. C) El mass spectrum of elemol (2) formed by Cope rearrangement of hedycaryol (1) during GC analysis. 
(S)-Hedycaryol ((S)-1, from HcS). Colorless oil. Yield: $20 \mathrm{mg}(0.09 \mathrm{mmol}, 43 \%)$. Optical rotation: $[\alpha]_{D}{ }^{25}=-21.3\left(c 0.29, \mathrm{C}_{6} \mathrm{H}_{6}\right)$. NMR spectroscopy: cf. Tables S4 - S6. GC/MS: cf. Figure S2.

$(R)$-Hedycaryol ((R)-1, from PtTPS5-C403A). Colorless oil. GC/MS: cf. Figure S2.

\section{Cope rearrangement of 1}

The Cope rearrangement of $(S)-1$ (from HcS, $25 \mathrm{mg}, 0.11 \mathrm{mmol}$ ) was conducted in benzene $(1.5 \mathrm{~mL})$ in a pressure tube $(2 \mathrm{~mL})$. The tube was tightly closed and heated to $130{ }^{\circ} \mathrm{C}$ with oil bath for $6 \mathrm{~h}$. The solvent was removed under reduced pressure and the product was purified by column chromatography on silica gel (pentane / diethyl ether $=4: 1$ ). The Cope rearrangement of $(R)-1$ (from PtTPS5-C403A) was performed analogously with crude enzyme product $(4 \mathrm{mg})$.

(+)-Elemol ((+)-2, from (S)-1). Colorless oil. Yield: $19 \mathrm{mg}(0.09 \mathrm{mmol}, 82 \%)$. Optical rotation: $[\alpha]_{\mathrm{D}}^{25}=+10.0\left(\mathrm{c} 0.21, \mathrm{C}_{6} \mathrm{H}_{6}\right)$. TLC (pentane / diethyl ether = 1:1): $R_{\mathrm{f}}=0.52$. GC (HP5-MS): I = 1564. IR (diamond ATR): $\tilde{v} / \mathrm{cm}^{-1}=2970$ (s), 2939 (s), 2864 (w), 1738 (s), 1441 (w), 1374 (s), 1228 (m), $1217(\mathrm{~m}), 909$ (m), 890 (m). HR-MS (APCl): calc. for $\left[\mathrm{C}_{15} \mathrm{H}_{25}\right]^{+} \mathrm{m} / \mathrm{z}=205.1951$; found: $\mathrm{m} / \mathrm{z}=205.1952$. NMR spectroscopy: cf. Table S2.

$(-)$-Elemol ((-)-2, from $(R)-1)$. Colorless oil. Yield: $1.4 \mathrm{mg}$. Optical rotation: $[\alpha]_{D}{ }^{25}=-$ 1.4 (c $\left.0.14, \mathrm{C}_{6} \mathrm{H}_{6}\right)$. TLC (pentane / diethyl ether $\left.=1: 1\right): R_{\mathrm{f}}=0.52$. GC (HP5-MS): $I=$ 1564. IR (diamond ATR): $\tilde{v} / \mathrm{cm}^{-1}=2970$ (s), 2939 (s), 2864 (w), 1738 (s), 1441 (w), $1374(\mathrm{~s}), 1228(\mathrm{~m}), 1217(\mathrm{~m}), 909(\mathrm{~m}), 890(\mathrm{~m})$. HR-MS (APCl): calc. for $\left[\mathrm{C}_{15} \mathrm{H}_{25}\right]^{+} \mathrm{m} / \mathrm{z}$ $=205.1951$; found: $m / z=205.1950$. NMR spectral data were identical to those of $(+)-$ 2. 


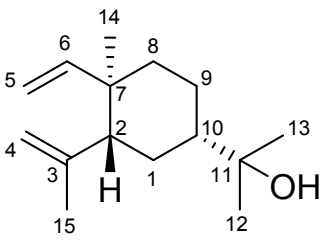

2

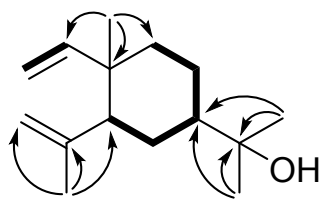

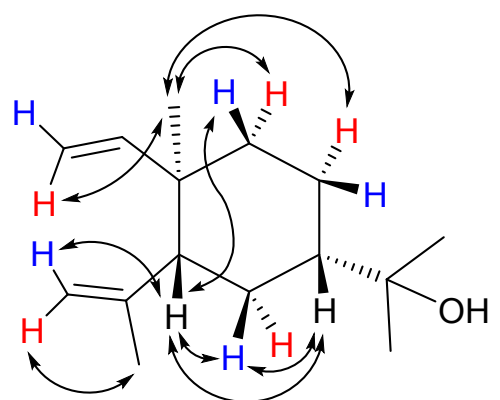

Figure S3. Structure elucidation of 2. Bold: ${ }^{1} \mathrm{H},{ }^{1} \mathrm{H}-\mathrm{COSY}$, single headed arrows: key $\mathrm{HMBC}$, and double headed arrows: key NOESY correlations.

Table S2. NMR data of elemol (2) in $\mathrm{C}_{6} \mathrm{D}_{6}$ recorded at $298 \mathrm{~K}$.

\begin{tabular}{|c|c|c|c|}
\hline $\mathrm{C}^{[\mathrm{a}]}$ & type & ${ }^{13} C^{[b]}$ & ${ }^{1} \mathrm{H}^{[\mathrm{b}]}$ \\
\hline \multirow[t]{2}{*}{1} & $\mathrm{CH}_{2}$ & 28.8 & $1.64(\mathrm{~m}, \mathrm{H})$ \\
\hline & & & $1.42(\mathrm{~m}, \mathrm{H})$ \\
\hline 2 & $\mathrm{CH}$ & 53.0 & $1.89(\mathrm{dd}, J=12.9,3.3)$ \\
\hline 3 & $\mathrm{C}_{\mathrm{q}}$ & 148.0 & - \\
\hline \multirow[t]{2}{*}{4} & $\mathrm{CH}_{2}$ & 112.5 & $4.92(\mathrm{~m}, \mathrm{H})$ \\
\hline & & & $4.71(\mathrm{~m}, \mathrm{H})$ \\
\hline \multirow[t]{2}{*}{5} & $\mathrm{CH}_{2}$ & 110.1 & $4.96(\mathrm{dd}, J=17.5,1.4, \mathrm{H})$ \\
\hline & & & $4.94(\mathrm{dd}, J=10.8,1.4, \mathrm{H})$ \\
\hline 6 & $\mathrm{CH}$ & 150.6 & $5.81(\mathrm{dd}, J=17.5,10.8)$ \\
\hline 7 & $\mathrm{C}_{\mathrm{q}}$ & 40.0 & - \\
\hline \multirow[t]{2}{*}{8} & $\mathrm{CH}_{2}$ & 40.2 & $1.42(\mathrm{~m}, \mathrm{H})$ \\
\hline & & & $1.34(\mathrm{~m}, \mathrm{H})$ \\
\hline \multirow[t]{2}{*}{9} & $\mathrm{CH}_{2}$ & 22.8 & $1.51(\mathrm{~m}, \mathrm{H})$ \\
\hline & & & $1.15(\mathrm{~m}, \mathrm{H})$ \\
\hline 10 & $\mathrm{CH}$ & 49.5 & $1.15(\mathrm{~m})$ \\
\hline 11 & $\mathrm{C}_{\mathrm{q}}$ & 71.8 & - \\
\hline 12 & $\mathrm{CH}_{3}$ & 27.3 & $1.01(\mathrm{~s})$ \\
\hline 13 & $\mathrm{CH}_{3}$ & 27.5 & $1.02(\mathrm{~s})$ \\
\hline 14 & $\mathrm{CH}_{3}$ & 16.8 & $0.99(\mathrm{~s})$ \\
\hline \multirow[t]{2}{*}{15} & $\mathrm{CH}_{3}$ & 25.2 & $1.72(\mathrm{dd}, J=1.4,0.8)$ \\
\hline & $\mathrm{OH}$ & - & 0.72 (br s) \\
\hline
\end{tabular}

[a] Carbon numbering and color code for diastereotopic hydrogens as shown in Figure S3. [b] Chemical shifts $\delta$ in ppm; multiplicity: $s=$ singlet, $d=$ doublet, $m=$ multiplet, br $=$ broad; coupling constants $\mathrm{J}$ are given in Hertz. 

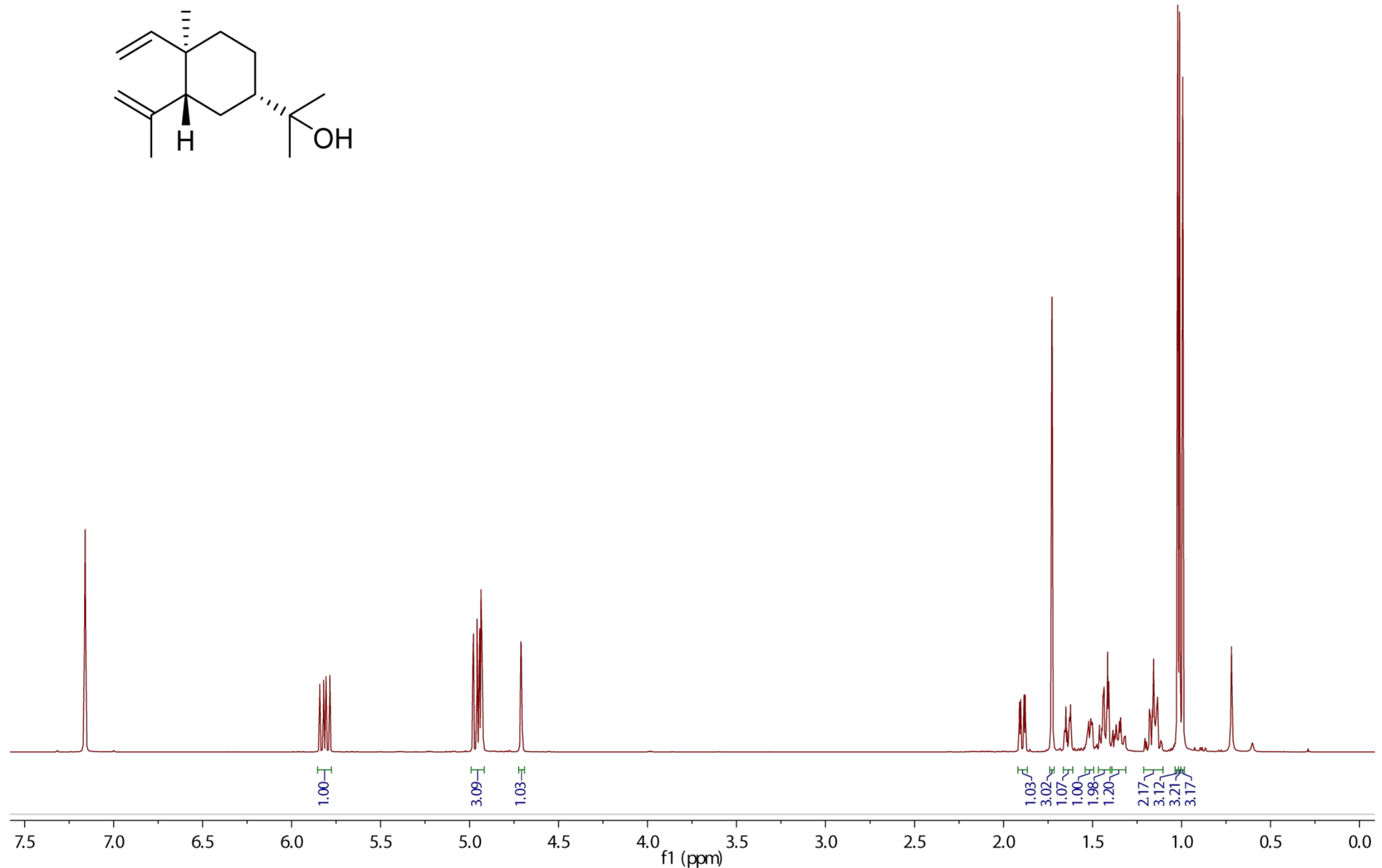

Figure S4. ${ }^{1} \mathrm{H}-\mathrm{NMR}$ spectrum of $2\left(700 \mathrm{MHz}, \mathrm{C}_{6} \mathrm{D}_{6}\right)$. 


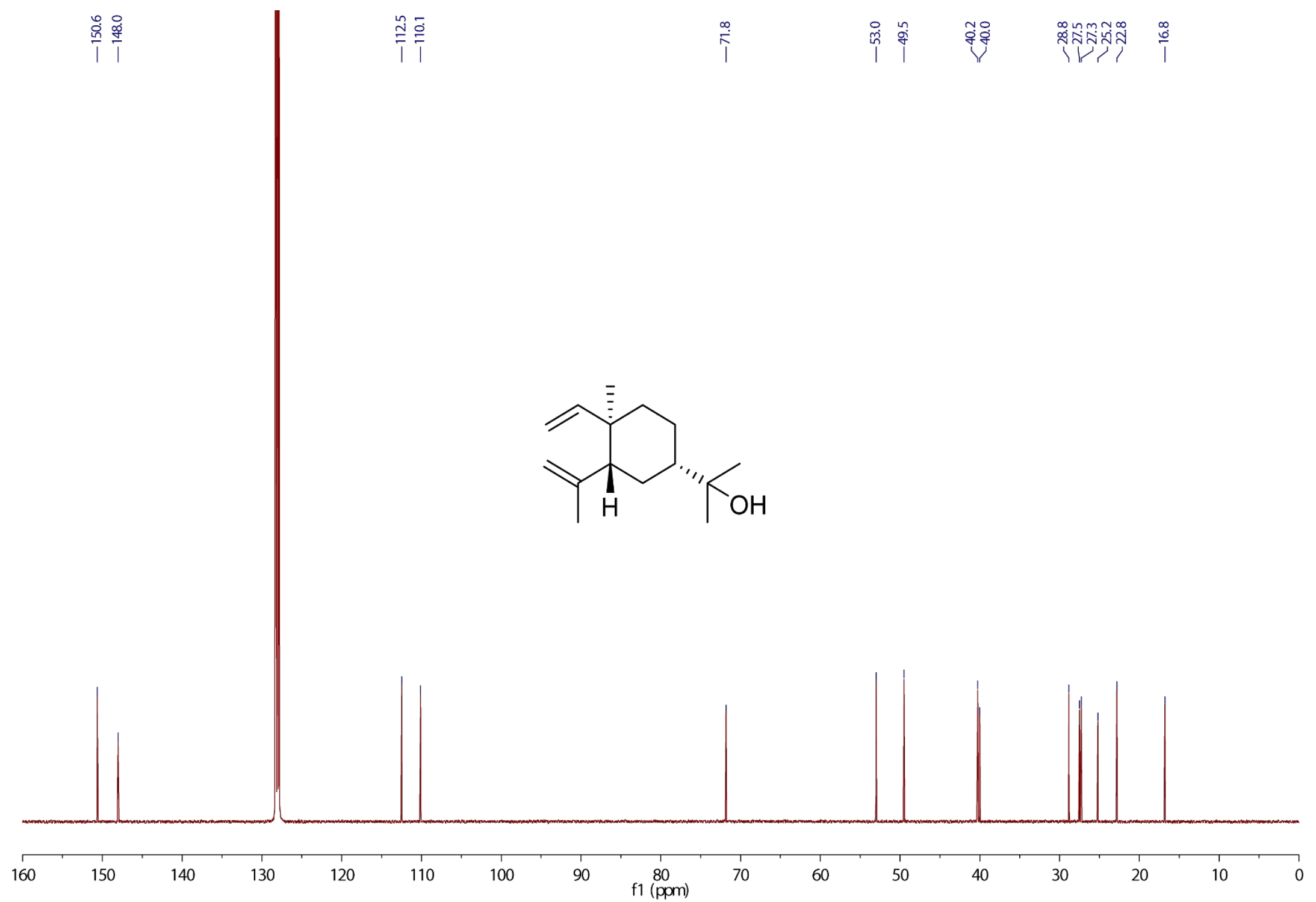

Figure S5. ${ }^{13} \mathrm{C}-\mathrm{NMR}$ spectrum of $2\left(176 \mathrm{MHz}, \mathrm{C}_{6} \mathrm{D}_{6}\right)$. 


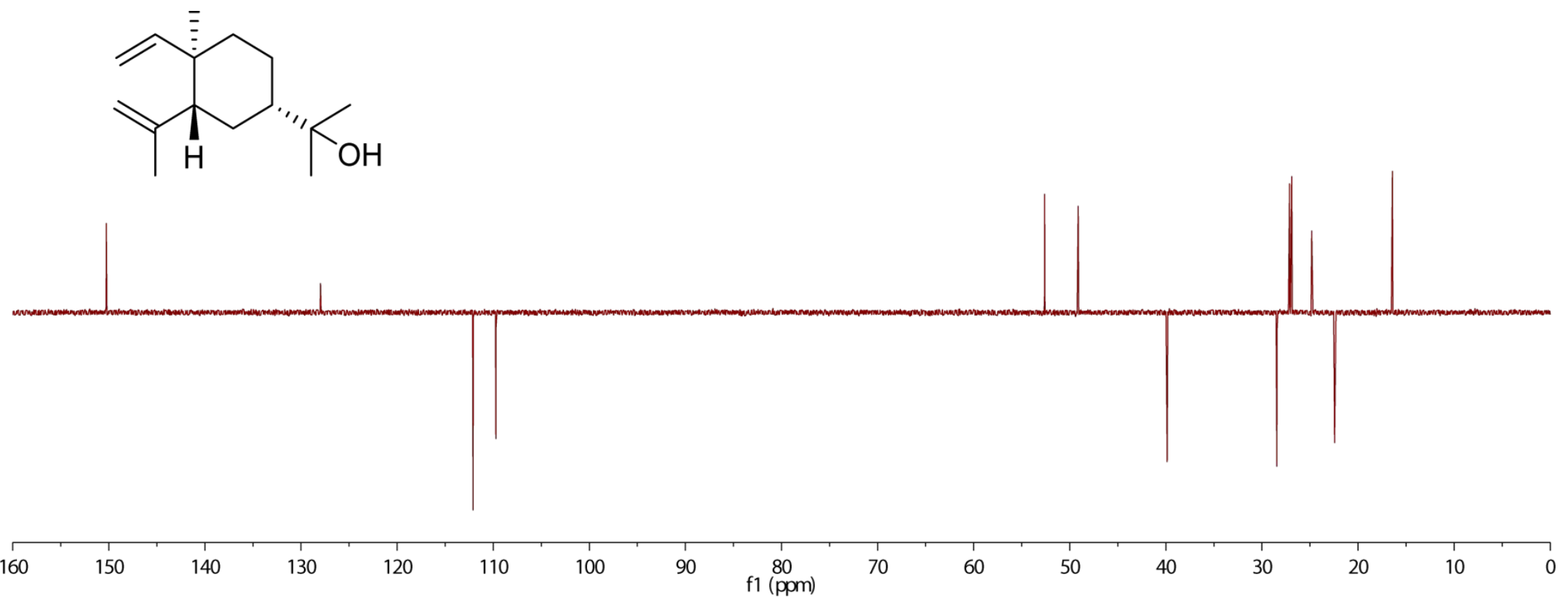

Figure S6. ${ }^{13} \mathrm{C}$-DEPT spectrum of $2\left(176 \mathrm{MHz}, \mathrm{C}_{6} \mathrm{D}_{6}\right)$. 


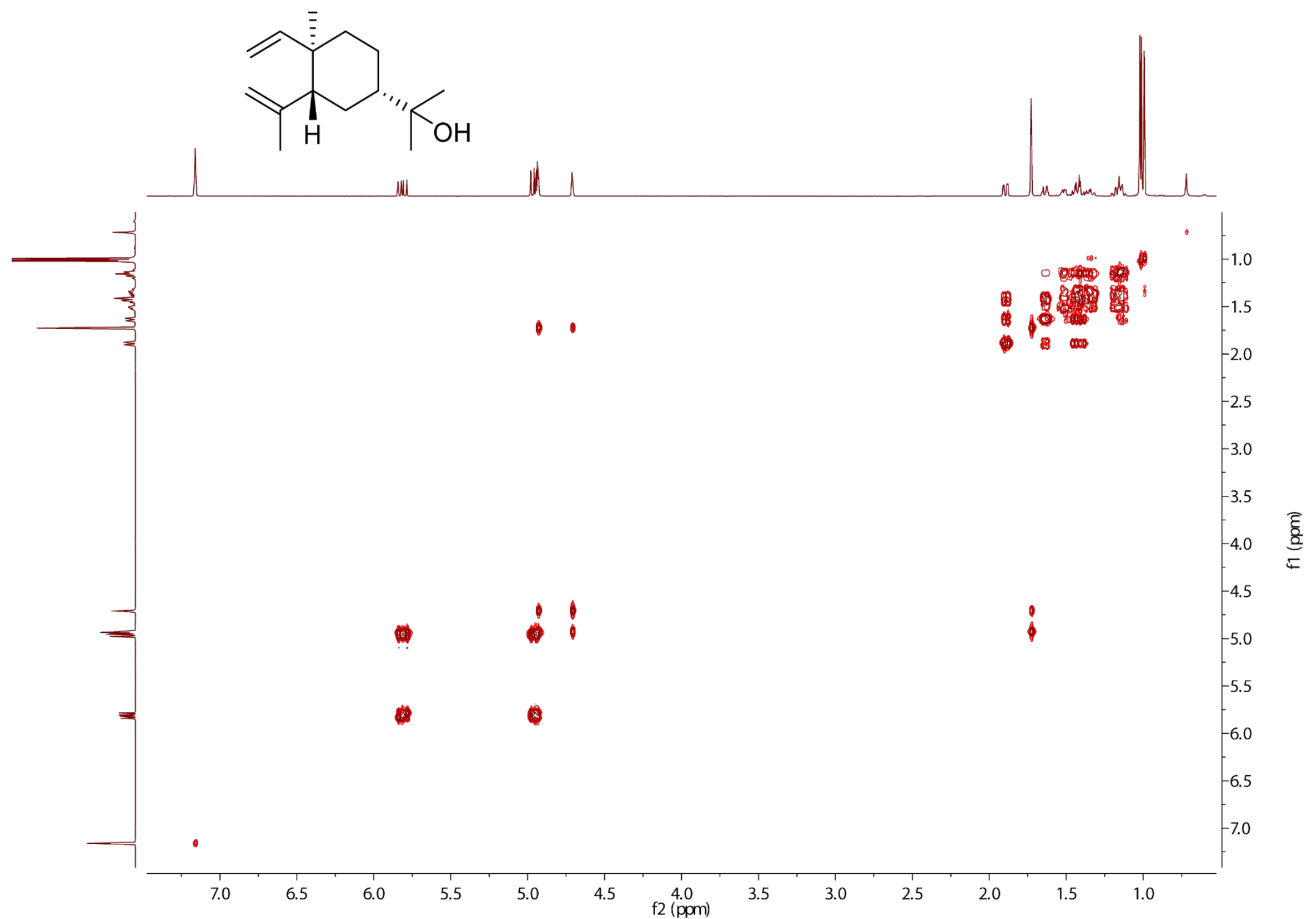

Figure S7. ${ }^{1} \mathrm{H}-{ }^{1} \mathrm{H}-\mathrm{COSY}$ spectrum of $2\left(700 \mathrm{MHz}, \mathrm{C}_{6} \mathrm{D}_{6}\right)$. 


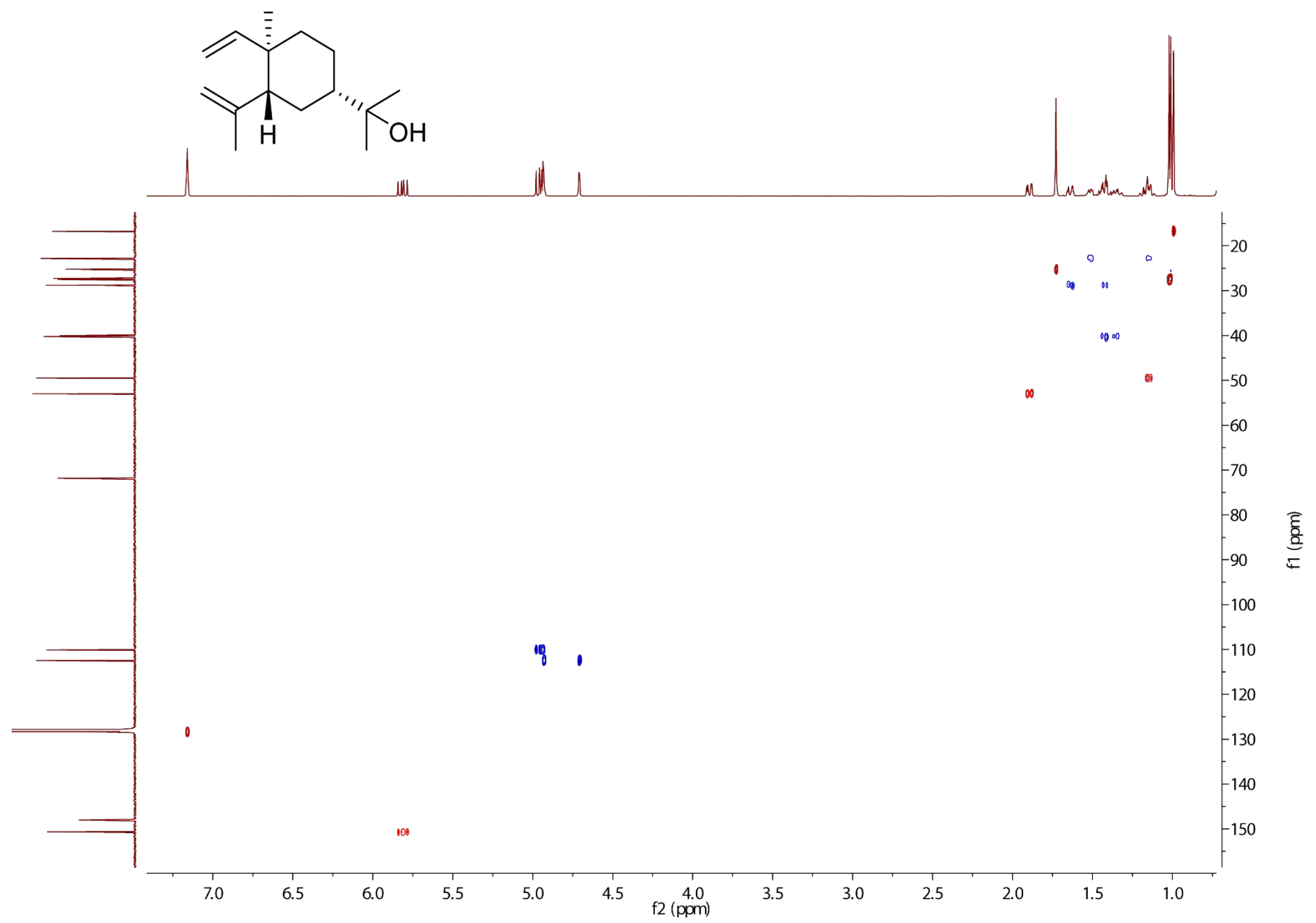

Figure S8. HSQC spectrum of $2\left(\mathrm{C}_{6} \mathrm{D}_{6}\right)$. 


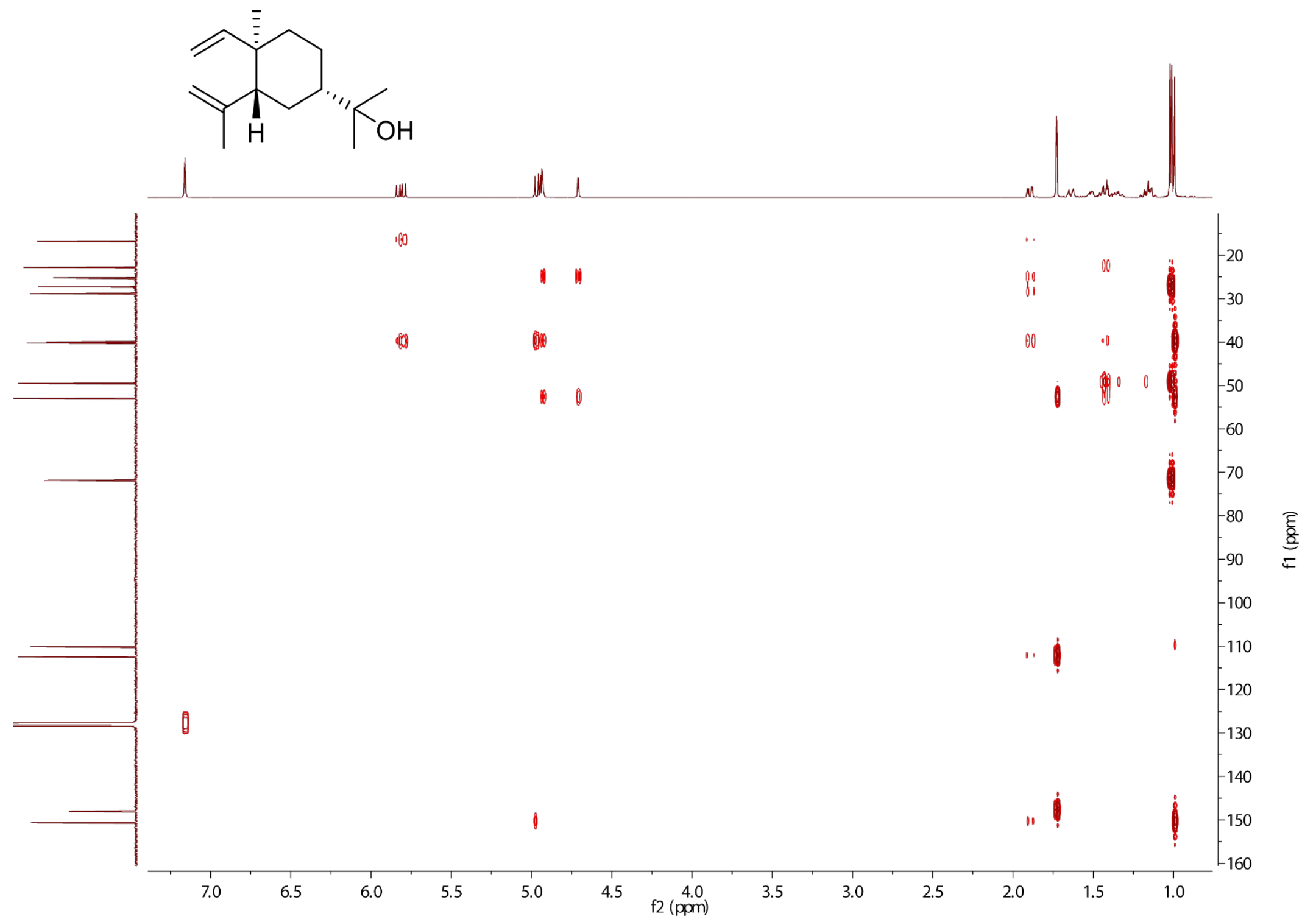

Figure S9. HMBC spectrum of $2\left(C_{6} D_{6}\right)$. 


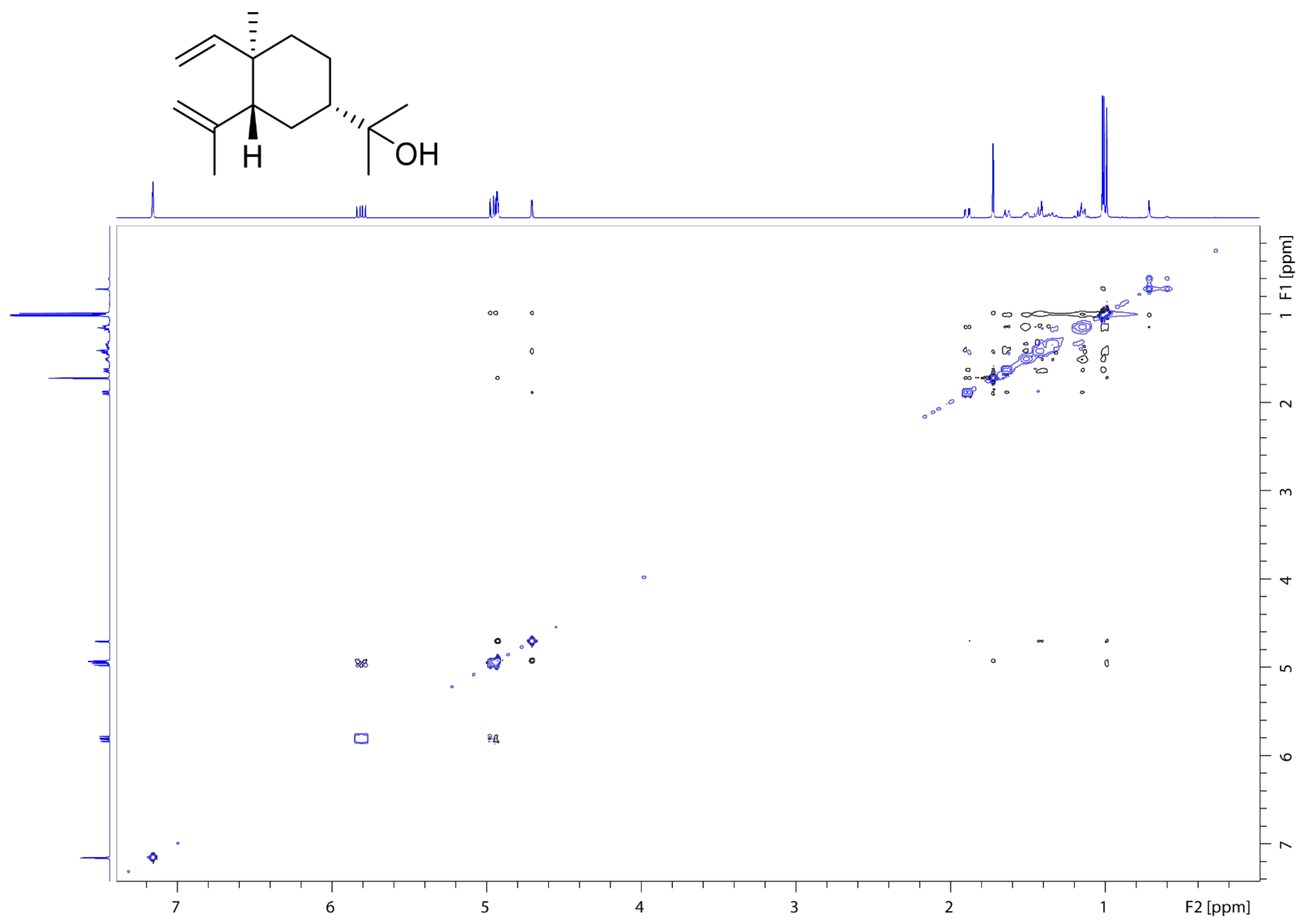

Figure S10. NOESY spectrum of $2\left(C_{6} D_{6}\right)$. 

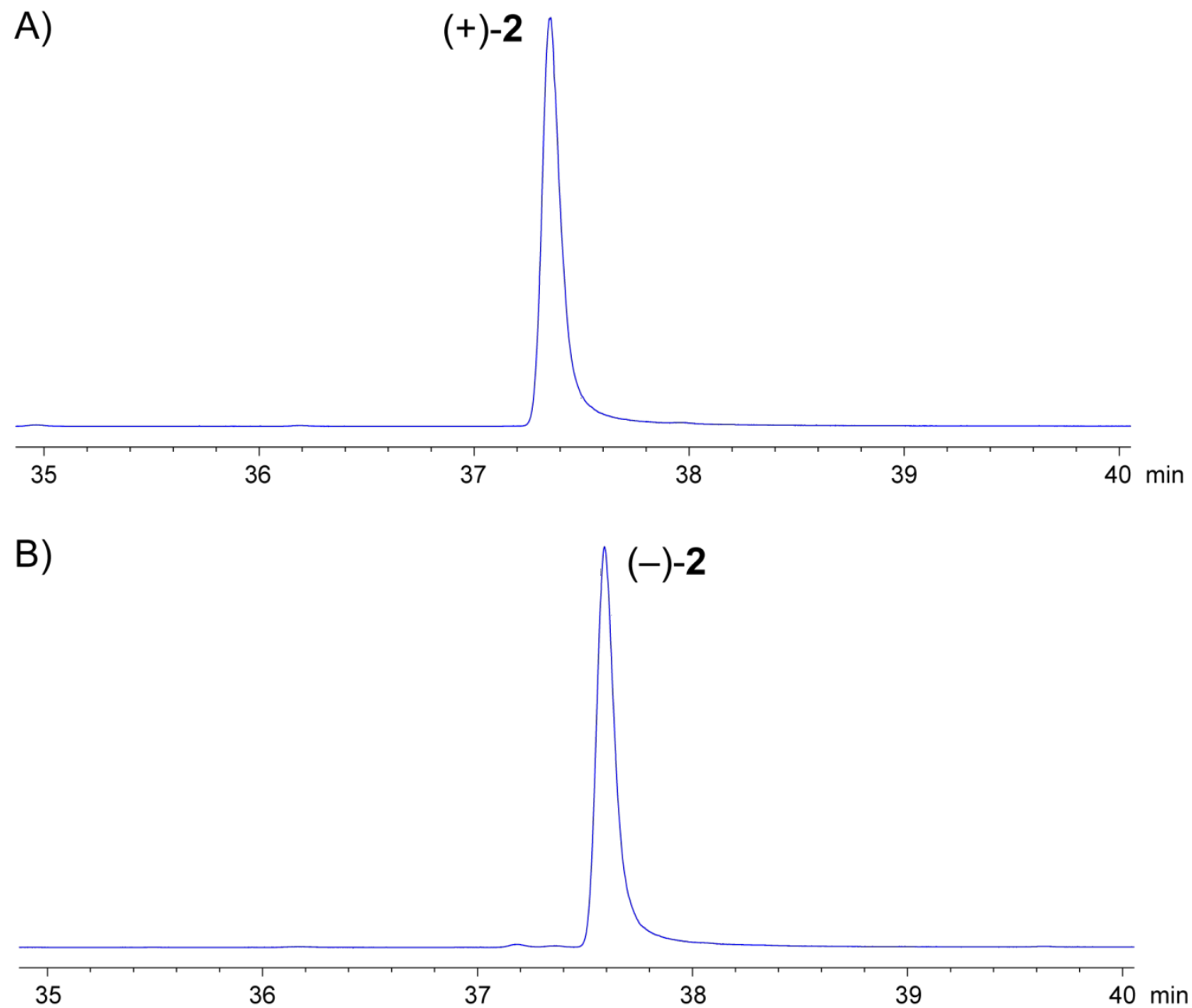

C)

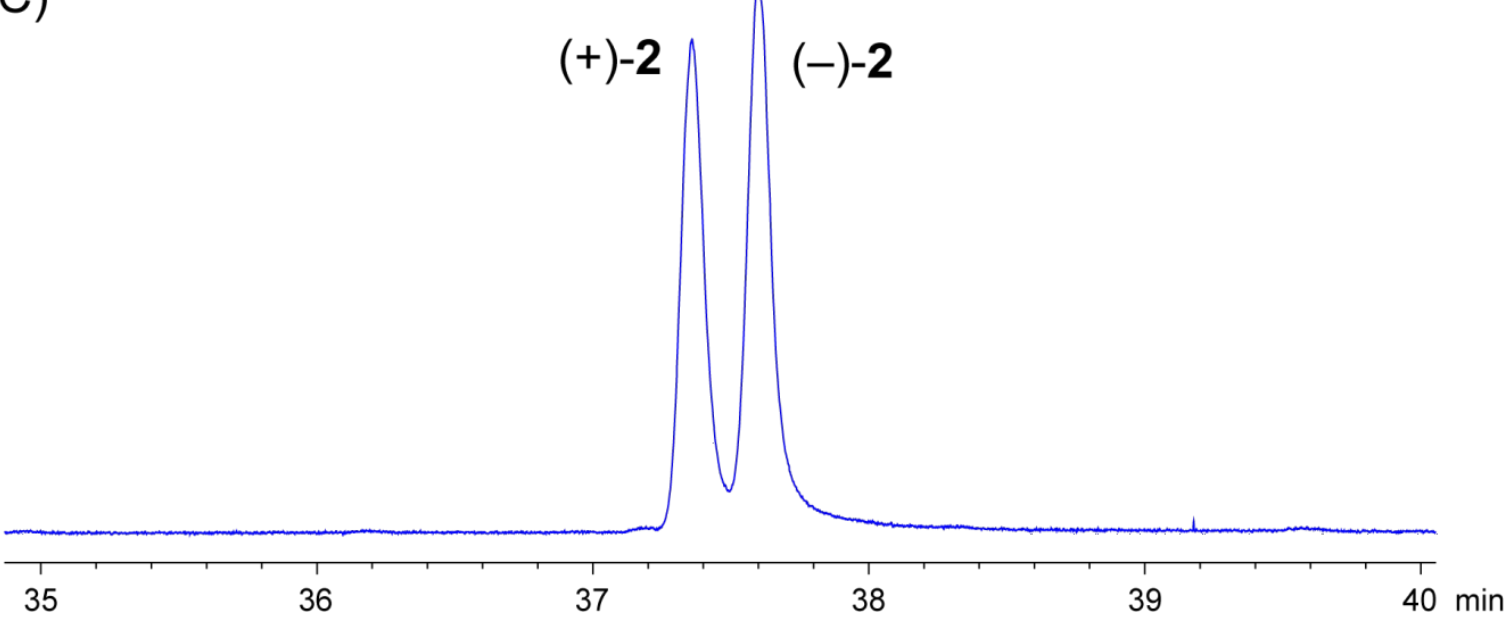

Figure S11. GC analysis of elemol on a chiral stationary phase. Gas chromatograms of A) (+)2 obtained by Cope rearrangement of (S)-1 from HcS, B) (-)-2 obtained by Cope rearrangement of $(R)-1$ from PpTPS5-C403A, C) a pseudoracemic mixture of $(+)-2$ and $(-)-2$ prepared by mixing the enzyme products in a 1:1 ratio. 


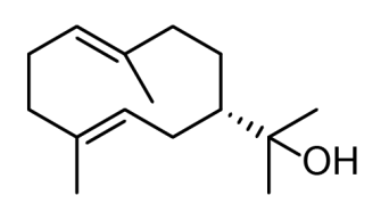

1

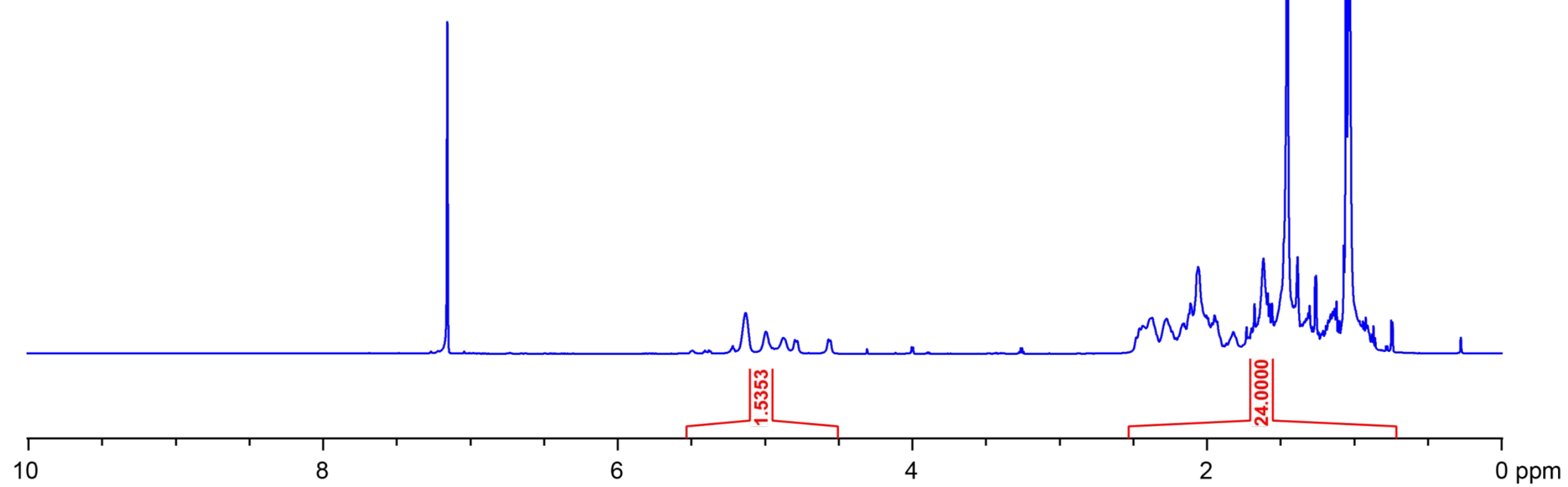

Figure S12. ${ }^{1} \mathrm{H}-\mathrm{NMR}$ spectrum of $1\left(700 \mathrm{MHz}, \mathrm{C}_{6} \mathrm{D}_{6}\right)$. 

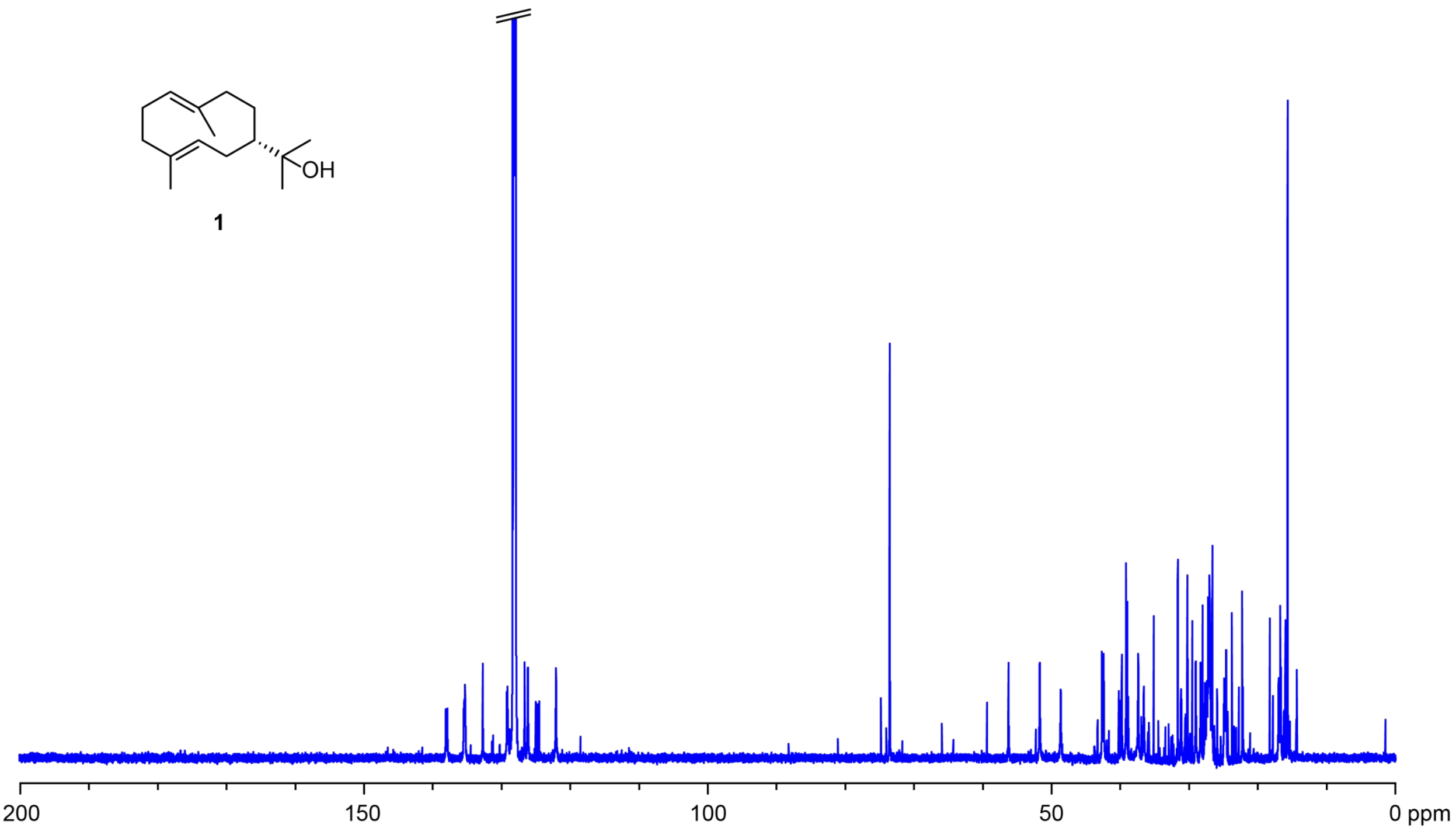

Figure S13. ${ }^{13} \mathrm{C}-\mathrm{NMR}$ spectrum of $1\left(176 \mathrm{MHz}, \mathrm{C}_{6} \mathrm{D}_{6}\right.$ ). 


\section{Isotopic labeling experiments}

Isotopic labelling experiments were conducted using the substrates and enzymes as listed in Table S3. For entries $1-15,17-20,25-36$ and $38-39$, the reaction mixtures contained substrates ( $1 \mathrm{mg}$ each) in aqueous $\mathrm{NH}_{4} \mathrm{HCO}_{3}$ solution ( $1 \mathrm{~mL}, 25 \mathrm{~mm}$ ), enzyme elution fractions (2 $\mathrm{mL}$ each) and incubation buffer $(5 \mathrm{~mL})$. For entries $21-24$ and 37 , the reaction mixtures contained substrates (1 mg each) in aqueous $\mathrm{NH}_{4} \mathrm{HCO}_{3}$ solution $(1 \mathrm{~mL}, 25 \mathrm{~mm}$ ) and incubation buffer $(5 \mathrm{~mL})$. Cell lysate $(2 \mathrm{~mL})$ was added and used without enzyme purification, because enzyme incubations with purified PtTPS5-C403A in combination with FPPS failed to give products for unknown reason. For entries 16 and 40, the reaction mixtures contained substrates ( $3 \mathrm{mg}$ each) in aqueous $\mathrm{NH}_{4} \mathrm{HCO}_{3}$ solution ( $2 \mathrm{~mL}, 25 \mathrm{~mm}$ ), enzyme elution fractions (4 mL each) and incubation buffer $(10 \mathrm{~mL})$. After incubation with shaking at $30{ }^{\circ} \mathrm{C}$ overnight, the reaction mixtures were extracted with $\mathrm{C}_{6} \mathrm{D}_{6}(0.6 \mathrm{~mL}+0.2 \mathrm{~mL})$. The extracts were dried with $\mathrm{MgSO}_{4}$ and analyzed by GC-MS and NMR.

Table S3. Summary of isotopic labeling experiments.

\begin{tabular}{|c|c|c|c|}
\hline entry[a] & substrates & enzymes / conditions & results shown in \\
\hline 1 & $\left(1-{ }^{13} \mathrm{C}\right) \mathrm{FPP}[2]$ & $\mathrm{HcS}^{[3]}$ & Figures S15, S23 \\
\hline 2 & $\left(2-{ }^{13} \mathrm{C}\right) \mathrm{FPP}[2]$ & $\mathrm{HcS}$ & Figures S14, S24 \\
\hline 3 & $\left(3-{ }^{13} \mathrm{C}\right) \mathrm{FPP}^{[2]}$ & $\mathrm{HcS}$ & Figure S14 \\
\hline 4 & $\left(4-{ }^{13} \mathrm{C}\right) \mathrm{FPP}^{[2]}$ & $\mathrm{HcS}$ & Figures S15, S25 \\
\hline 5 & $(5-13 \mathrm{C}) \mathrm{FPP}[2]$ & $\mathrm{HcS}$ & Figures S15, S26 \\
\hline 6 & $\left(6-{ }^{13} \mathrm{C}\right) \mathrm{FPP}[2]$ & $\mathrm{HcS}$ & Figures S14, S27 \\
\hline 7 & $\left(7-{ }^{13} \mathrm{C}\right) \mathrm{FPP}^{[2]}$ & $\mathrm{HcS}$ & Figure S14 \\
\hline 8 & $\left(8-{ }^{13} \mathrm{C}\right) \mathrm{FPP}[2]$ & $\mathrm{HcS}$ & Figures S15, S28 \\
\hline 9 & $\left(9-{ }^{13} \mathrm{C}\right) \mathrm{FPP}[2]$ & $\mathrm{HcS}$ & Figures S15, S29 \\
\hline 10 & $\left(10-{ }^{13} \mathrm{C}\right) \mathrm{FPP}[2]$ & $\mathrm{HcS}$ & Figures S15, S30 \\
\hline 11 & $\left(11-{ }^{13} \mathrm{C}\right) \mathrm{FPP}^{[2]}$ & $\mathrm{HcS}$ & Figures S14, S30 \\
\hline 12 & $\left(12-{ }^{13} \mathrm{C}\right) \mathrm{FPP}[2]$ & $\mathrm{HcS}$ & Figures S16, S30 \\
\hline 13 & $\left(9-{ }^{13} \mathrm{C}\right) \mathrm{GPP}[4]+\mathrm{IPP}$ & FPPS, ${ }^{[5]} \mathrm{HcS}$ & Figures S16, S31 \\
\hline 14 & $\left(14-{ }^{13} \mathrm{C}\right) \mathrm{FPP}[2]$ & $\mathrm{HcS}$ & Figures S16, S31 \\
\hline 15 & $\left(15-{ }^{13} \mathrm{C}\right) \mathrm{FPP}[2]$ & $\mathrm{HcS}$ & Figure S16 \\
\hline 16 & $\left({ }^{13} \mathrm{C}_{15}\right) \mathrm{FPP}[2]$ & $\mathrm{HcS}$ & Figures S17, S18, S19 \\
\hline 17 & $(R)-\left(1-{ }^{13} \mathrm{C}, 1-2 \mathrm{H}\right) \mathrm{IPP}[6]$ & IDI, ${ }^{[6,7]}$ FPPS, HcS & Figures S23, S26, S29 \\
\hline 18 & $(S)-\left(1-{ }^{13} \mathrm{C}, 1-2 \mathrm{H}\right) \mid \mathrm{PP}[6]$ & IDI, FPPS, HcS & Figures S23, S26, S29 \\
\hline 19 & DMAPP $+(E)-\left(4-{ }^{13} C, 4-{ }^{2} H\right) I P P[8]$ & FPPS, HcS & Figures S25, S28 \\
\hline 20 & DMAPP + (Z)-(4-13C,4-2H)IPP[8] & FPPS, HcS & Figures S25, S28 \\
\hline 21 & $(R)-\left(1-{ }^{13} \mathrm{C}, 1-2 \mathrm{H}\right) \mathrm{IPP}$ & IDI, FPPS, PtTPS5-C403A & Figures S23, S26, S29 \\
\hline 22 & $(S)-\left(1-{ }^{13} \mathrm{C}, 1-{ }^{2} \mathrm{H}\right) \mathrm{IPP}$ & IDI, FPPS, PtTPS5-C403A & Figures S23, S26, S29 \\
\hline 23 & DMAPP $+(E)-\left(4-{ }^{13} C, 4-{ }^{2} H\right) I P P$ & FPPS, PtTPS5-C403A & Figures S25, S28 \\
\hline 24 & DMAPP + (Z)-(4-13 C,4-2H)IPP & FPPS, PtTPS5-C403A & Figures S25, S28 \\
\hline 25 & $(1-13 \mathrm{C}) \mathrm{FPP}$ & PtTPS5-C403A & Figure S33 \\
\hline 26 & $\left(2-{ }^{13} \mathrm{C}\right) \mathrm{FPP}$ & PtTPS5-C403A & Figure S32 \\
\hline 27 & $\left(3-{ }^{13} \mathrm{C}\right) \mathrm{FPP}$ & PtTPS5-C403A & Figure S32 \\
\hline 28 & $\left(4-{ }^{13} \mathrm{C}\right) \mathrm{FPP}$ & PtTPS5-C403A & Figure S33 \\
\hline 29 & $\left(5-{ }^{13} \mathrm{C}\right) \mathrm{FPP}$ & PtTPS5-C403A & Figure S33 \\
\hline 30 & $\left(6-{ }^{13} \mathrm{C}\right) \mathrm{FPP}$ & PtTPS5-C403A & Figure S32 \\
\hline 31 & $(7-13 \mathrm{C}) \mathrm{FPP}$ & PtTPS5-C403A & Figure S32 \\
\hline 32 & $\left(8-{ }^{13} \mathrm{C}\right) \mathrm{FPP}$ & PtTPS5-C403A & Figure S33 \\
\hline
\end{tabular}




\begin{tabular}{|c|c|c|c|}
\hline 33 & $\left(9-{ }^{13} \mathrm{C}\right) \mathrm{FPP}$ & PtTPS5-C403A & Figure S33 \\
\hline 34 & $\left(10-{ }^{13} \mathrm{C}\right) \mathrm{FPP}$ & PtTPS5-C403A & Figure S33 \\
\hline 35 & $\left(11-{ }^{13} \mathrm{C}\right) \mathrm{FPP}$ & PtTPS5-C403A & Figure S32 \\
\hline 36 & $\left(12-{ }^{13} \mathrm{C}\right) \mathrm{FPP}$ & PtTPS5-C403A & Figure S34 \\
\hline 37 & $\left(9-{ }^{13} \mathrm{C}\right) \mathrm{GPP}+\mathrm{IPP}$ & FPPS, PtTPS5-C403A & Figure S34 \\
\hline 38 & $\left(14-{ }^{13} \mathrm{C}\right) \mathrm{FPP}$ & PtTPS5-C403A & Figure S34 \\
\hline 39 & $\left(15-{ }^{13} \mathrm{C}\right) \mathrm{FPP}$ & PtTPS5-C403A & Figure S34 \\
\hline 40 & $\left({ }^{13} \mathrm{C}_{15}\right) \mathrm{FPP}$ & PtTPS5-C403A & Figures S35, S36, S37 \\
\hline $41(1)$ & $(S)-\left(1-{ }^{13} C\right)-1$ & $130^{\circ} \mathrm{C}, 3 \mathrm{~h}, \mathrm{C}_{6} \mathrm{D}_{6}$ & Figure S38 \\
\hline $42(2)$ & $(S)-\left(2-{ }^{13} \mathrm{C}\right)-1$ & $130^{\circ} \mathrm{C}, 3 \mathrm{~h}, \mathrm{C}_{6} \mathrm{D}_{6}$ & Figure S38 \\
\hline $43(3)$ & $(S)-\left(3-{ }^{13} C\right)-1$ & $130^{\circ} \mathrm{C}, 3 \mathrm{~h}, \mathrm{C}_{6} \mathrm{D}_{6}$ & Figure S38 \\
\hline $44(4)$ & $(S)-\left(4-{ }^{13} C\right)-1$ & $130^{\circ} \mathrm{C}, 3 \mathrm{~h}, \mathrm{C}_{6} \mathrm{D}_{6}$ & Figure S38 \\
\hline $45(5)$ & $(S)-\left(5-{ }^{13} C\right)-1$ & $130^{\circ} \mathrm{C}, 3 \mathrm{~h}, \mathrm{C}_{6} \mathrm{D}_{6}$ & Figure S38 \\
\hline $46(6)$ & $(S)-\left(6-{ }^{13} \mathrm{C}\right)-1$ & $130^{\circ} \mathrm{C}, 3 \mathrm{~h}, \mathrm{C}_{6} \mathrm{D}_{6}$ & Figure S38 \\
\hline $47(7)$ & $(S)-\left(7-{ }^{13} C\right)-1$ & $130^{\circ} \mathrm{C}, 3 \mathrm{~h}, \mathrm{C}_{6} \mathrm{D}_{6}$ & Figure S38 \\
\hline $48(8)$ & $(S)-\left(8-{ }^{13} C\right)-1$ & $130^{\circ} \mathrm{C}, 3 \mathrm{~h}, \mathrm{C}_{6} \mathrm{D}_{6}$ & Figure S38 \\
\hline 49 (9) & $(S)-\left(9-{ }^{13} C\right)-1$ & $130^{\circ} \mathrm{C}, 3 \mathrm{~h}, \mathrm{C}_{6} \mathrm{D}_{6}$ & Figure S38 \\
\hline $50(10)$ & $(S)-\left(10-{ }^{13} C\right)-1$ & $130^{\circ} \mathrm{C}, 3 \mathrm{~h}, \mathrm{C}_{6} \mathrm{D}_{6}$ & Figure S38 \\
\hline $51(11)$ & $(S)-\left(11-{ }^{13} C\right)-1$ & $130^{\circ} \mathrm{C}, 3 \mathrm{~h}, \mathrm{C}_{6} \mathrm{D}_{6}$ & Figure S38 \\
\hline $52(12)$ & $(S)-\left(12-{ }^{13} C\right)-1$ & $130^{\circ} \mathrm{C}, 3 \mathrm{~h}, \mathrm{C}_{6} \mathrm{D}_{6}$ & Figure S38 \\
\hline $53(13)$ & $(S)-\left(13-{ }^{13} C\right)-1$ & $130^{\circ} \mathrm{C}, 3 \mathrm{~h}, \mathrm{C}_{6} \mathrm{D}_{6}$ & Figure S38 \\
\hline $54(14)$ & $(S)-\left(14-{ }^{13} C\right)-1$ & $130^{\circ} \mathrm{C}, 3 \mathrm{~h}, \mathrm{C}_{6} \mathrm{D}_{6}$ & Figure S38 \\
\hline $55(15)$ & $(S)-\left(15-{ }^{13} C\right)-1$ & $130^{\circ} \mathrm{C}, 3 \mathrm{~h}, \mathrm{C}_{6} \mathrm{D}_{6}$ & Figure S38 \\
\hline $56(17)$ & $(1 S, 5 R, 9 R, 10 S)-\left(1,5,9-{ }^{13} C_{3}, 1,5,9-2 \mathrm{H}_{3}\right)-1$ & $130^{\circ} \mathrm{C}, 3 \mathrm{~h}, \mathrm{C}_{6} \mathrm{D}_{6}$ & Figure S39, S41, S43 \\
\hline $57(18)$ & $(1 R, 5 S, 9 S, 10 S)-\left(1,5,9-{ }^{13} C_{3}, 1,5,9-2 \mathrm{H}_{3}\right)-1$ & $130^{\circ} \mathrm{C}, 3 \mathrm{~h}, \mathrm{C}_{6} \mathrm{D}_{6}$ & Figure S39, S41, S43 \\
\hline $58(19)$ & $(4 S, 8 S, 10 S)-\left(4,8-{ }^{13} \mathrm{C}_{2}, 4,8-{ }^{2} \mathrm{H}_{2}\right)-1$ & $130^{\circ} \mathrm{C}, 3 \mathrm{~h}, \mathrm{C}_{6} \mathrm{D}_{6}$ & Figure S40, S42 \\
\hline $59(20)$ & $(4 R, 8 R, 10 S)-\left(4,8-{ }^{13} \mathrm{C}_{2}, 4,8-{ }^{2} \mathrm{H}_{2}\right)-1$ & $130^{\circ} \mathrm{C}, 3 \mathrm{~h}, \mathrm{C}_{6} \mathrm{D}_{6}$ & Figure S40, S42 \\
\hline $60(21)$ & $(1 S, 5 R, 9 R, 10 R)-\left(1,5,9-{ }^{13} C_{3}, 1,5,9-2 \mathrm{H}_{3}\right)-1$ & $130^{\circ} \mathrm{C}, 3 \mathrm{~h}, \mathrm{C}_{6} \mathrm{D}_{6}$ & Figure S39, S41, S43 \\
\hline $61(22)$ & $(1 R, 5 S, 9 S, 10 R)-\left(1,5,9-{ }^{13} \mathrm{C}_{3}, 1,5,9-{ }^{2} \mathrm{H}_{3}\right)-1$ & $130^{\circ} \mathrm{C}, 3 \mathrm{~h}, \mathrm{C}_{6} \mathrm{D}_{6}$ & Figure $\mathrm{S} 39, \mathrm{~S} 41, \mathrm{~S} 43$ \\
\hline $62(23)$ & $(4 S, 8 S, 10 R)-\left(4,8-{ }^{13} \mathrm{C}_{2}, 4,8-{ }^{2} \mathrm{H}_{2}\right)-1$ & $130^{\circ} \mathrm{C}, 3 \mathrm{~h}, \mathrm{C}_{6} \mathrm{D}_{6}$ & Figure S40, S42 \\
\hline $63(24)$ & $(4 R, 8 R, 10 R)-\left(4,8-{ }^{-13} \mathrm{C}_{2}, 4,8-{ }^{-2} \mathrm{H}_{2}\right)-1$ & $130^{\circ} \mathrm{C}, 3 \mathrm{~h}, \mathrm{C}_{6} \mathrm{D}_{6}$ & Figure $S 40, S 42$ \\
\hline
\end{tabular}

[a] Numbers in brackets refer to the entry of the corresponding experiment for the enzymatic preparation of labeled 1. 

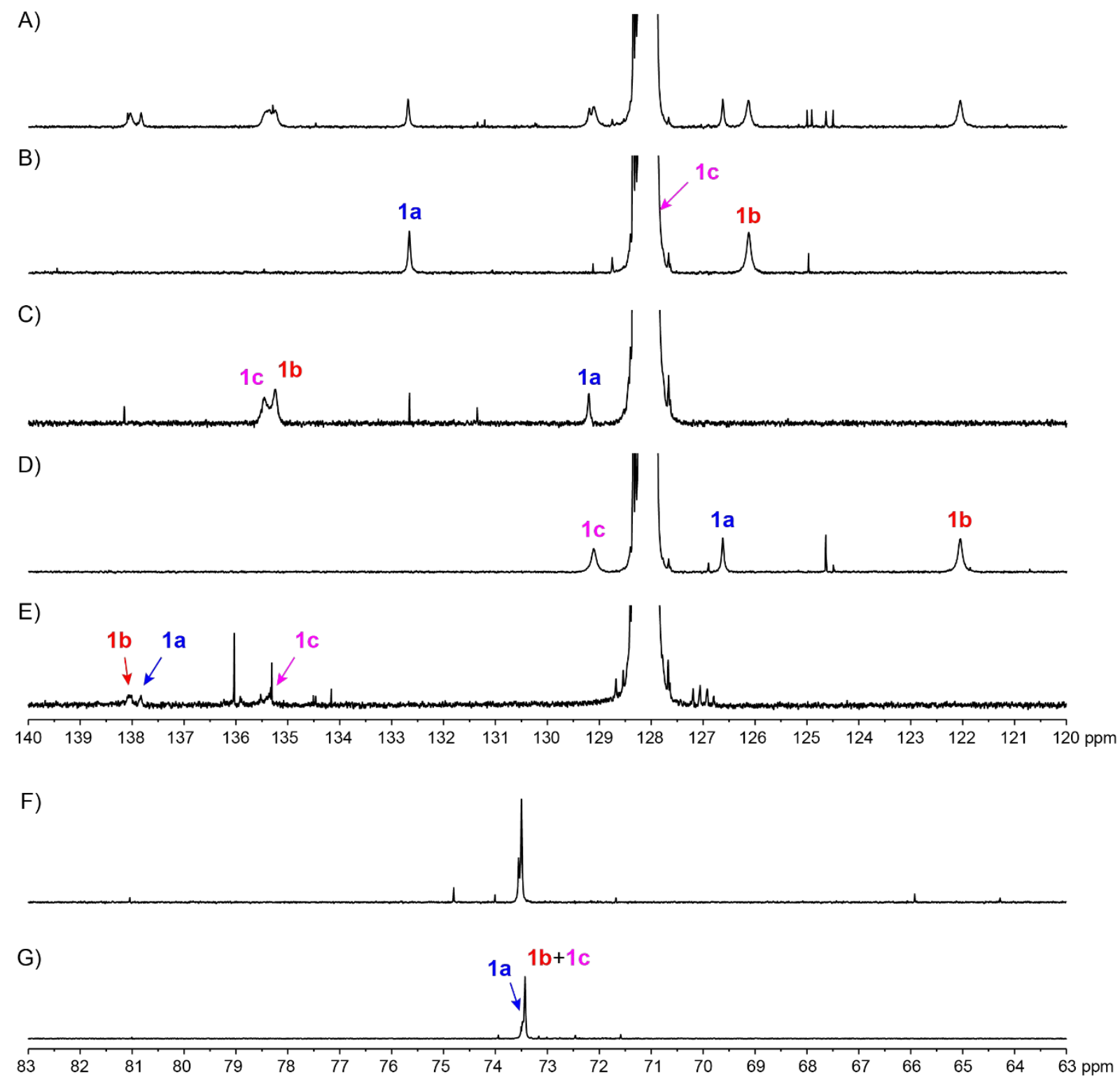

Figure S14. Partial ${ }^{13} \mathrm{C}-\mathrm{NMR}$ spectra of 1 obtained with $\mathrm{HcS}$. The olefinic region of $\mathrm{A}$ ) unlabeled 1, B) $\left(2-{ }^{13} \mathrm{C}\right)-1$ obtained from $\left.\left(2-{ }^{13} \mathrm{C}\right) \mathrm{FPP}, \mathrm{C}\right)\left(3-{ }^{13} \mathrm{C}\right)-1$ obtained from $\left.\left(3-{ }^{13} \mathrm{C}\right) \mathrm{FPP}, \mathrm{D}\right)$ $\left(6-{ }^{13} \mathrm{C}\right)-1$ obtained from $\left(6-{ }^{13} \mathrm{C}\right) \mathrm{FPP}$, and $\left.\mathrm{E}\right)\left(7-{ }^{13} \mathrm{C}\right)-1$ obtained from $\left(7-{ }^{13} \mathrm{C}\right) \mathrm{FPP}$. The region for hydroxylated carbons of $F$ ) unlabeled 1 , and $G)\left(11-{ }^{13} \mathrm{C}\right)-1$ obtained from $\left(11-{ }^{13} \mathrm{C}\right) \mathrm{FPP}$. 
A)

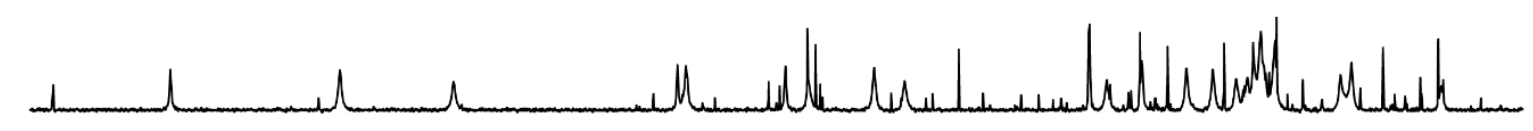

B) 1 1a

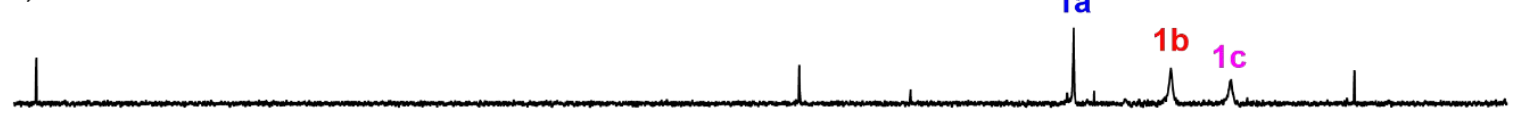

C)

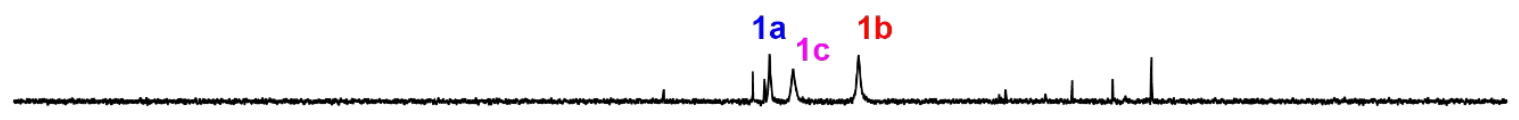

D)

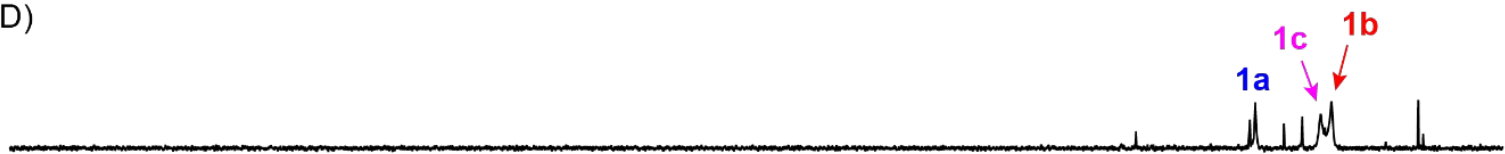

E) $1 \mathrm{a} \quad 1 \mathrm{~b}$

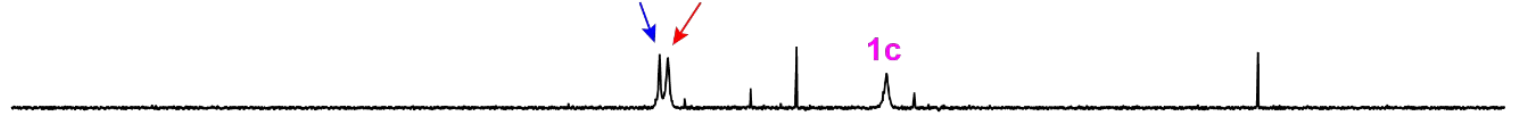

F)

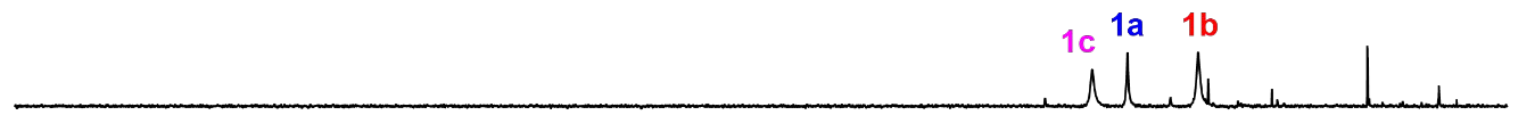

G)

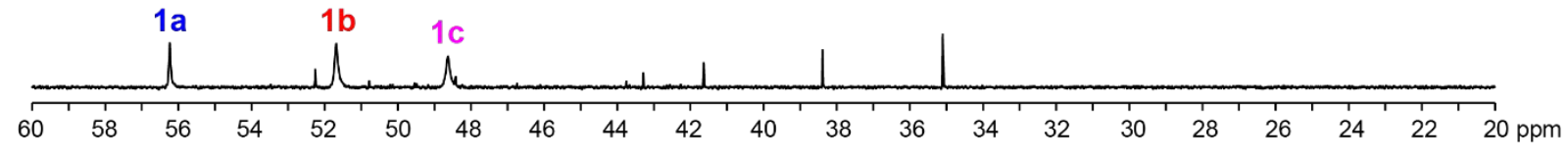

Figure S15. Partial ${ }^{13} \mathrm{C}-\mathrm{NMR}$ spectra of 1 obtained with HcS. The methine and methylene group region of $A)$ unlabeled $1, B)\left(1-{ }^{13} \mathrm{C}\right)-1$ obtained from $\left.\left(1-{ }^{13} \mathrm{C}\right) \mathrm{FPP}, \mathrm{C}\right)\left(4-{ }^{13} \mathrm{C}\right)-1$ obtained

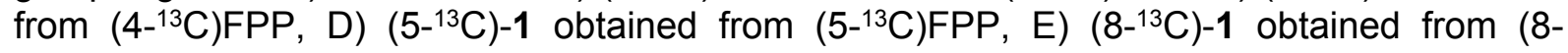
$\left.{ }^{13} \mathrm{C}\right)$ FPP, F) $\left(9-{ }^{13} \mathrm{C}\right)-1$ obtained from $\left(9-{ }^{13} \mathrm{C}\right) \mathrm{FPP}$, and $\left.\mathrm{G}\right)\left(10-{ }^{13} \mathrm{C}\right)-1$ obtained from $\left(10-{ }^{13} \mathrm{C}\right) \mathrm{FPP}$. 
A)

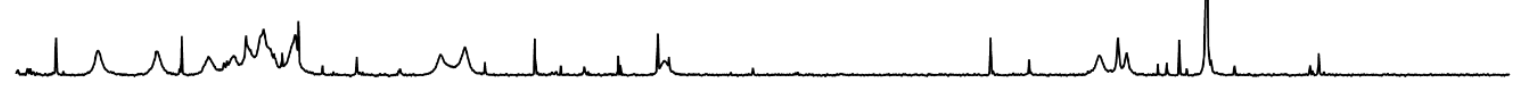

B)

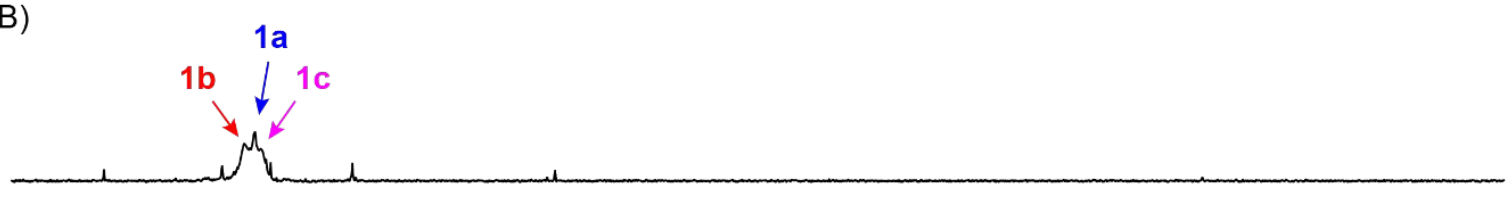

C)

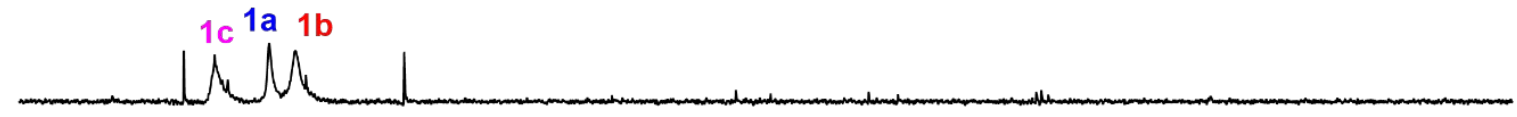

D)

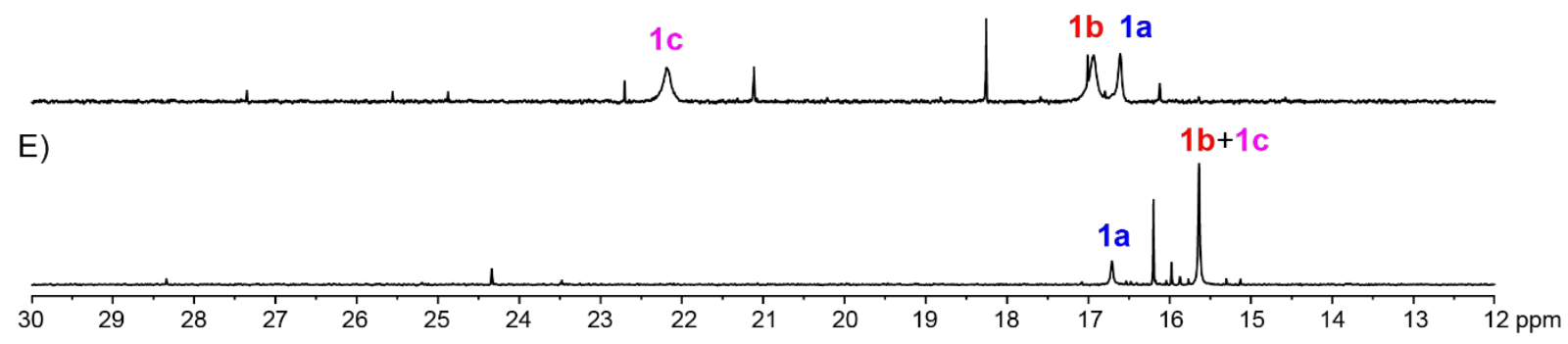

Figure S16. Partial ${ }^{13} \mathrm{C}-\mathrm{NMR}$ spectra of 1 obtained with $\mathrm{HcS}$. The methyl group region of $\mathrm{A}$ ) unlabeled 1, B) $\left(12-{ }^{13} \mathrm{C}\right)-1$ obtained from $\left.\left(12-{ }^{13} \mathrm{C}\right) \mathrm{FPP}, \mathrm{C}\right)\left(13^{-13} \mathrm{C}\right)-1$ obtained from (13$\left.{ }^{13} \mathrm{C}\right) \mathrm{FPP}$, D) $\left(14-{ }^{13} \mathrm{C}\right)-1$ obtained from $\left(14-{ }^{13} \mathrm{C}\right) \mathrm{FPP}$, and $\left.\mathrm{E}\right)\left(15^{-13} \mathrm{C}\right)-1$ obtained from (15$\left.{ }^{13} \mathrm{C}\right) \mathrm{FPP}$. 


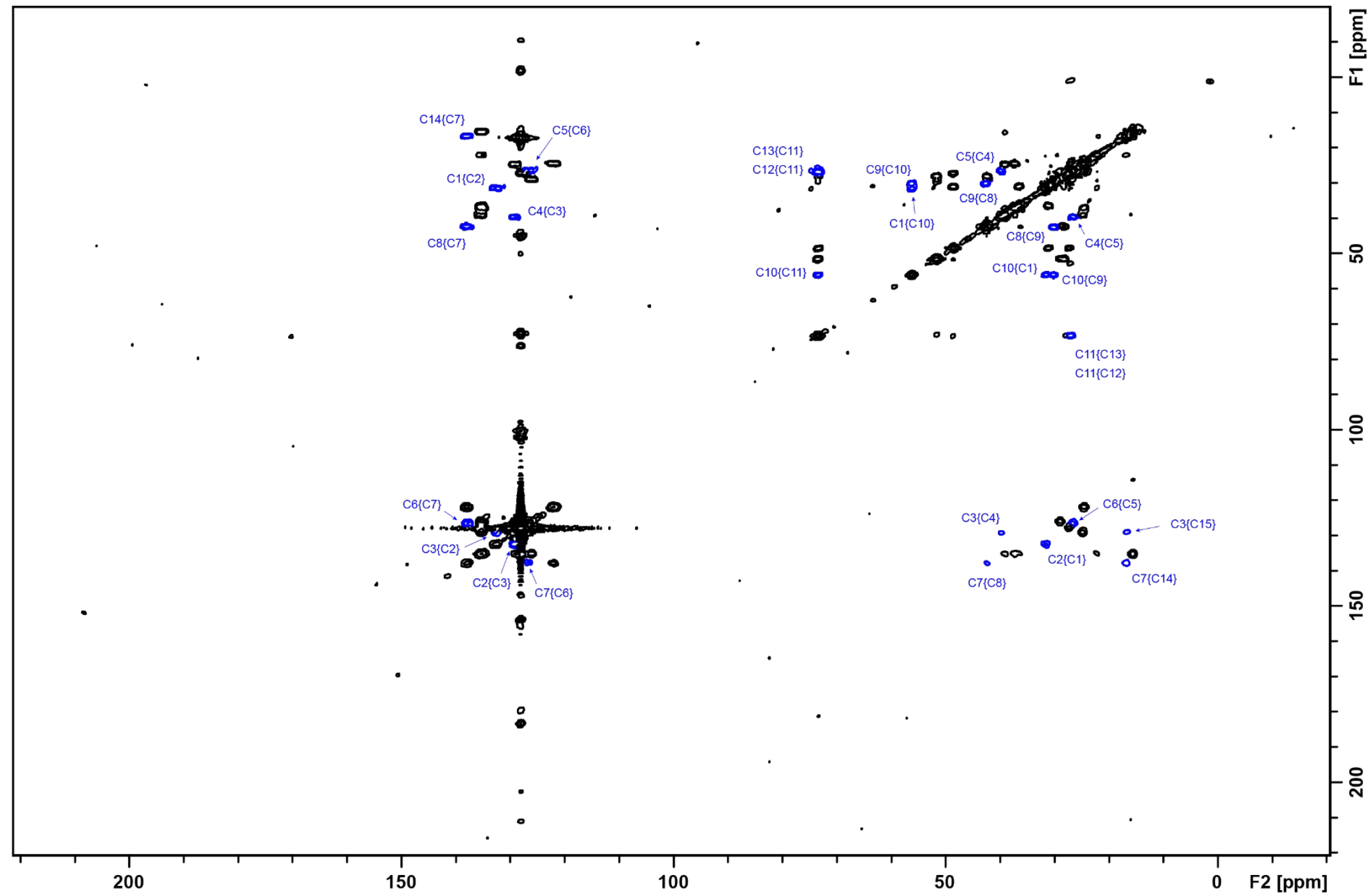

Figure S17. ${ }^{13} \mathrm{C},{ }^{13} \mathrm{C}-\mathrm{COSY}$ NMR of $\left({ }^{13} \mathrm{C}_{15}\right)-1$ obtained with HcS from $\left({ }^{13} \mathrm{C}_{15}\right)$ FPP. The crosspeaks colored in blue form a contiguous spin system of conformer 1a. 


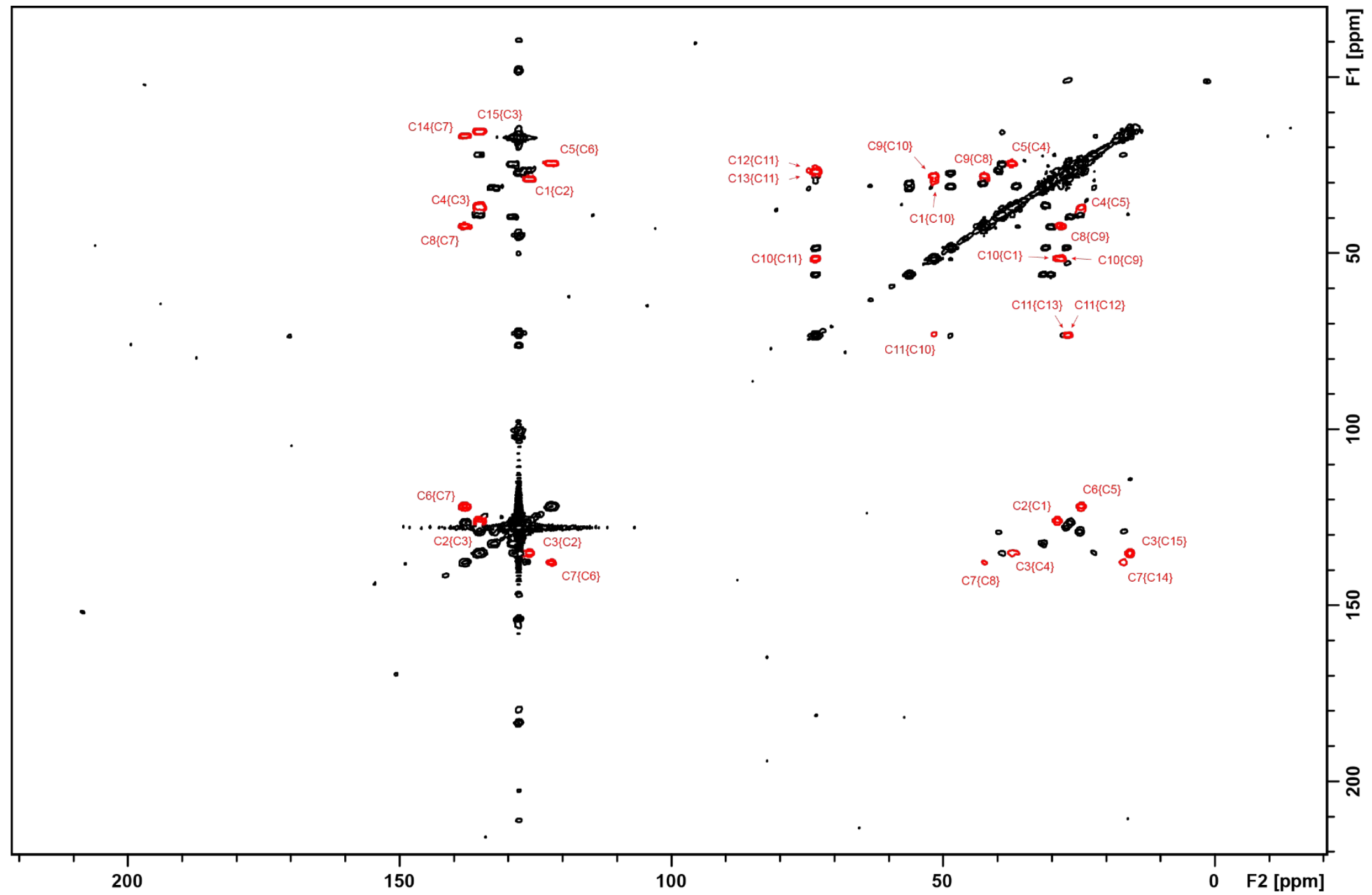

Figure S18. ${ }^{13} \mathrm{C},{ }^{13} \mathrm{C}-\mathrm{COSY}$ NMR of $\left({ }^{13} \mathrm{C}_{15}\right)$-1 obtained with HcS from $\left({ }^{13} \mathrm{C}_{15}\right)$ FPP. The crosspeaks colored in red form a contiguous spin system of conformer $\mathbf{1 b}$. 


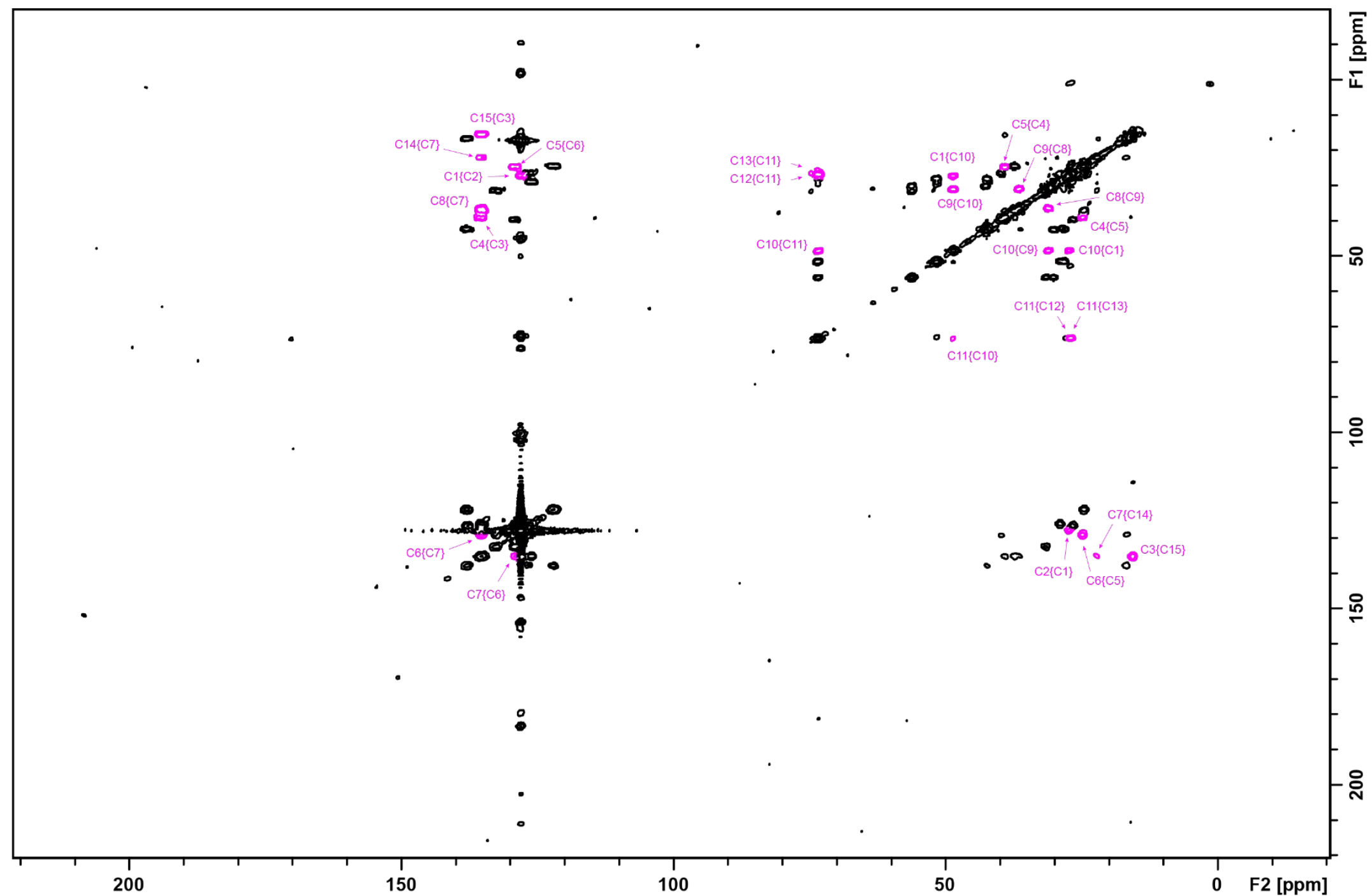

Figure S19. ${ }^{13} \mathrm{C},{ }^{13} \mathrm{C}$-COSY NMR of $\left({ }^{13} \mathrm{C}_{15}\right)-1$ obtained with $\mathrm{HcS}$ from $\left({ }^{13} \mathrm{C}_{15}\right)$ FPP. The crosspeaks colored in purple form a contiguous spin system of conformer 1c. 


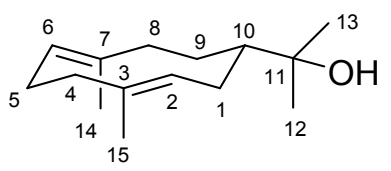

$1 a$
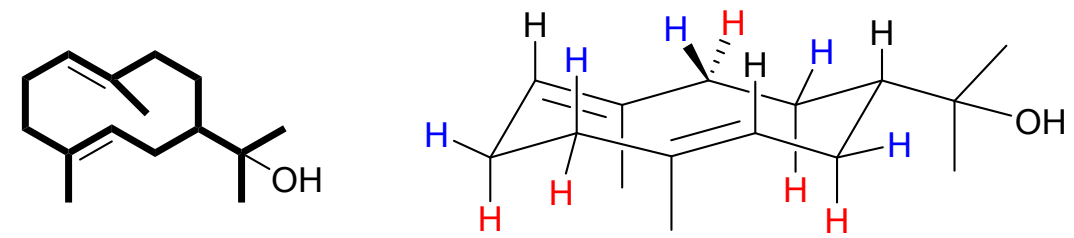

Figure S20. Structure elucidation of 1a. Bold: ${ }^{13} \mathrm{C},{ }^{13} \mathrm{C}-\mathrm{COSY}$ correlations.

Table S4. NMR data of hedycaryol (conformer 1a) in $\mathrm{C}_{6} \mathrm{D}_{6}$ recorded at $298 \mathrm{~K}$.

\begin{tabular}{|c|c|c|c|}
\hline $\mathrm{C}^{[\mathrm{a}]}$ & type & ${ }^{13} \mathrm{C}$ & ${ }^{1} \mathrm{H}$ \\
\hline \multirow[t]{2}{*}{1} & $\mathrm{CH}_{2}$ & 31.6 & $2.47(\mathrm{H})$ \\
\hline & & & $1.69(\mathrm{H})$ \\
\hline 2 & $\mathrm{CH}$ & 132.7 & 4.56 \\
\hline 3 & $\mathrm{C}_{\mathrm{q}}$ & 129.2 & - \\
\hline \multirow[t]{2}{*}{4} & $\mathrm{CH}_{2}$ & 39.8 & $2.12(\mathrm{H})$ \\
\hline & & & $1.95(\mathrm{H})$ \\
\hline \multirow[t]{2}{*}{5} & $\mathrm{CH}_{2}$ & 26.6 & $2.24(\mathrm{H})$ \\
\hline & & & $2.04(\mathrm{H})$ \\
\hline 6 & $\mathrm{CH}$ & 126.6 & 4.78 \\
\hline 7 & $\mathrm{C}_{\mathrm{q}}$ & 137.8 & - \\
\hline \multirow[t]{2}{*}{8} & $\mathrm{CH}_{2}$ & 42.6 & $2.36(\mathrm{H})$ \\
\hline & & & $1.94(\mathrm{H})$ \\
\hline \multirow[t]{2}{*}{9} & $\mathrm{CH}_{2}$ & 30.2 & $1.91(\mathrm{H})$ \\
\hline & & & $1.03(\mathrm{H})$ \\
\hline 10 & $\mathrm{CH}$ & 56.2 & 1.12 \\
\hline 11 & $\mathrm{C}_{\mathrm{q}}$ & 73.5 & - \\
\hline 12 & $\mathrm{CH}_{3}$ & 27.1 & 1.04 \\
\hline 13 & $\mathrm{CH}_{3}$ & 27.0 & 1.02 \\
\hline 14 & $\mathrm{CH}_{3}$ & 16.6 & 1.39 \\
\hline 15 & $\mathrm{CH}_{3}$ & 16.7 & 1.46 \\
\hline
\end{tabular}

[a] Carbon numbering and color code for diastereotopic hydrogens as shown in Figure S20. 


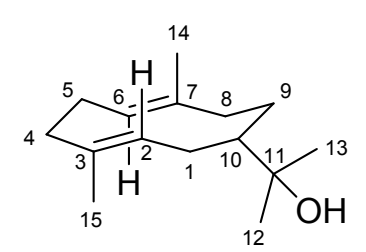

1b

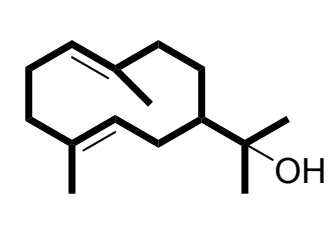

Figure S21. Structure elucidation of $1 \mathrm{~b}$. Bold: ${ }^{13} \mathrm{C},{ }^{13} \mathrm{C}-\mathrm{COSY}$ correlations.

Table S5. NMR data of hedycaryol (conformer 1b) in $\mathrm{C}_{6} \mathrm{D}_{6}$ recorded at $298 \mathrm{~K}$.

\begin{tabular}{|c|c|c|c|}
\hline $\mathrm{C}^{[\mathrm{a}]}$ & type & ${ }^{13} \mathrm{C}$ & ${ }^{1} \mathrm{H}$ \\
\hline \multirow[t]{2}{*}{1} & $\mathrm{CH}_{2}$ & 29.0 & $2.44(\mathrm{H})$ \\
\hline & & & $1.41(\mathrm{H})$ \\
\hline 2 & $\mathrm{CH}$ & 126.1 & 5.13 \\
\hline 3 & $\mathrm{C}_{\mathrm{q}}$ & 135.3 & - \\
\hline \multirow[t]{2}{*}{4} & $\mathrm{CH}_{2}$ & 37.4 & $2.17(\mathrm{H})$ \\
\hline & & & $2.06(\mathrm{H})$ \\
\hline \multirow[t]{2}{*}{5} & $\mathrm{CH}_{2}$ & 24.6 & $2.28(\mathrm{H})$ \\
\hline & & & $2.00(\mathrm{H})$ \\
\hline 6 & $\mathrm{CH}$ & 122.1 & 4.98 \\
\hline 7 & $\mathrm{C}_{\mathrm{q}}$ & 138.0 & - \\
\hline \multirow[t]{2}{*}{8} & $\mathrm{CH}_{2}$ & 42.4 & $2.10(\mathrm{H})$ \\
\hline & & & $1.82(\mathrm{H})$ \\
\hline \multirow[t]{2}{*}{9} & $\mathrm{CH}_{2}$ & 28.3 & $1.59(\mathrm{H})$ \\
\hline & & & $1.00(\mathrm{H})$ \\
\hline 10 & $\mathrm{CH}$ & 51.7 & 1.15 \\
\hline 11 & $\mathrm{C}_{\mathrm{q}}$ & 73.4 & - \\
\hline 12 & $\mathrm{CH}_{3}$ & 27.2 & 1.04 \\
\hline 13 & $\mathrm{CH}_{3}$ & 26.7 & 1.02 \\
\hline 14 & $\mathrm{CH}_{3}$ & 16.9 & 1.46 \\
\hline 15 & $\mathrm{CH}_{3}$ & 15.6 & 1.46 \\
\hline
\end{tabular}

[a] Carbon numbering and color code for diastereotopic hydrogens as shown in Figure S21. 


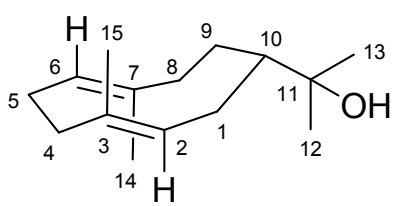

$1 \mathrm{~b}$
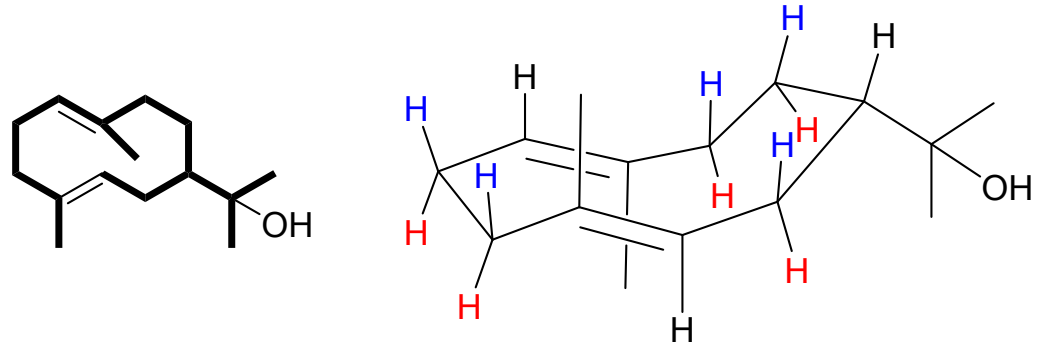

Figure S22. Structure elucidation of 1c. Bold: ${ }^{13} \mathrm{C},{ }^{13} \mathrm{C}-\mathrm{COSY}$ correlations.

Table S6. NMR data of hedycaryol (conformer 1c) in $\mathrm{C}_{6} \mathrm{D}_{6}$ recorded at $298 \mathrm{~K}$.

\begin{tabular}{|c|c|c|c|}
\hline $\mathrm{C}^{[\mathrm{a}]}$ & type & ${ }^{13} \mathrm{C}$ & ${ }^{1} \mathrm{H}$ \\
\hline \multirow[t]{2}{*}{1} & $\mathrm{CH}_{2}$ & 27.4 & $2.40(\mathrm{H})$ \\
\hline & & & $1.48(\mathrm{H})$ \\
\hline 2 & $\mathrm{CH}$ & 127.8 & 5.14 \\
\hline 3 & $\mathrm{C}_{\mathrm{q}}$ & 135.5 & - \\
\hline \multirow[t]{2}{*}{4} & $\mathrm{CH}_{2}$ & 39.1 & $2.07(\mathrm{H})$ \\
\hline & & & $2.05(\mathrm{H})$ \\
\hline \multirow[t]{2}{*}{5} & $\mathrm{CH}_{2}$ & 24.9 & $2.28(\mathrm{H})$ \\
\hline & & & $2.00(\mathrm{H})$ \\
\hline 6 & $\mathrm{CH}$ & 129.1 & 4.87 \\
\hline 7 & $\mathrm{C}_{\mathrm{q}}$ & 135.4 & - \\
\hline \multirow[t]{2}{*}{8} & $\mathrm{CH}_{2}$ & 36.6 & $2.38(\mathrm{H})$ \\
\hline & & & $1.64(\mathrm{H})$ \\
\hline \multirow[t]{2}{*}{9} & $\mathrm{CH}_{2}$ & 31.1 & $1.49(\mathrm{H})$ \\
\hline & & & $1.44(\mathrm{H})$ \\
\hline 10 & $\mathrm{CH}$ & 48.6 & 1.32 \\
\hline 11 & $\mathrm{C}_{\mathrm{q}}$ & 73.4 & - \\
\hline 12 & $\mathrm{CH}_{3}$ & 27.0 & 1.04 \\
\hline 13 & $\mathrm{CH}_{3}$ & 27.6 & 1.02 \\
\hline 14 & $\mathrm{CH}_{3}$ & 22.2 & 1.62 \\
\hline 15 & $\mathrm{CH}_{3}$ & 15.6 & 1.46 \\
\hline
\end{tabular}

[a] Carbon numbering and color code for diastereotopic hydrogens as shown in Figure S22. 

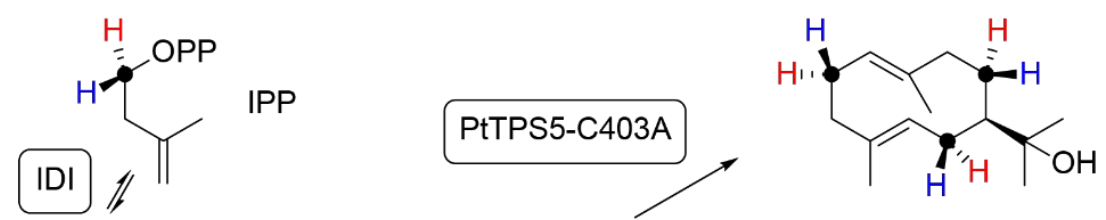

$(R)-1$
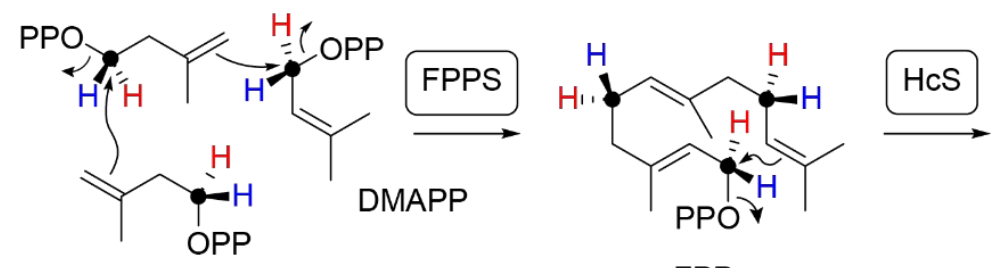

FPP

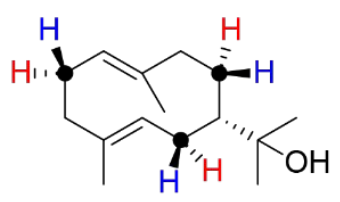

$(S)-1$

A)

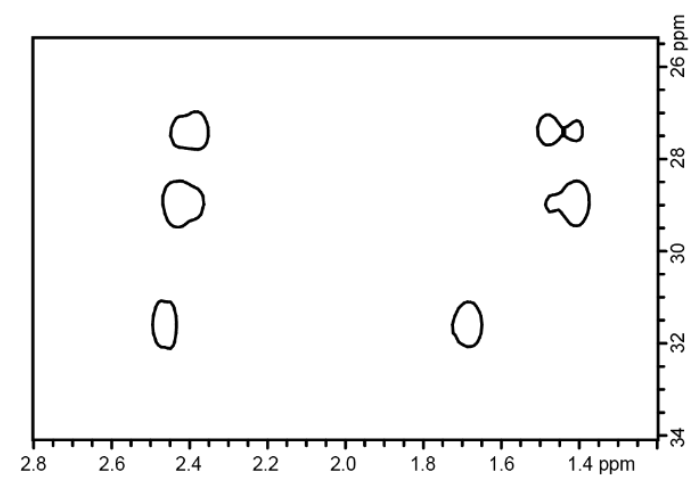

B) $\mathrm{H}={ }^{2} \mathrm{H}$

$(S)-1$
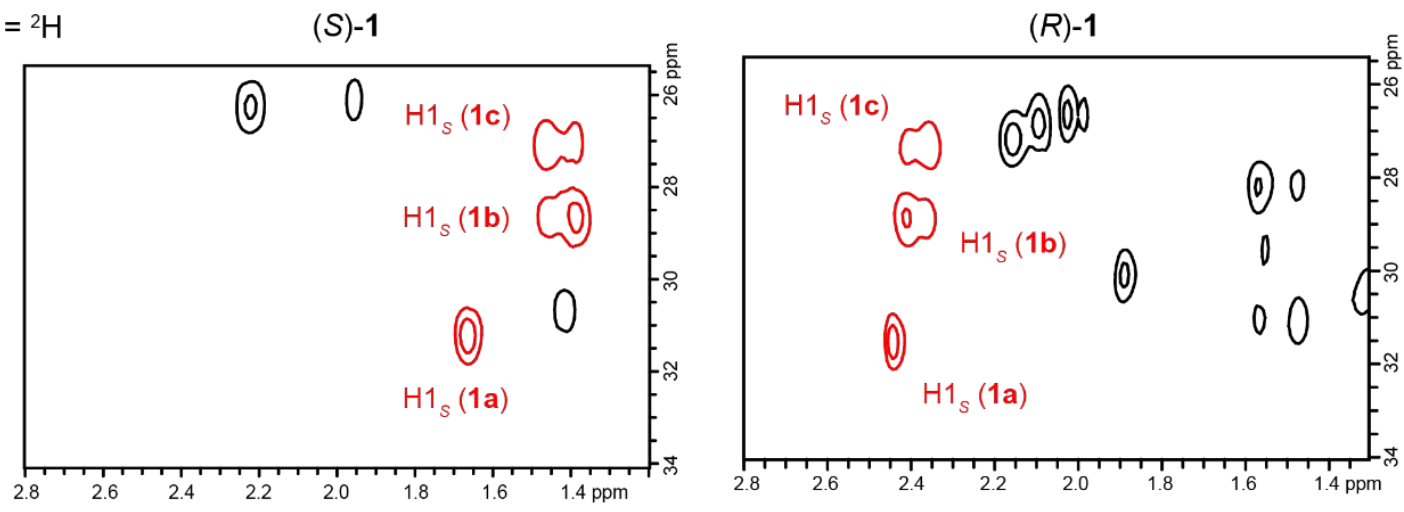

C) $\mathrm{H}={ }^{2} \mathrm{H}$

$(S)-1$

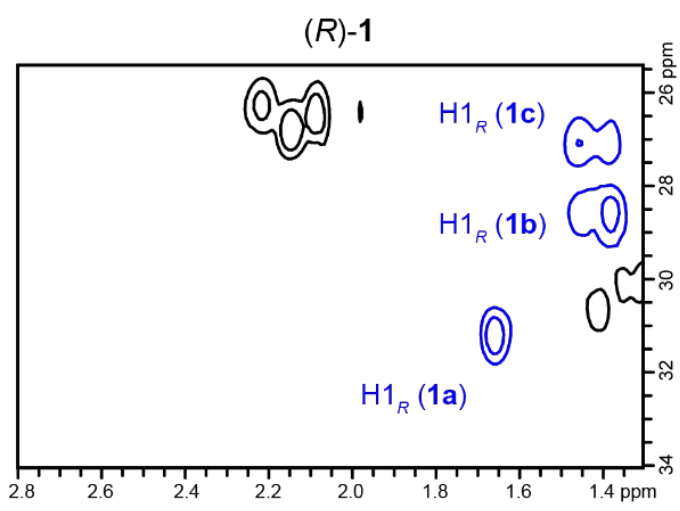

Figure S23. Partial HSQC spectra showing the region for $\mathrm{C} 1$ of $1 . \mathrm{A})\left(1-{ }^{13} \mathrm{C}\right)-1$ obtained with HcS from $\left.\left(1-{ }^{13} \mathrm{C}\right) \mathrm{FPP}, \mathrm{B}\right)$ labeled 1 obtained from $(R)-\left(1-{ }^{13} \mathrm{C}, 1-2 \mathrm{H}\right) \mathrm{IPP}$ with HcS (left) and with PpTPS5-C403A (right), C) labeled 1 obtained from DMAPP and $(S)-\left(1-{ }^{13} \mathrm{C}, 1-2 \mathrm{H}\right) \mathrm{IPP}$ with $\mathrm{HcS}$ (left) and with PpTPS5-C403A (right). Conversions of labeled IPP were performed with addition of IDI and FPPS. Black dots represent ${ }^{13} \mathrm{C}$-labeled carbons. Crosspeaks of deuterated carbons are slightly upfield shifted in both dimensions. 


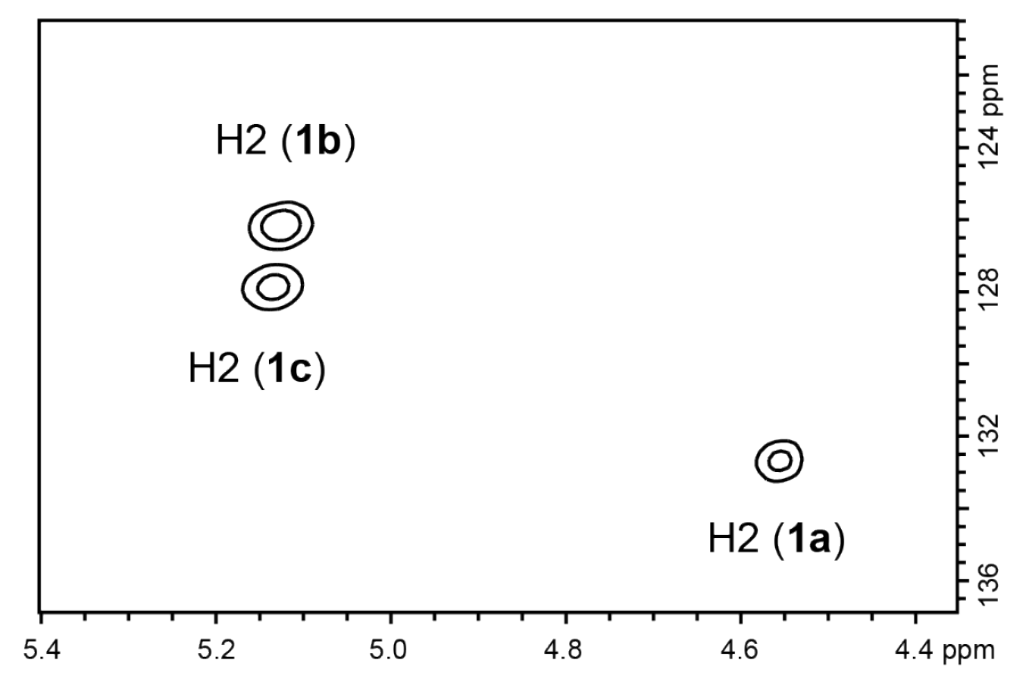

Figure S24. Partial HSQC spectrum of $\left(2-{ }^{13} \mathrm{C}\right)-1$ obtained with HcS from $\left(2-{ }^{13} \mathrm{C}\right) \mathrm{FPP}$ showing the region for $\mathrm{C} 2$ of 1. 

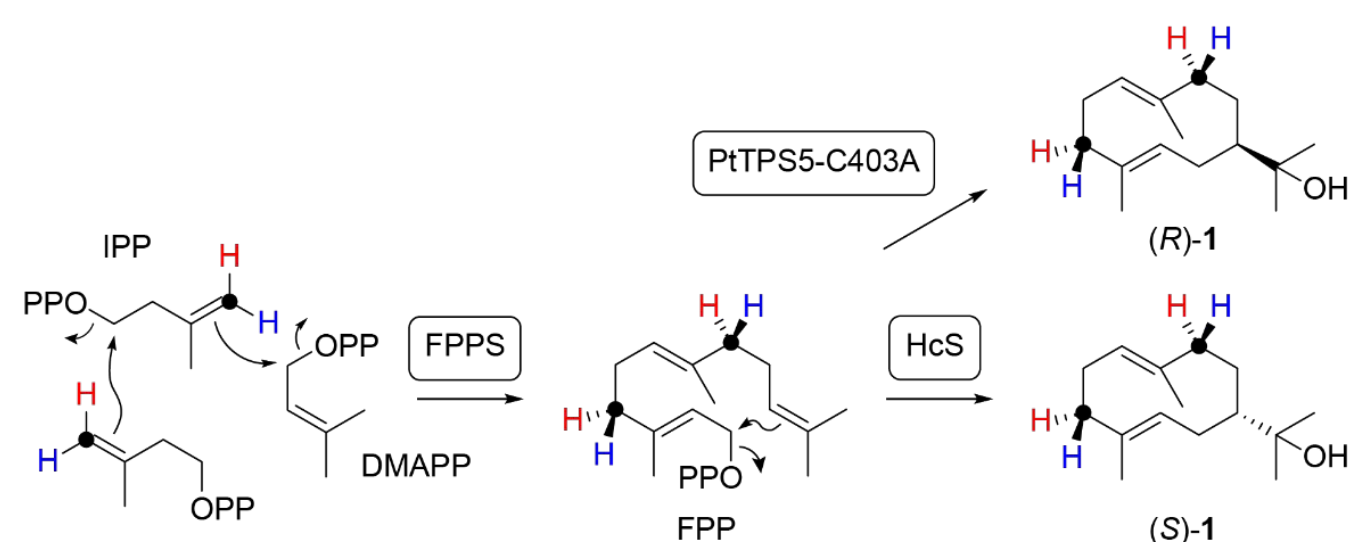

A)

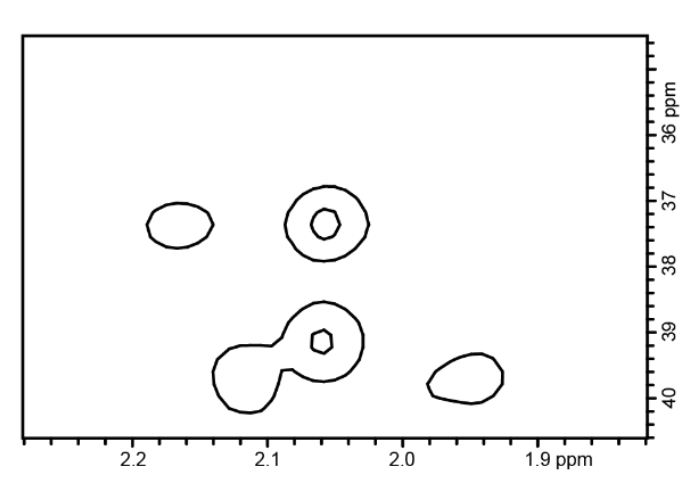

B) $\mathrm{H}={ }^{2} \mathrm{H}$

$(S)-1$

$(R)-1$
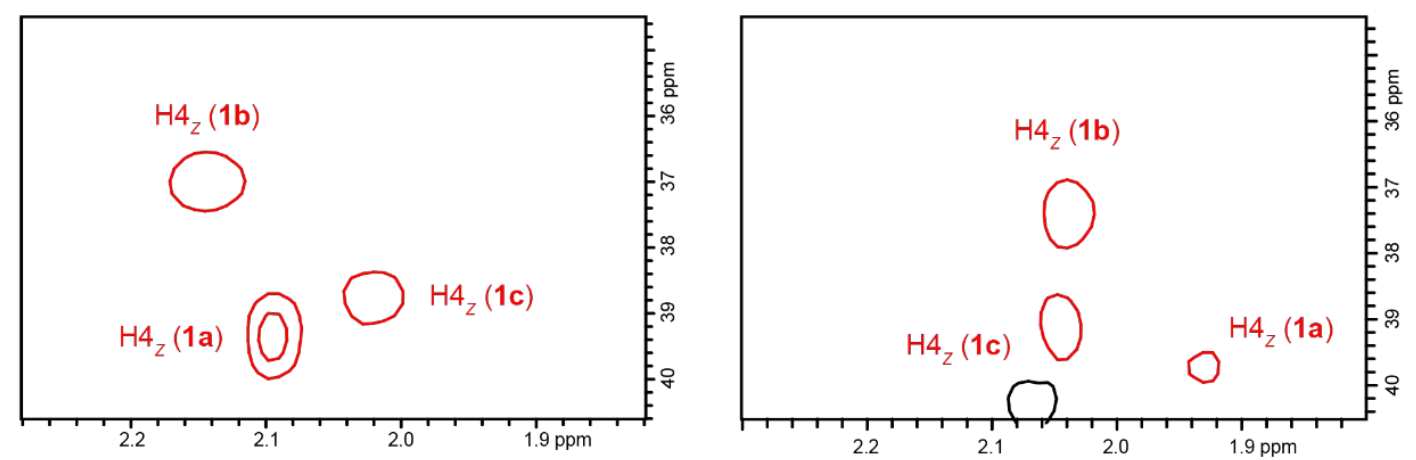

C) $\mathrm{H}={ }^{2} \mathrm{H}$

$(S)-1$

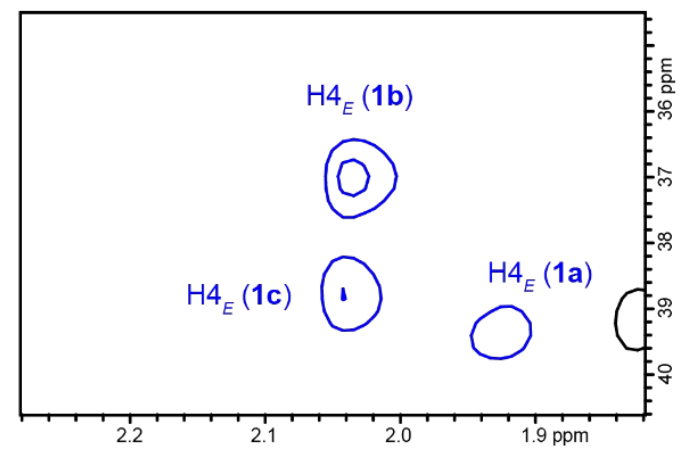

$(R)-1$

Figure S25. Partial HSQC spectra showing the region for C4 of 1. A) (4-13C)-1 obtained with $\mathrm{HcS}$ from $\left.\left(4-{ }^{13} \mathrm{C}\right) \mathrm{FPP}, \mathrm{B}\right)$ labeled 1 obtained from DMAPP and $(E)-\left(1-{ }^{13} \mathrm{C}, 1-{ }^{2} \mathrm{H}\right) \mathrm{IPP}$ with $\mathrm{HcS}$ (left) and with PpTPS5-C403A (right), C) labeled 1 obtained from DMAPP and $(Z)-\left(1-{ }^{13} C, 1-\right.$ ${ }^{2} \mathrm{H}$ )IPP with HcS (left) and with PpTPS5-C403A (right). Conversions of labeled IPP were performed with addition of FPPS. Black dots represent ${ }^{13} \mathrm{C}$-labeled carbons. Crosspeaks of deuterated carbons are slightly upfield shifted in both dimensions. 

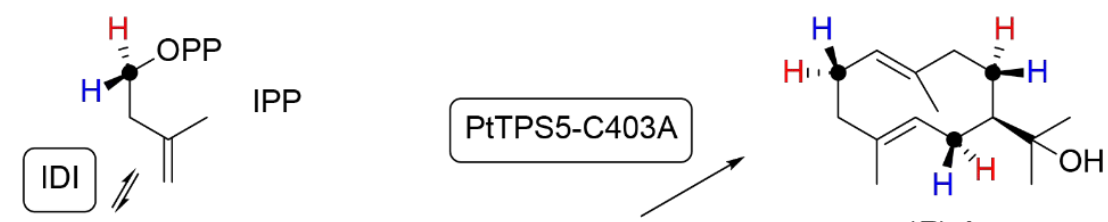

(R)-1

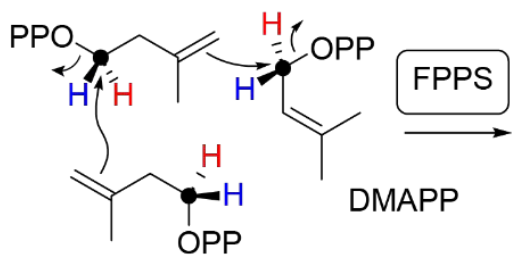

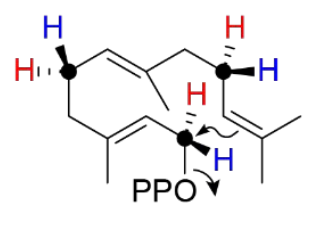

FPP
$\mathrm{HcS}$<smiles>CC1=CC[C@H](C)[C@@H](C(C)(C)O)C1</smiles>

(S)-1

A)

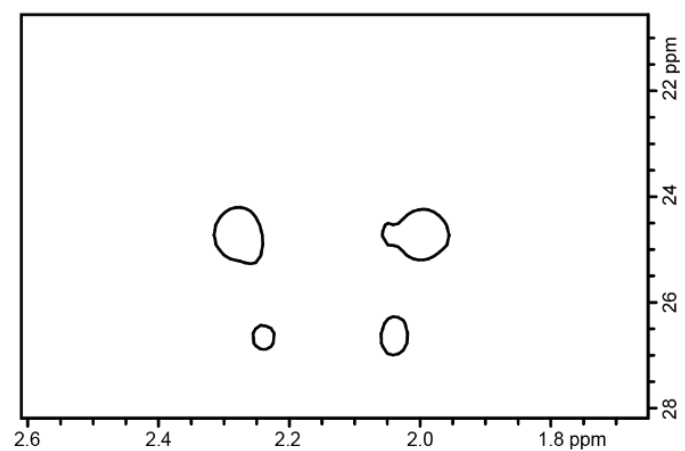

B) $\mathrm{H}={ }^{2} \mathrm{H}$

$(S)-1$

$(R)-1$
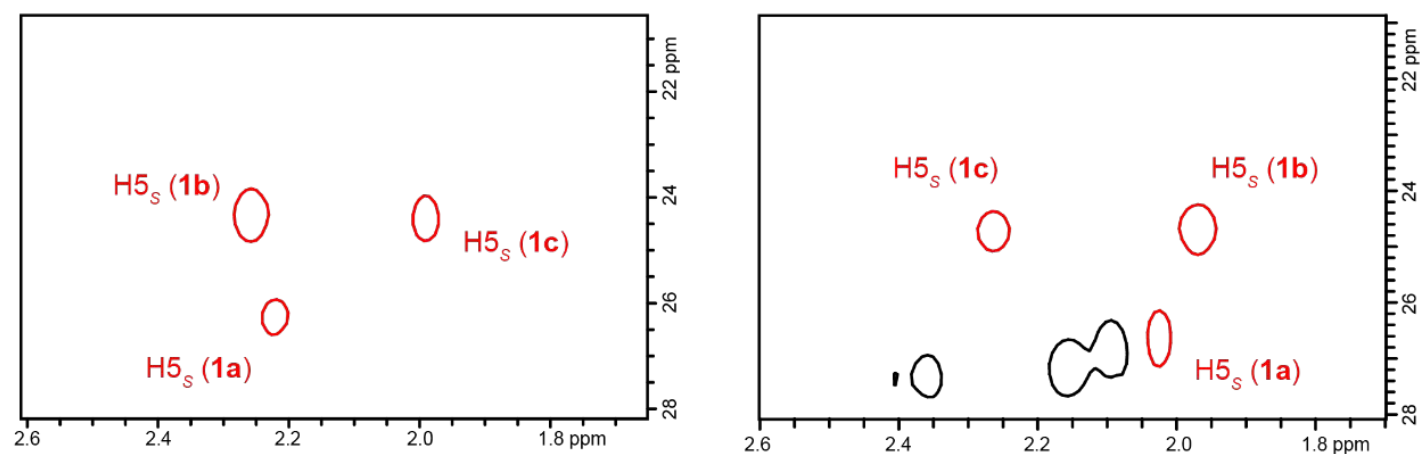

C) $\mathrm{H}={ }^{2} \mathrm{H}$

$(S)-1$

(R)-1
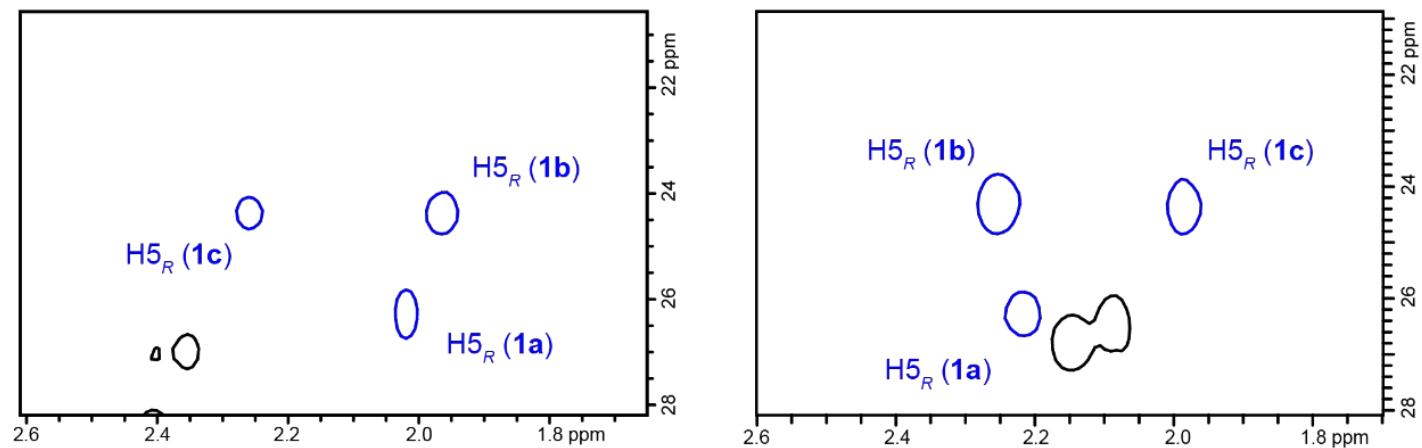

Figure S26. Partial HSQC spectra showing the region for $\mathrm{C} 5$ of 1 . A) $\left(5-{ }^{13} \mathrm{C}\right)-1$ obtained with HcS from $\left(5-{ }^{13} \mathrm{C}\right)$ FPP, B) labeled 1 obtained from $(R)-\left(1-{ }^{13} \mathrm{C}, 1-{ }^{2} \mathrm{H}\right) \mathrm{IPP}$ with HcS (left) and with PpTPS5-C403A (right), C) labeled 1 obtained from DMAPP and $(S)-\left(1-{ }^{13} C, 1-2 H\right) I P P$ with HcS (left) and with PpTPS5-C403A (right). Conversions of labeled IPP were performed with addition of IDI and FPPS. Black dots represent ${ }^{13} \mathrm{C}$-labeled carbons. Crosspeaks of deuterated carbons are slightly upfield shifted in both dimensions. 


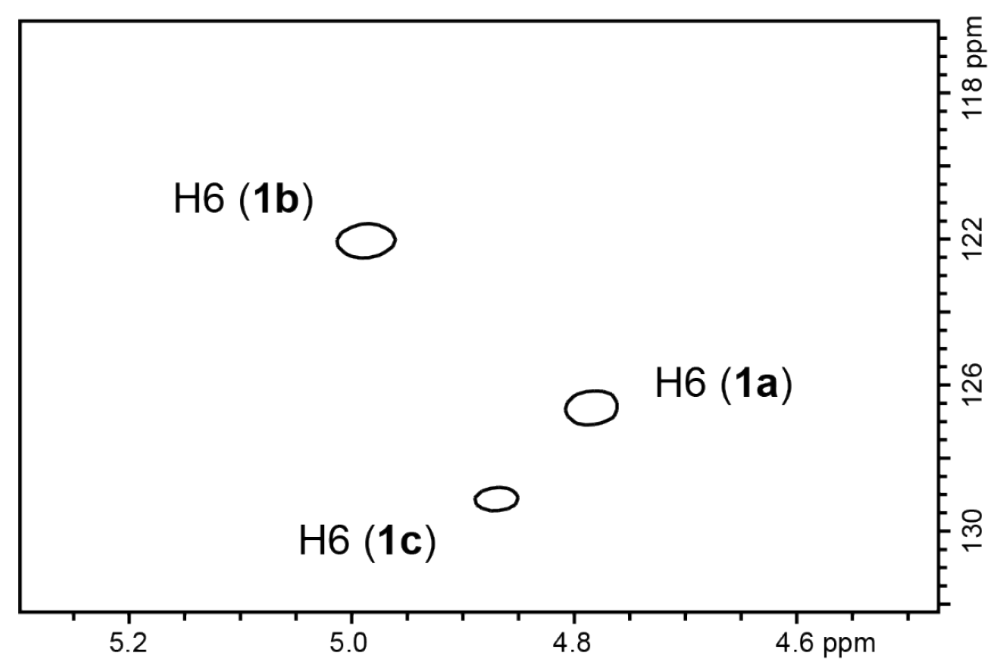

Figure S27. Partial HSQC spectrum of $\left(6-{ }^{13} \mathrm{C}\right)-1$ obtained with HcS from $\left(6-{ }^{13} \mathrm{C}\right) \mathrm{FPP}$ showing the region for $\mathrm{C} 6$ of 1 . 

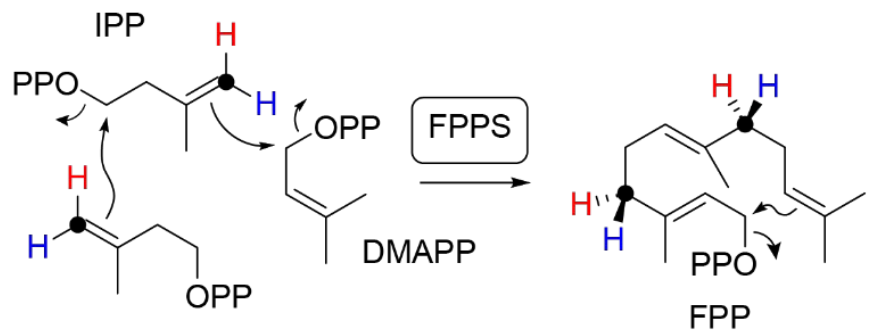

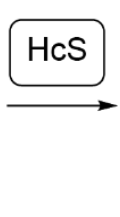

PPP<smiles>[H][Z11]1([H])CC=C2CC(C(C)(C)O)C[C@H]1[C@H]2C</smiles>

(R)-1

A)

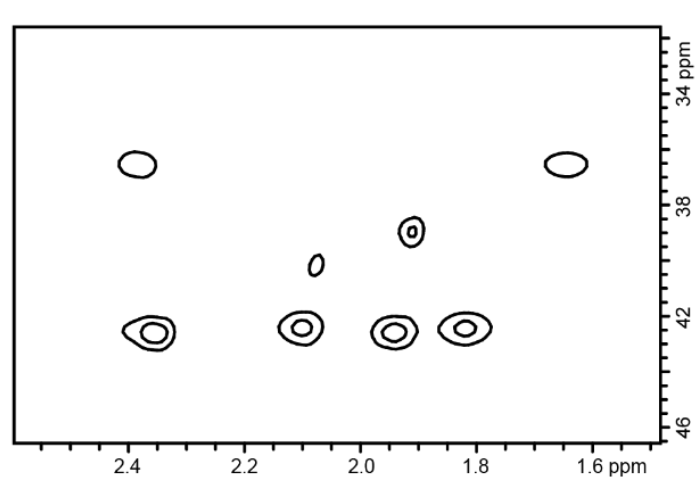

B) $\mathrm{H}={ }^{2} \mathrm{H}$

(S)-1

(R)-1

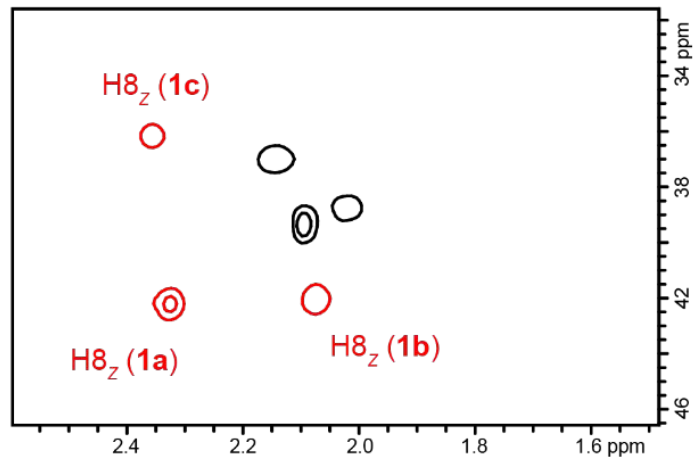

C) $\mathrm{H}={ }^{2} \mathrm{H}$

(S)-1
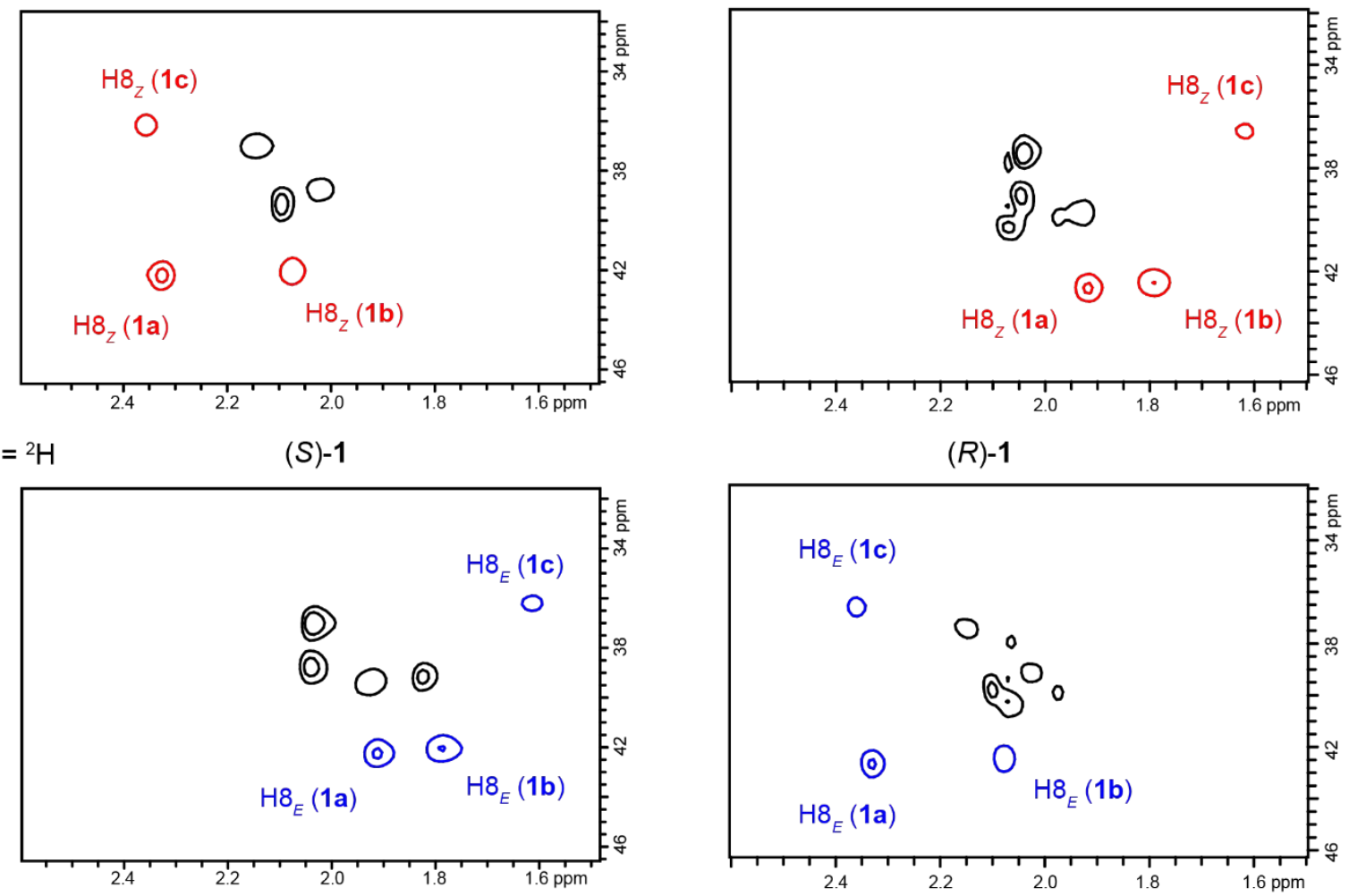

(S)-1

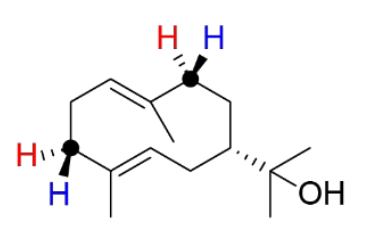



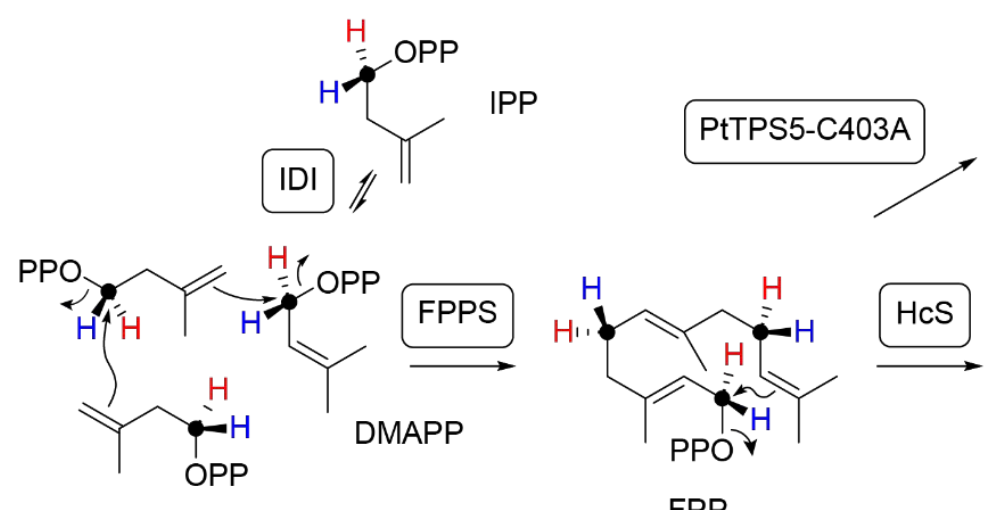

FPP

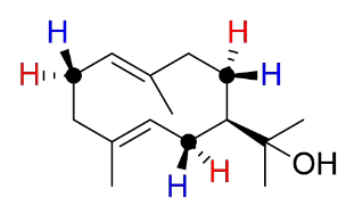

(R)-1

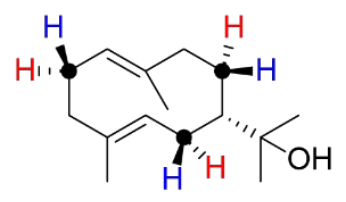

(S)-1

A)

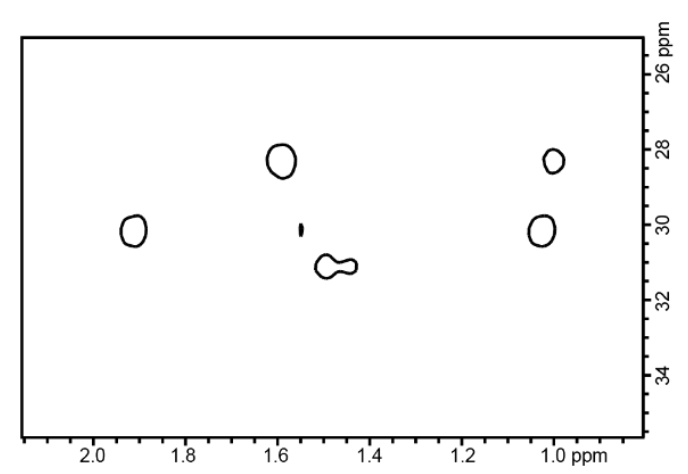

B) $\mathrm{H}={ }^{2} \mathrm{H}$

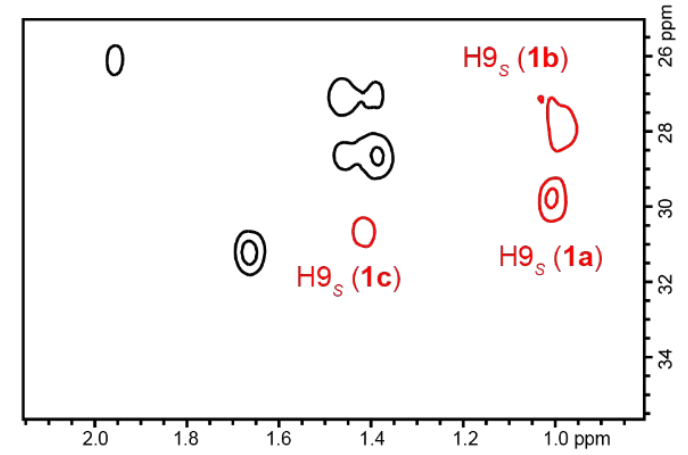

C) $\mathrm{H}={ }^{2} \mathrm{H}$

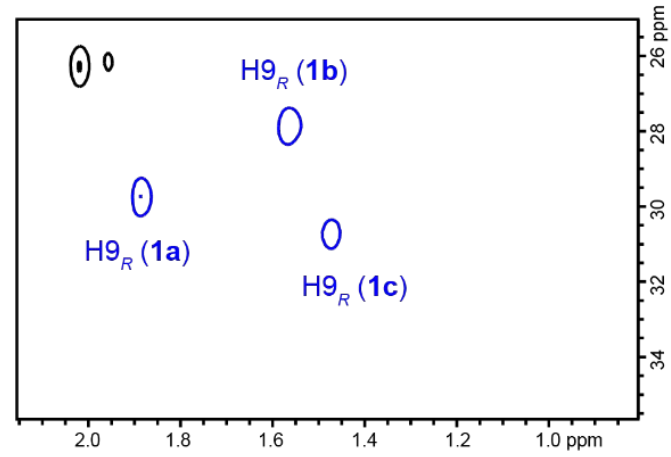

(R)-1

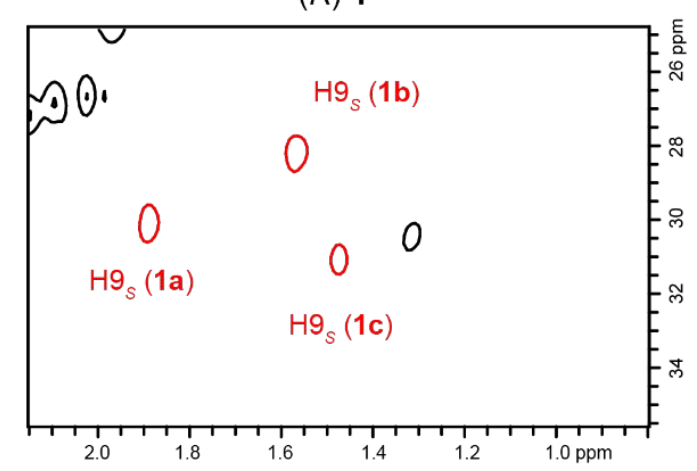

(R)-1

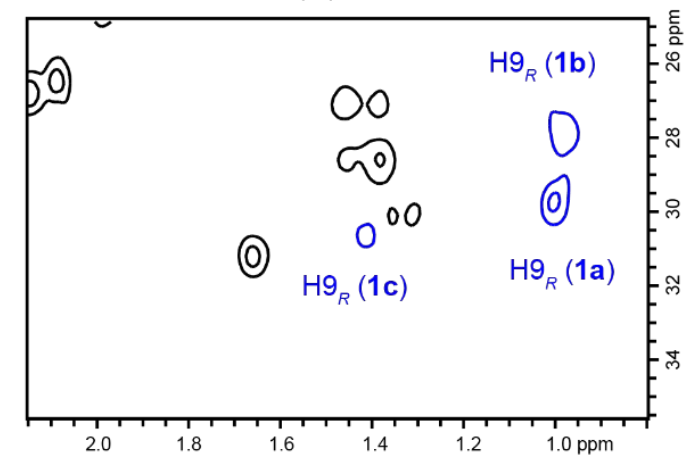

Figure S29. Partial HSQC spectra showing the region for C9 of 1. A) $\left(9-{ }^{13} \mathrm{C}\right)-1$ obtained with $\mathrm{HcS}$ from $\left.\left(9-{ }^{13} \mathrm{C}\right) \mathrm{FPP}, \mathrm{B}\right)$ labeled 1 obtained from $(R)-\left(1-{ }^{13} \mathrm{C}, 1-{ }^{2} \mathrm{H}\right) \mathrm{IPP}$ with $\mathrm{HcS}$ (left) and with PpTPS5-C403A (right), C) labeled 1 obtained from DMAPP and $(S)-\left(1-{ }^{13} C, 1-2 \mathrm{H}\right)$ IPP with HcS (left) and with PpTPS5-C403A (right). Conversions of labeled IPP were performed with addition of IDI and FPPS. Black dots represent ${ }^{13} \mathrm{C}$-labeled carbons. Crosspeaks of deuterated carbons are slightly upfield shifted in both dimensions. 
A)

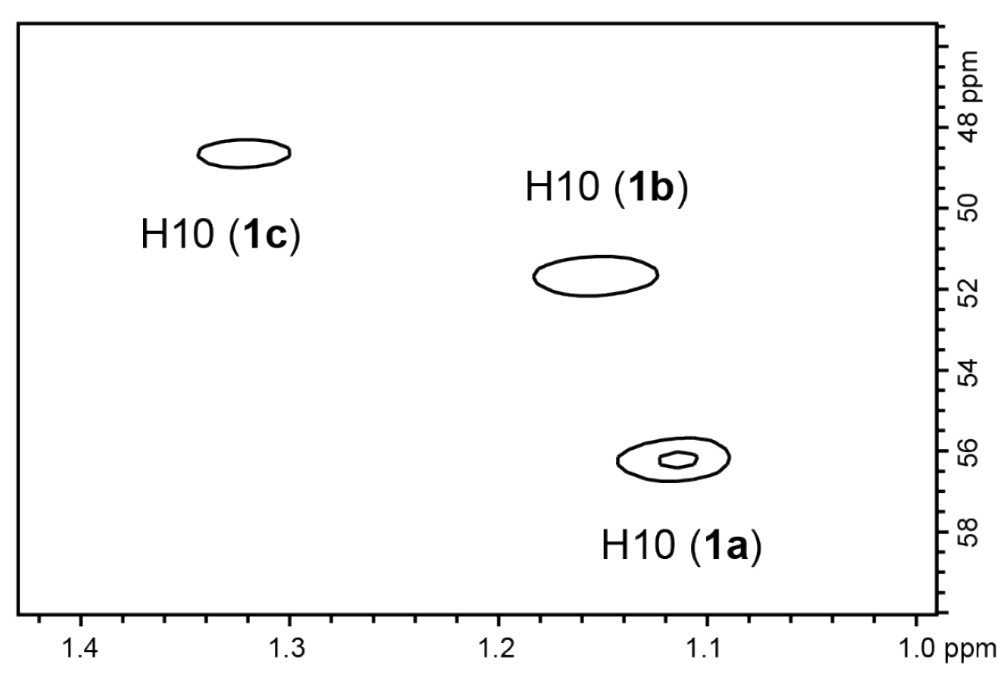

B)

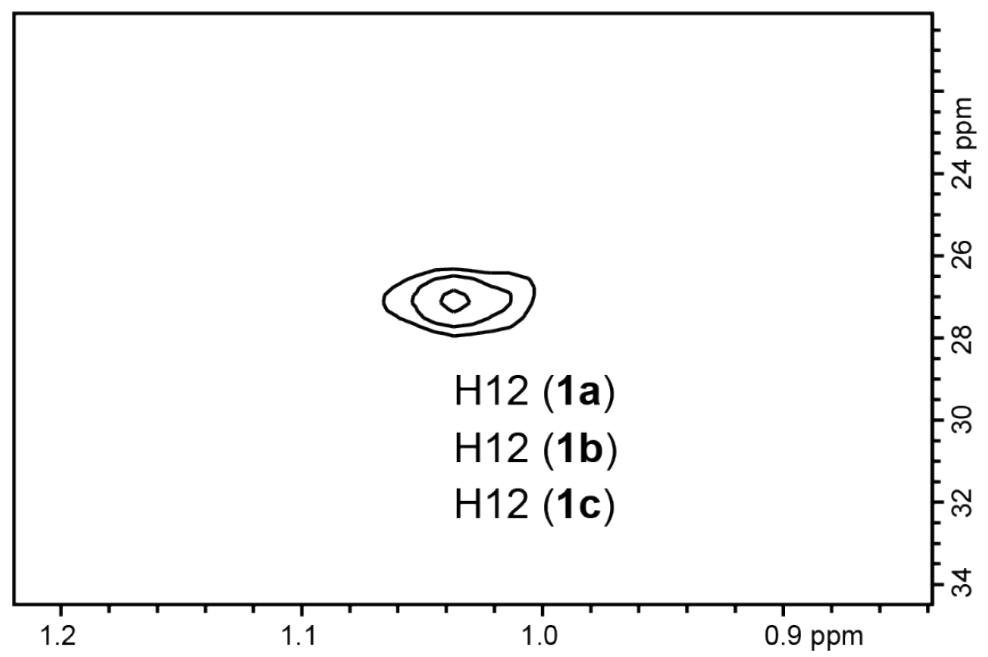

C)

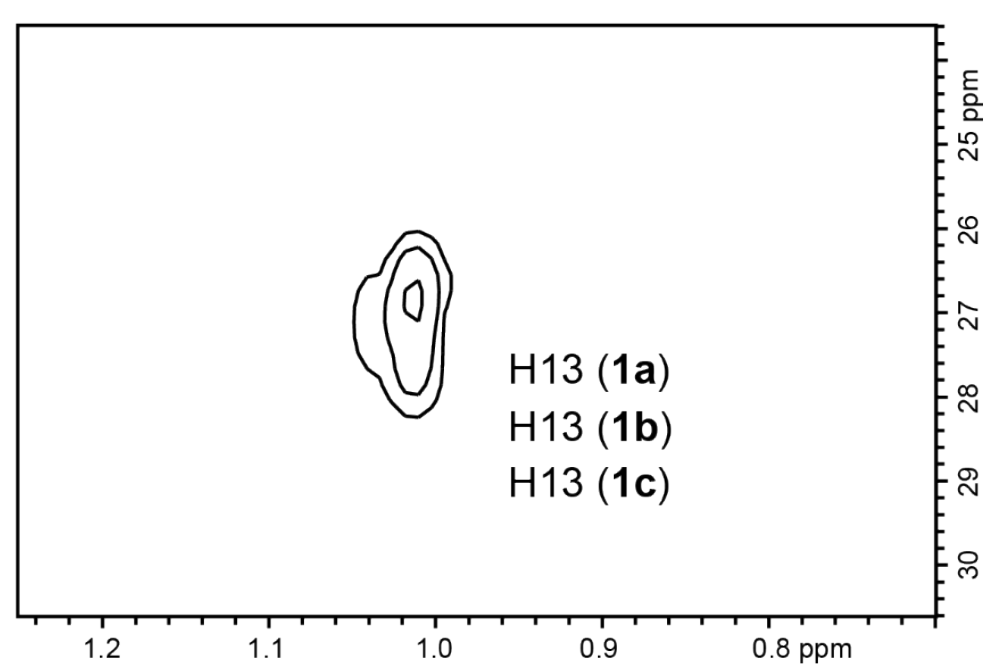

Figure S30. Partial HSQC spectra of $A)\left(10-{ }^{13} \mathrm{C}\right)-1$ obtained with HcS from $\left(10-{ }^{13} \mathrm{C}\right) \mathrm{FPP}$ showing the region for $\mathrm{C} 10$ of 1 , B) $\left(12-{ }^{13} \mathrm{C}\right)-1$ obtained with $\mathrm{HcS}$ from $\left(12-{ }^{13} \mathrm{C}\right) \mathrm{FPP}$ showing the region for $\mathrm{C} 12$ of 1 , and $\mathrm{C})\left(13^{13} \mathrm{C}\right)-\mathbf{1}$ obtained with $\mathrm{HcS}$ from $\left(13^{-13} \mathrm{C}\right) \mathrm{FPP}$ showing the region for $\mathrm{C} 13$ of 1 . 


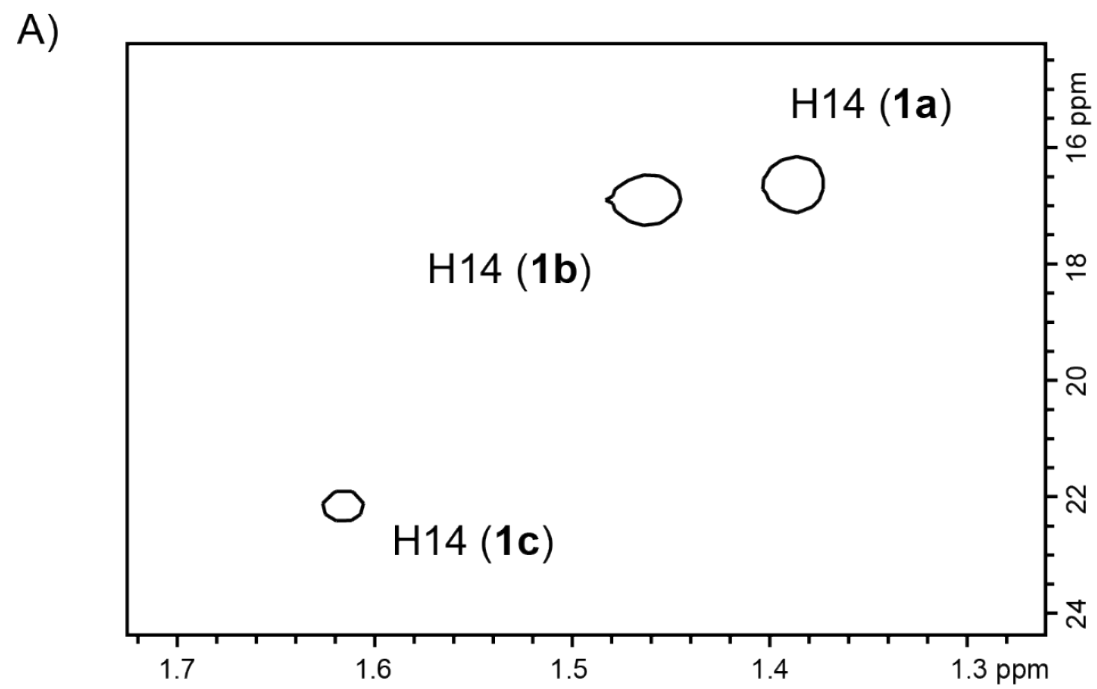

B)

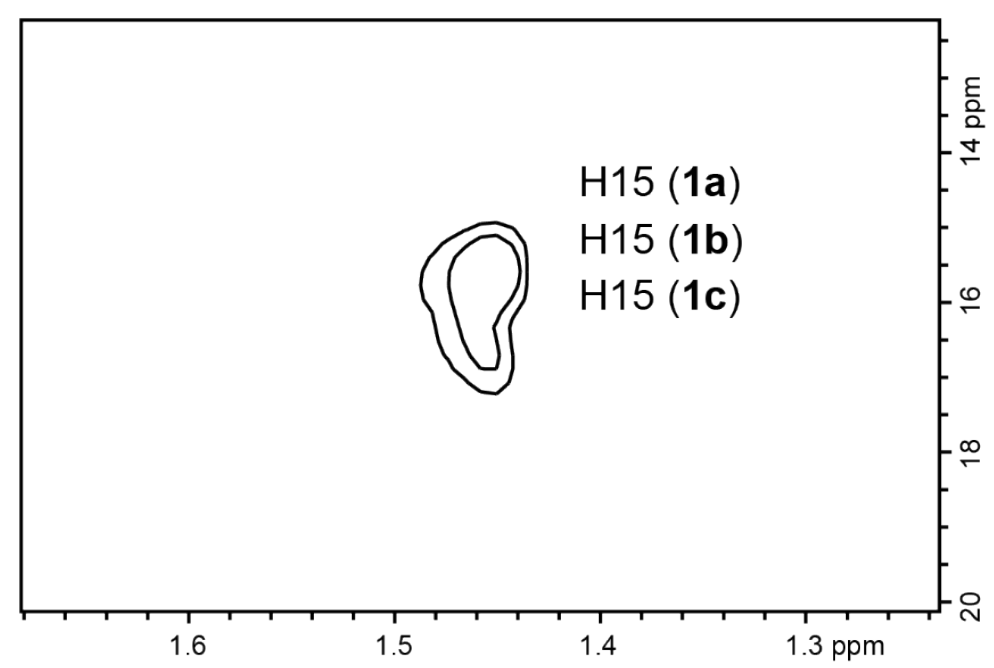

Figure S31. Partial HSQC spectra of A) $\left(14-{ }^{13} \mathrm{C}\right)-1$ obtained with HcS from $\left(14-{ }^{13} \mathrm{C}\right) \mathrm{FPP}$ showing the region for $\mathrm{C} 14$ of 1 , and $\mathrm{B})\left(15-{ }^{13} \mathrm{C}\right)-1$ obtained with $\mathrm{HcS}$ from $\left(15-{ }^{13} \mathrm{C}\right) \mathrm{FPP}$ showing the region for $\mathrm{C} 15$ of 1 . 
A)

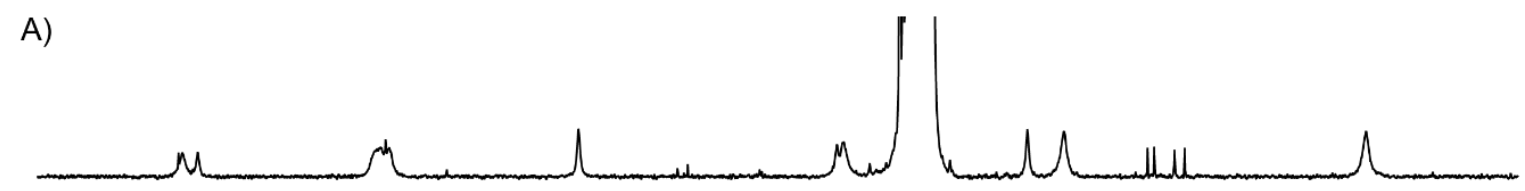

B)
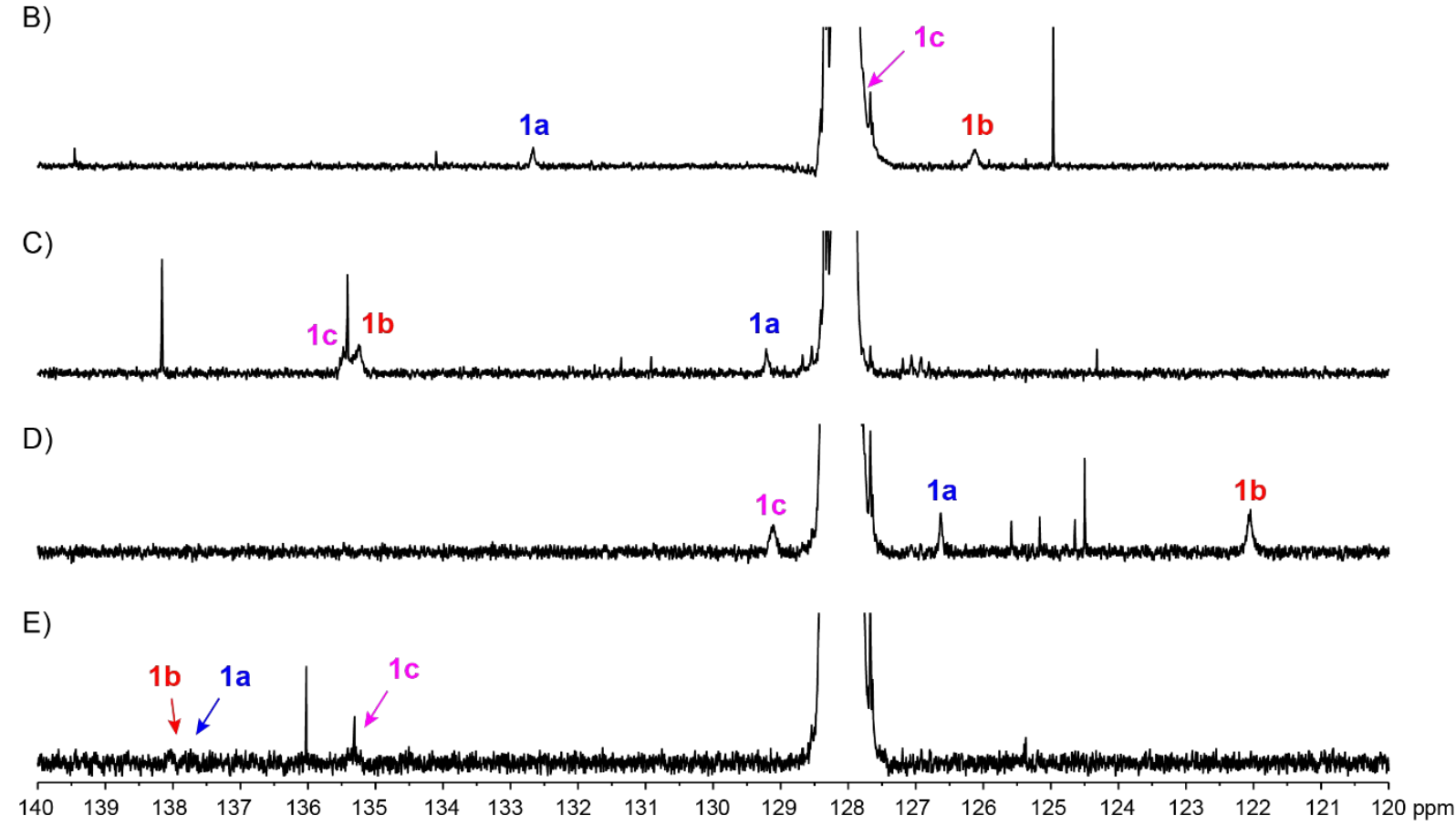

F)

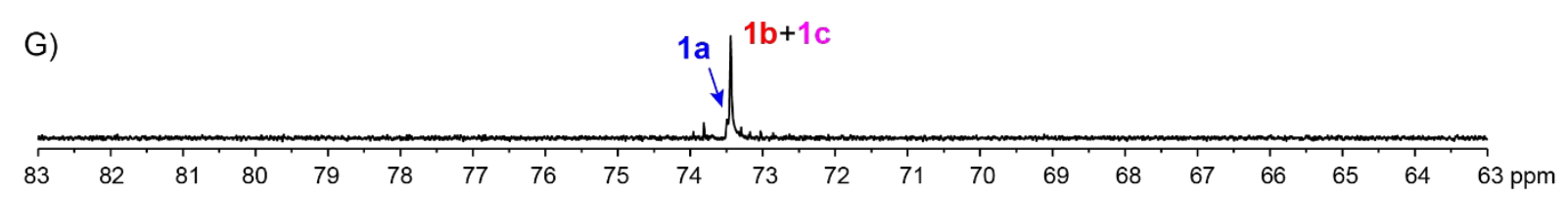

Figure S32. Partial ${ }^{13} \mathrm{C}-\mathrm{NMR}$ spectra of 1 obtained with PtTPS5-C403A. The olefinic region of A) unlabeled 1, B) $\left(2-{ }^{13} \mathrm{C}\right)-1$ obtained from $\left.\left(2-{ }^{13} \mathrm{C}\right) \mathrm{FPP}, \mathrm{C}\right)\left(3-{ }^{13} \mathrm{C}\right)-1$ obtained from $\left(3^{-13} \mathrm{C}\right) \mathrm{FPP}$, D) $\left(6-{ }^{13} \mathrm{C}\right)-1$ obtained from $\left(6-{ }^{13} \mathrm{C}\right) \mathrm{FPP}$, and $\left.\mathrm{E}\right)\left(7-{ }^{13} \mathrm{C}\right)-1$ obtained from $\left(7-{ }^{13} \mathrm{C}\right) \mathrm{FPP}$. The region for hydroxylated carbons of $F)$ unlabeled 1 , and $G)\left(11-{ }^{13} \mathrm{C}\right)-1$ obtained from $\left(11^{13} \mathrm{C}\right) \mathrm{FPP}$. 
A)

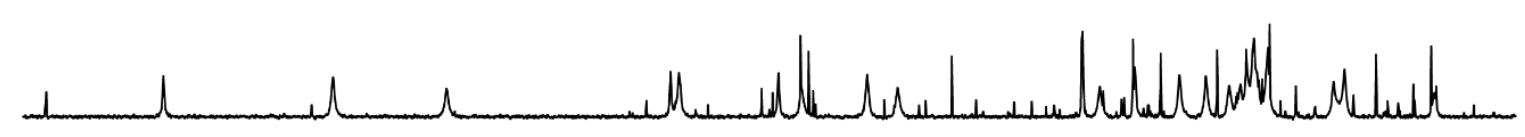

B)

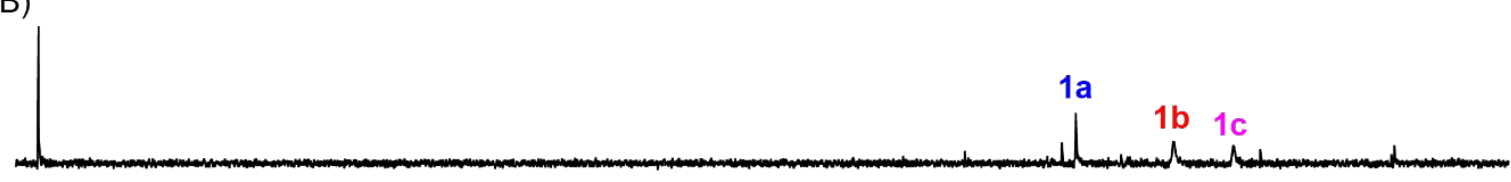

C)

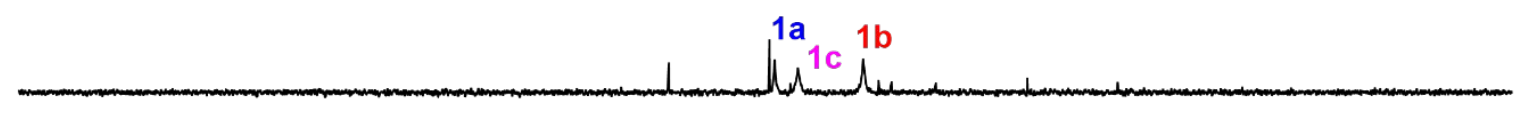

D)

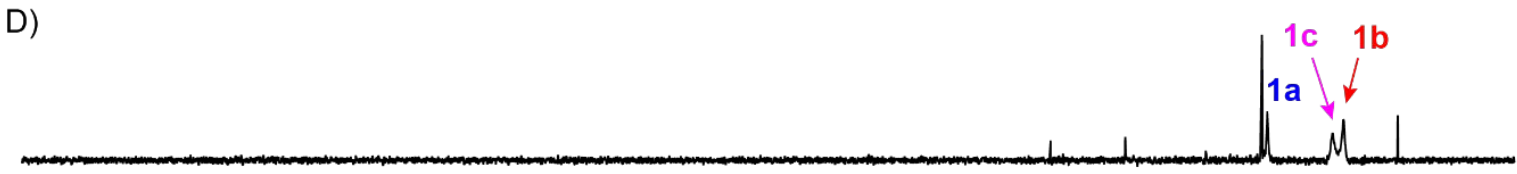

E)

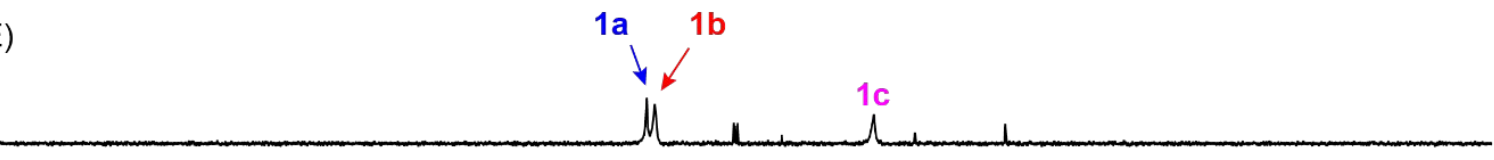

F)

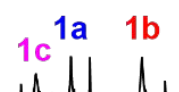

G)

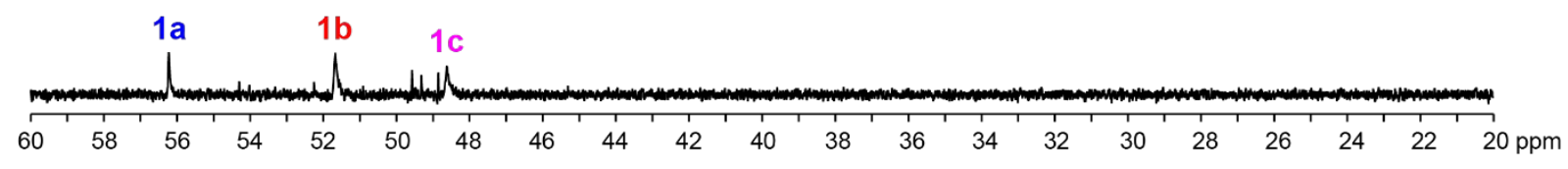

Figure S33. Partial ${ }^{13} \mathrm{C}-\mathrm{NMR}$ spectra of 1 obtained with PtTPS5-C403A. The methine and methylene group region of $A)$ unlabeled $1, B)\left(1-{ }^{13} C\right)-1$ obtained from $\left.\left(1-{ }^{13} C\right) F P P, C\right)\left(4-{ }^{13} C\right)-1$ obtained from $\left.\left(4-{ }^{13} \mathrm{C}\right) \mathrm{FPP}, \mathrm{D}\right)\left(5^{-{ }^{13} \mathrm{C}}\right)-1$ obtained from $\left.\left(5-{ }^{13} \mathrm{C}\right) \mathrm{FPP}, \mathrm{E}\right)\left(\mathrm{8}^{-13} \mathrm{C}\right)-1$ obtained from $\left.\left(8-{ }^{13} \mathrm{C}\right) \mathrm{FPP}, \mathrm{F}\right)\left(9-{ }^{13} \mathrm{C}\right)-1$ obtained from $\left(9-{ }^{13} \mathrm{C}\right) \mathrm{FPP}$, and $\left.\mathrm{G}\right)\left(10-{ }^{13} \mathrm{C}\right)-1$ obtained from $(10-$ $\left.{ }^{13} \mathrm{C}\right) \mathrm{FPP}$. 
A)

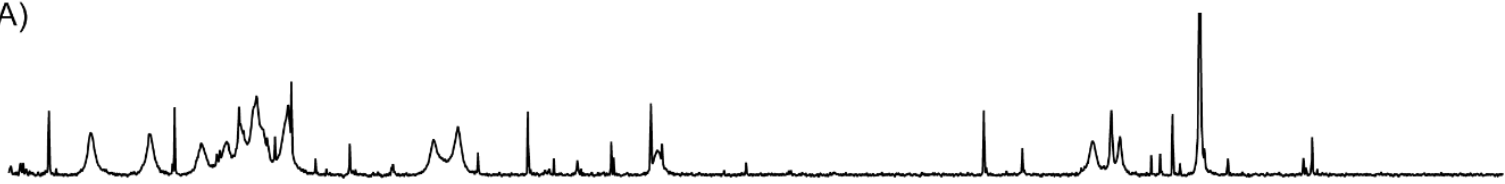

B)

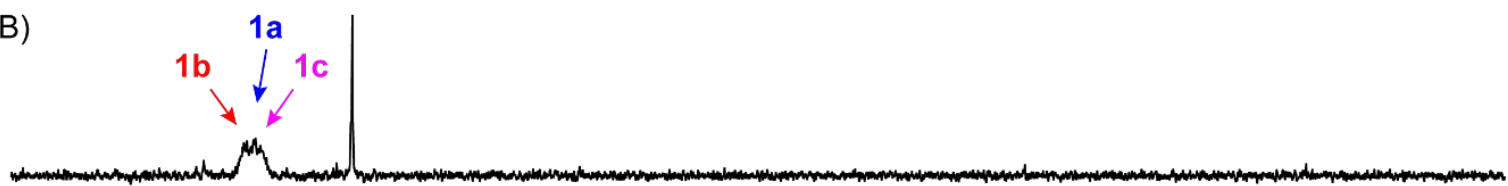

C)

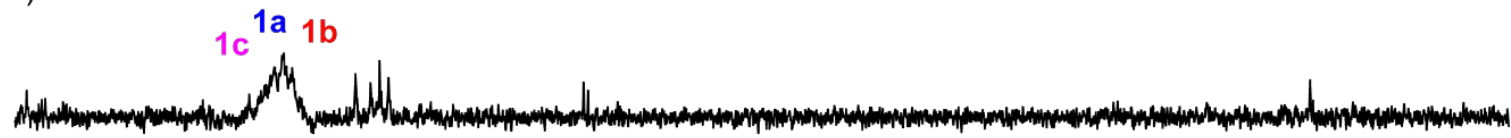

D)

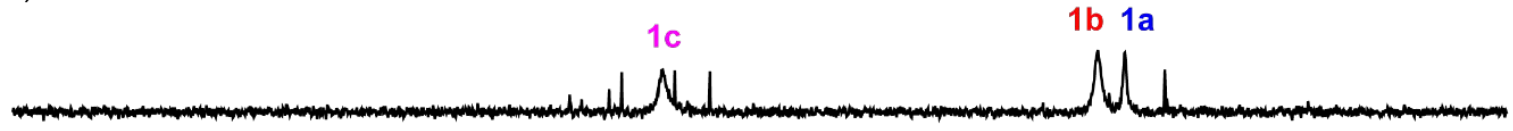

E)

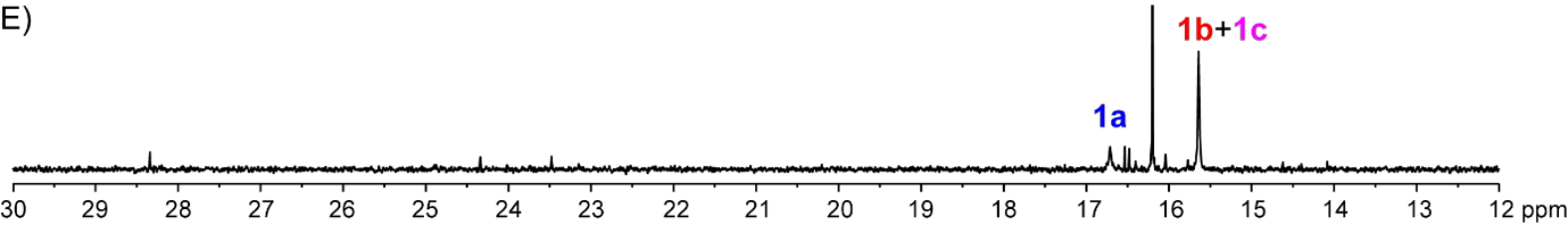

Figure S34. Partial ${ }^{13} \mathrm{C}-\mathrm{NMR}$ spectra of 1 obtained with PtTPS5-C403A. The methyl group region of $A$ ) unlabeled $1, B)\left(12-{ }^{13} \mathrm{C}\right)-1$ obtained from $\left.\left(12-{ }^{13} \mathrm{C}\right) \mathrm{FPP}, \mathrm{C}\right)\left(13-{ }^{-13} \mathrm{C}\right)-1$ obtained from $\left.\left(13-{ }^{13} \mathrm{C}\right) \mathrm{FPP}, \mathrm{D}\right)\left(14-{ }^{13} \mathrm{C}\right)-1$ obtained from $\left(14-{ }^{13} \mathrm{C}\right) \mathrm{FPP}$, and $\left.\mathrm{E}\right)\left(15^{-13} \mathrm{C}\right)-1$ obtained from (15$\left.{ }^{13} \mathrm{C}\right) \mathrm{FPP}$. 


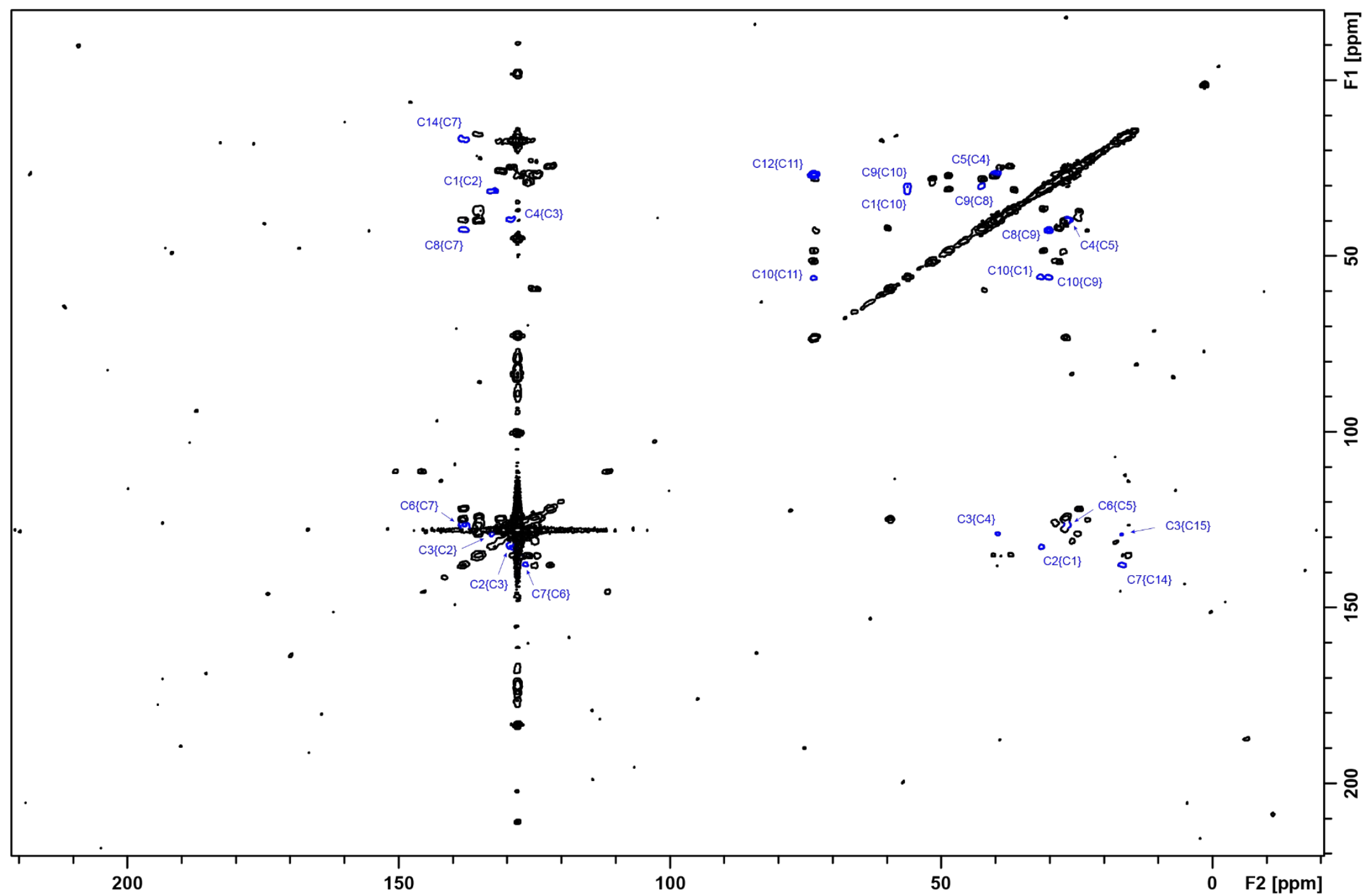

Figure S35. ${ }^{13} \mathrm{C},{ }^{13} \mathrm{C}-\mathrm{COSY}$ NMR of $\left({ }^{13} \mathrm{C}_{15}\right)-1$ obtained with PtTPS5-C403A from $\left({ }^{13} \mathrm{C}{ }_{15}\right)$ FPP. The crosspeaks colored in blue form a contiguous spin system of conformer $\mathbf{1 a}$. 


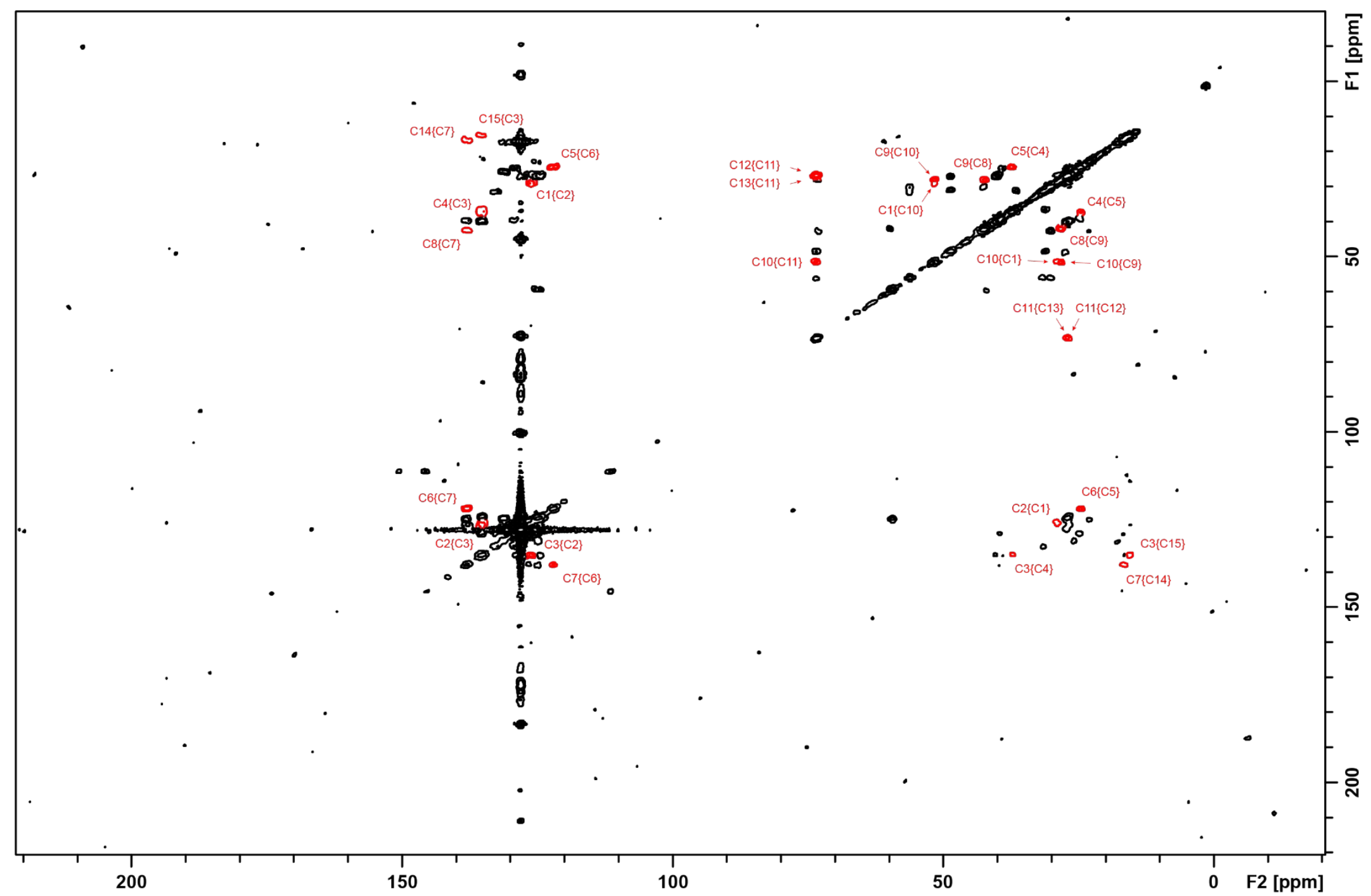

Figure S36. ${ }^{13} \mathrm{C},{ }^{13} \mathrm{C}$-COSY NMR of $\left({ }^{13} \mathrm{C}_{15}\right)$-1 obtained with PtTPS5-C403A from $\left({ }^{13} \mathrm{C}_{15}\right)$ FPP. The crosspeaks colored in red form a contiguous spin system of conformer $\mathbf{1 b}$. 


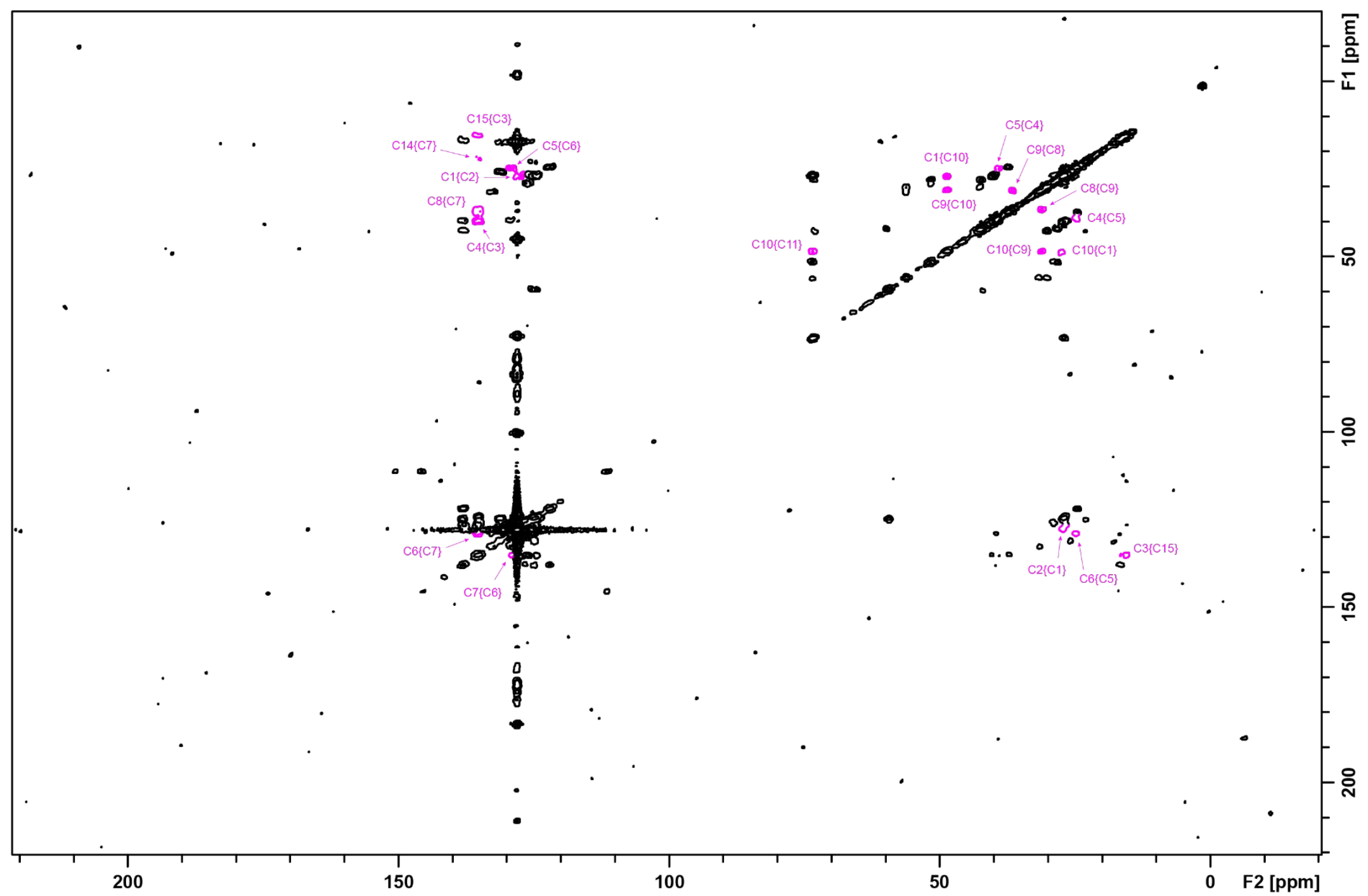

Figure S37. ${ }^{13} \mathrm{C},{ }^{13} \mathrm{C}$-COSY NMR of $\left({ }^{13} \mathrm{C}_{15}\right)-1$ obtained with PtTPS5-C403A from $\left({ }^{13} \mathrm{C}{ }_{15}\right)$ FPP. The crosspeaks colored in purple form a contiguous spin system of conformer $1 \mathrm{c}$. 
Cope rearrangements of labeled compounds

For the labeled isotopomers of 1, the Cope rearrangement reactions (entries $41-63$ in Table S3) were carried out in the NMR solvent $\mathrm{C}_{6} \mathrm{D}_{6}(1.0 \mathrm{~mL})$. The corresponding labeled hedycaryol solutions were transferred to a pressure tube ( $2 \mathrm{~mL}$; Ace Glass, Vineland, NJ, USA), closed and heated to $130{ }^{\circ} \mathrm{C}$ with oil bath for $3 \mathrm{~h}$. The samples were then carefully concentrated to ca. $0.5 \mathrm{~mL} \mathrm{C}_{6} \mathrm{D}_{6}$ under a stream of argon and analyzed by GC/MS and NMR. 


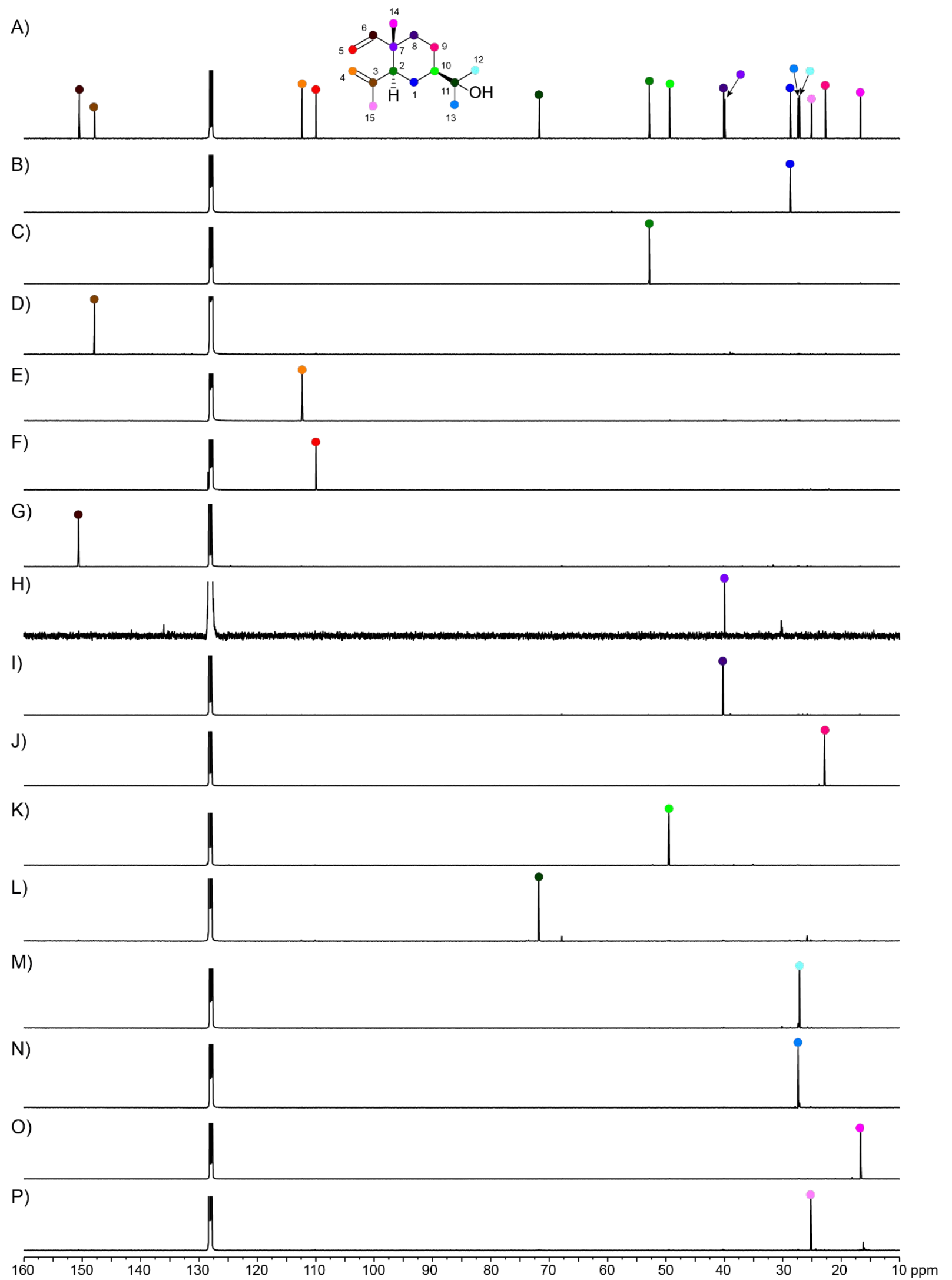

Figure S38. ${ }^{13} \mathrm{C}$-NMR spectra of $\left.A\right)$ unlabeled 2 and $\left.B\right)-P$ ) the 15 isotopomers of $\left({ }^{13} C\right)-2$ obtained by Cope rearrangement of the corresponding isotopomers of 1 . The spectra in $B$ ) $\mathrm{P})$ are for compounds obtained from $\left(1-{ }^{13} \mathrm{C}\right) \mathrm{FPP}-\left(15-{ }^{13} \mathrm{C}\right) \mathrm{FPP}$ in the order of increasing carbon number. Carbon numbering of 2 follows FPP numbering. 


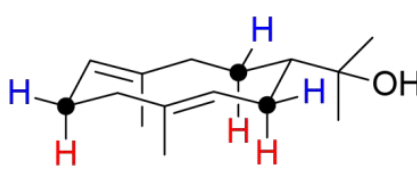

$(S)-1$

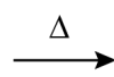

(-

$(+)-2$

A)

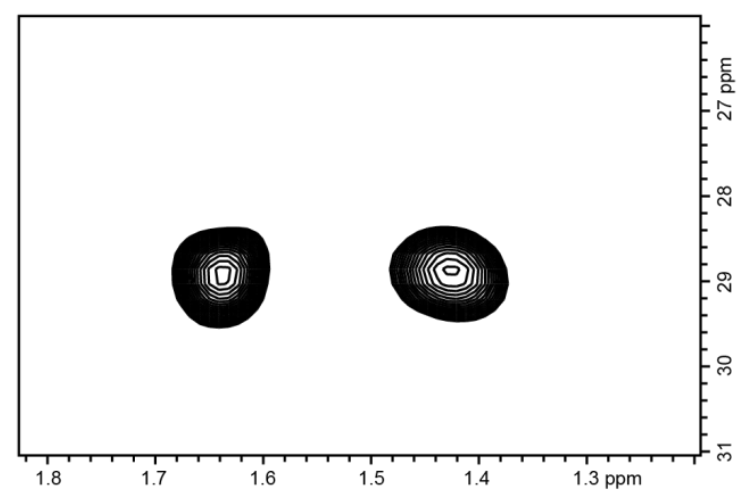

B) $\mathrm{H}={ }^{2} \mathrm{H}$

$(+)-2$

$(-)-2$
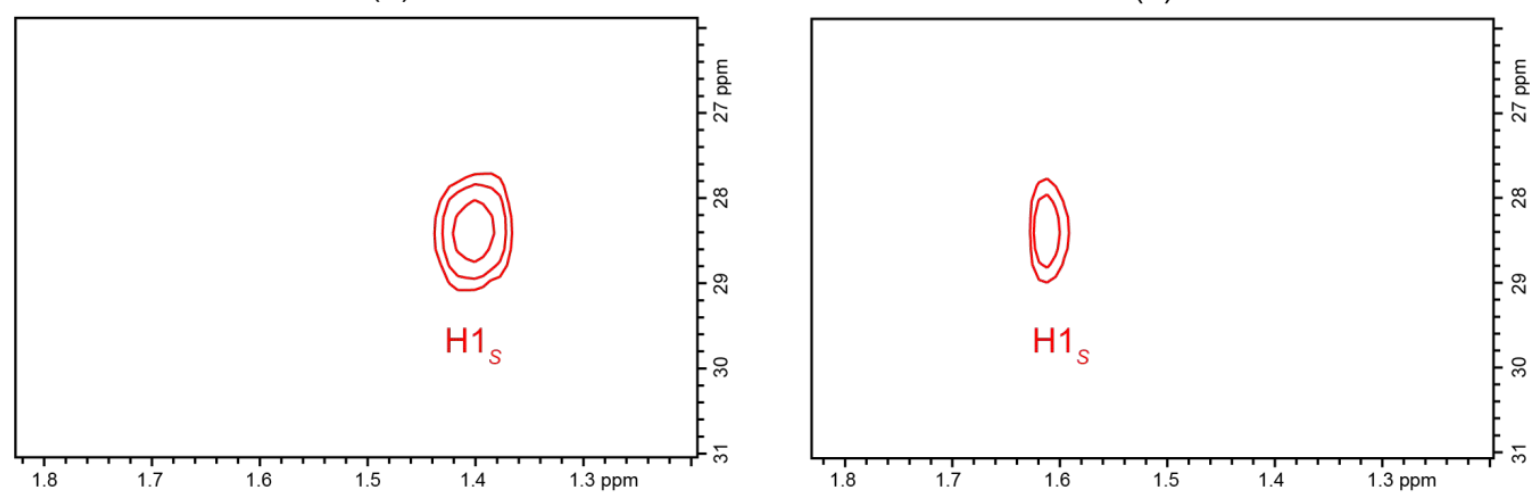

C) $\mathrm{H}={ }^{2} \mathrm{H}$
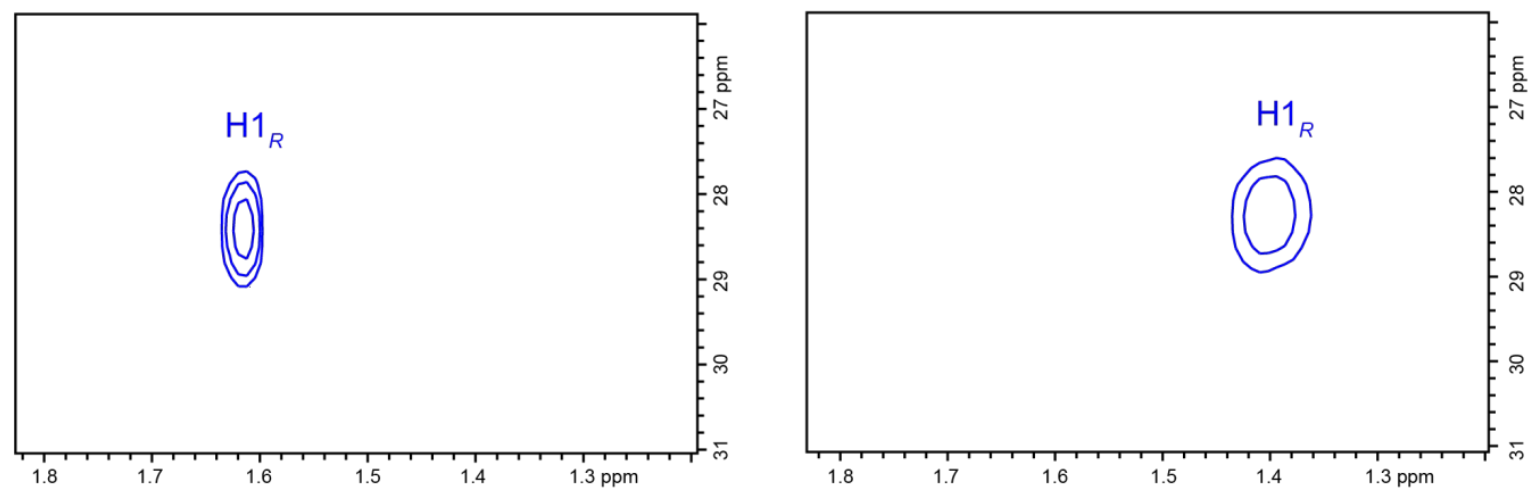

Figure S39. HSQC spectra of Cope rearrangement products of $\left.A)\left(1-{ }^{13} \mathrm{C}\right)-1, B\right)$ $(1 \mathrm{~S}, 5 R, 9 R, 10 S)-\left(1,5,9-{ }^{13} \mathrm{C}_{3}, 1,5,9-{ }^{2} \mathrm{H}_{3}\right)-1$ obtained from $(R)-\left(1-{ }^{13} \mathrm{C}, 1-{ }^{2} \mathrm{H}\right) \mathrm{IPP}$ with $\mathrm{HcS}$ (left) and $(1 S, 5 R, 9 R, 10 R)-\left(1,5,9-{ }^{13} \mathrm{C}_{3}, 1,5,9-{ }^{2} \mathrm{H}_{3}\right)-1$ obtained from $(R)-\left(1-{ }^{13} \mathrm{C}, 1-{ }^{2} \mathrm{H}\right)$ IPP with PtTPS5C403A (right), and C) $(1 R, 5 S, 9 S, 10 S)-\left(1,5,9-{ }^{13} \mathrm{C}_{3}, 1,5,9-{ }^{2} \mathrm{H}_{3}\right)-1$ obtained from $(S)-\left(1-{ }^{13} \mathrm{C}, 1-\right.$ $\left.{ }^{2} \mathrm{H}\right) \mathrm{IPP}$ with $\mathrm{HcS}$ (left) and $(1 R, 5 S, 9 S, 10 R)-\left(1,5,9-{ }^{13} \mathrm{C}_{3}, 1,5,9-{ }^{2} \mathrm{H}_{3}\right)-1$ obtained from $(S)-\left(1-{ }^{13} \mathrm{C}, 1-\right.$ $\left.{ }^{2} \mathrm{H}\right)$ IPP with PtTPS5-C403A (right). Black dots represent ${ }^{13} \mathrm{C}$-labeled carbons. Crosspeaks of deuterated carbons are slightly upfield shifted in both dimensions. 


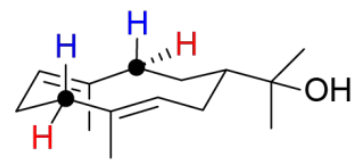

$(S)-1$
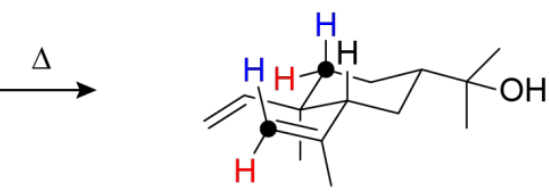

$(+)-2$

A)

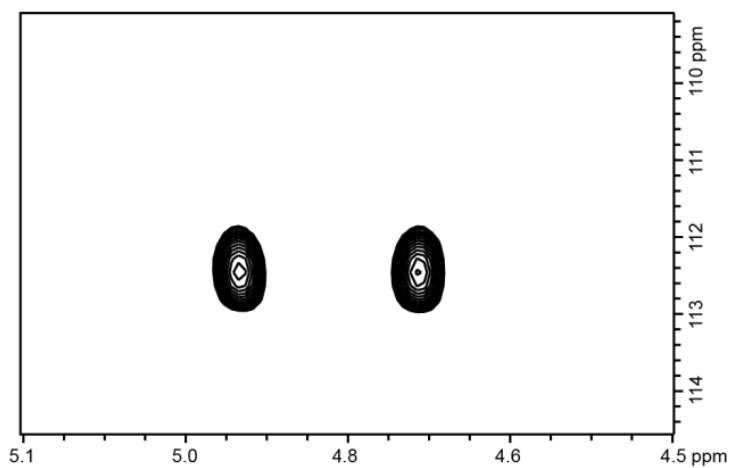

B) $\mathrm{H}={ }^{2} \mathrm{H}$

$(+)-2$

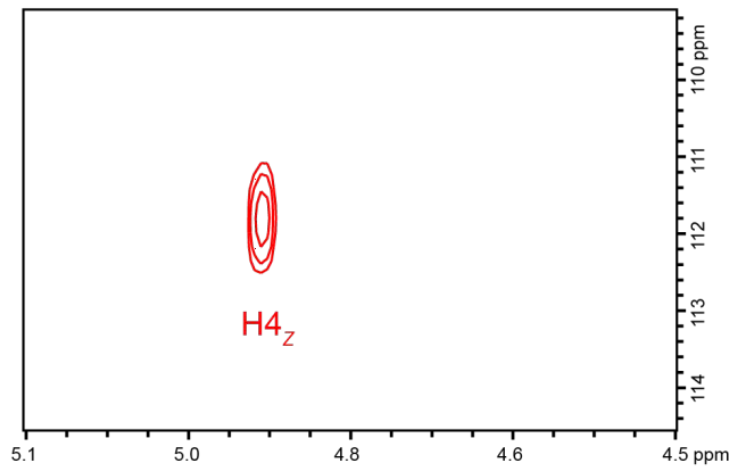

C) $\mathrm{H}={ }^{2} \mathrm{H}$

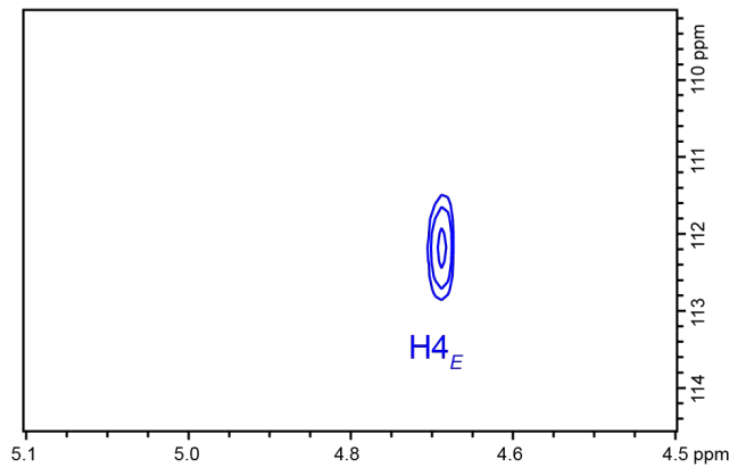

$(-)-2$
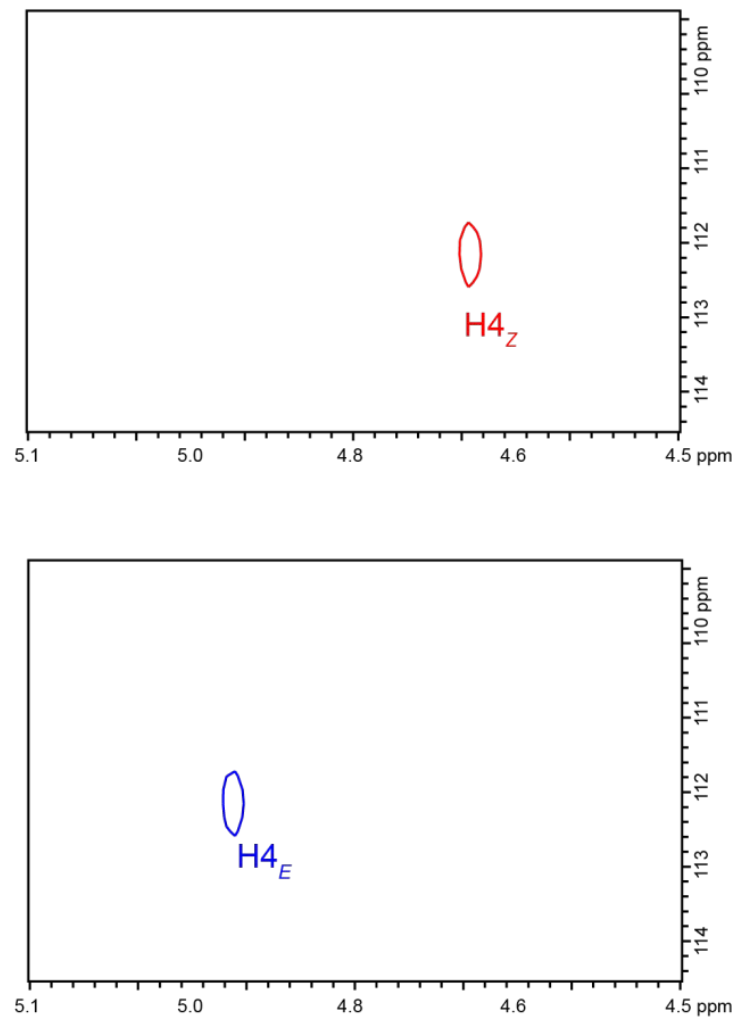

Figure S40. HSQC spectra of Cope rearrangement products of A) $\left(4-{ }^{13} \mathrm{C}\right)-1$, B) $(4 S, 8 S, 10 S)$ $\left(4,8-{ }^{13} \mathrm{C}_{2}, 4,8-{ }^{2} \mathrm{H}_{2}\right)-1$ obtained from $(E)-\left(4-{ }^{13} \mathrm{C}, 4-2 \mathrm{H}\right) \mathrm{IPP}$ with $\mathrm{HcS}$ (left) and $(4 S, 8 S, 10 R)-(4,8-$ $\left.{ }^{13} \mathrm{C}_{2}, 4,8-{ }^{2} \mathrm{H}_{2}\right)-1$ obtained from $(E)-\left(4-{ }^{13} \mathrm{C}, 4-{ }^{2} \mathrm{H}\right)$ IPP with PtTPS5-C403A (right), and $\mathrm{C}$ ) $(4 R, 8 R, 10 S)-\left(4,8-{ }^{13} \mathrm{C}_{2}, 4,8-{ }^{2} \mathrm{H}_{2}\right)-1$ obtained from (Z)-(4-13 C,4-2 $\left.\mathrm{H}\right)$ IPP with HcS (left) and $(4 R, 8 R, 10 R)-\left(4,8-{ }^{13} \mathrm{C}_{2}, 4,8-{ }^{2} \mathrm{H}_{2}\right)-1$ obtained from $(\mathrm{Z})-\left(4-{ }^{13} \mathrm{C}, 4-{ }^{2} \mathrm{H}\right)$ IPP with PtTPS5-C403A (right). Black dots represent ${ }^{13} \mathrm{C}$-labeled carbons. Crosspeaks of deuterated carbons are slightly upfield shifted in both dimensions. 


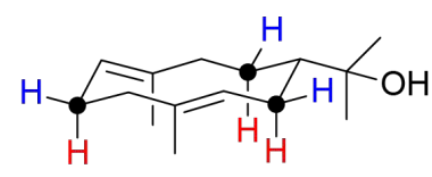

(S)-1

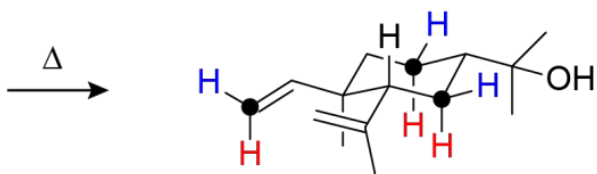

(+)-2

A)

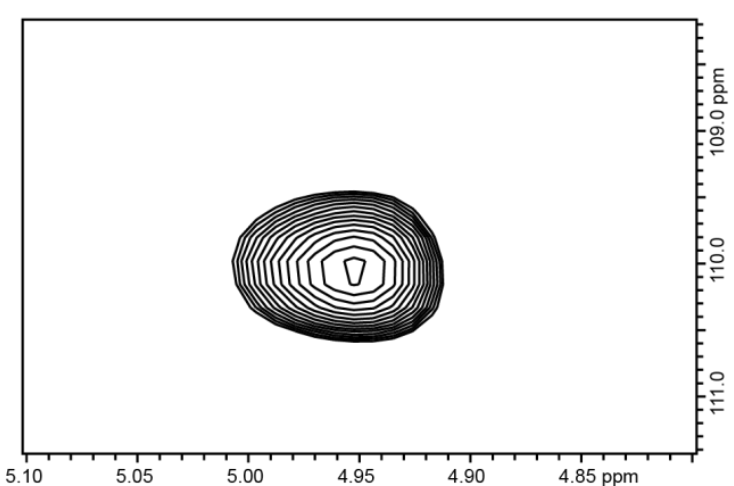

B) $\mathrm{H}={ }^{2} \mathrm{H}$

$(+)-2$

$(-)-2$

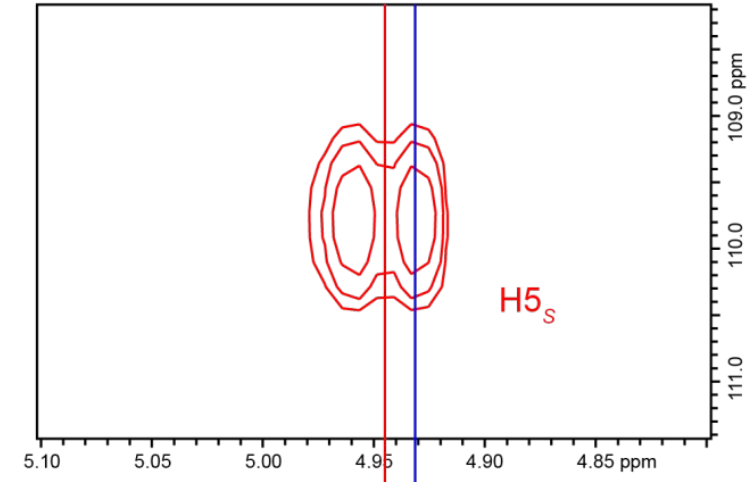

C) $\mathrm{H}={ }^{2} \mathrm{H}$
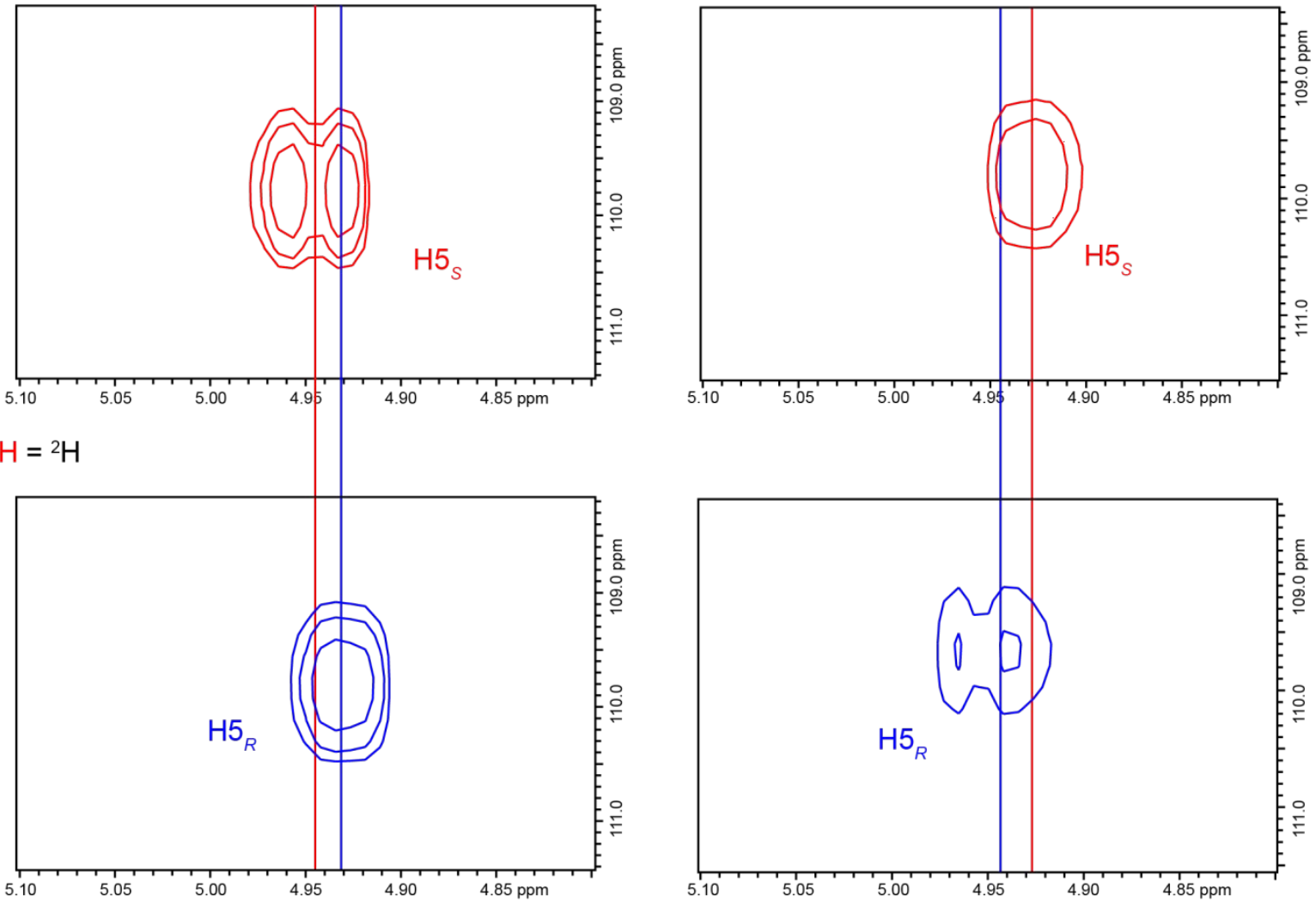

Figure S41. HSQC spectra of Cope rearrangement products of $\left.A)\left(5-{ }^{13} \mathrm{C}\right)-1, \mathrm{~B}\right)$ $(1 \mathrm{~S}, 5 R, 9 R, 10 S)-\left(1,5,9-{ }^{13} \mathrm{C}_{3}, 1,5,9-2 \mathrm{H}_{3}\right)-1$ obtained from $(R)-\left(1-{ }^{13} \mathrm{C}, 1-{ }^{2} \mathrm{H}\right) \mathrm{IPP}$ with $\mathrm{HcS}$ (left) and $(1 S, 5 R, 9 R, 10 R)-\left(1,5,9-{ }^{13} \mathrm{C}_{3}, 1,5,9-{ }^{2} \mathrm{H}_{3}\right)-1$ obtained from $(R)-\left(1-{ }^{13} \mathrm{C}, 1-2 \mathrm{H}\right)$ IPP with PtTPS5C403A (right), and C) $(1 R, 5 S, 9 S, 10 S)-\left(1,5,9-{ }^{13} \mathrm{C}_{3}, 1,5,9-{ }^{2} \mathrm{H}_{3}\right)-1$ obtained from $(S)-\left(1-{ }^{13} \mathrm{C}, 1-\right.$ $\left.{ }^{2} \mathrm{H}\right) \mathrm{IPP}$ with $\mathrm{HcS}$ (left) and $(1 R, 5 S, 9 S, 10 R)-\left(1,5,9-{ }^{13} \mathrm{C}_{3}, 1,5,9-{ }^{2} \mathrm{H}_{3}\right)-1$ obtained from $(S)-\left(1-{ }^{13} \mathrm{C}, 1-\right.$ $\left.{ }^{2} \mathrm{H}\right)$ IPP with PtTPS5-C403A (right). Black dots represent ${ }^{13} \mathrm{C}$-labeled carbons. Crosspeaks of deuterated carbons are slightly upfield shifted in both dimensions. 


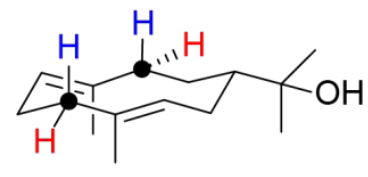

$(S)-1$

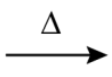

A)

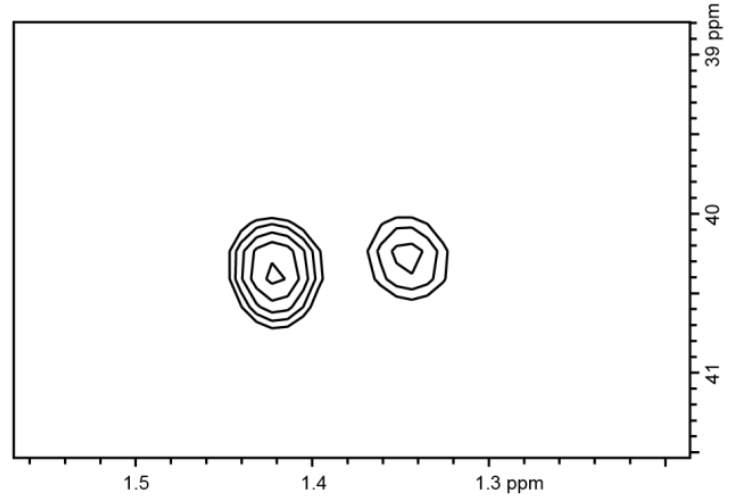

B) $\mathrm{H}={ }^{2} \mathrm{H}$

$(+)-2$

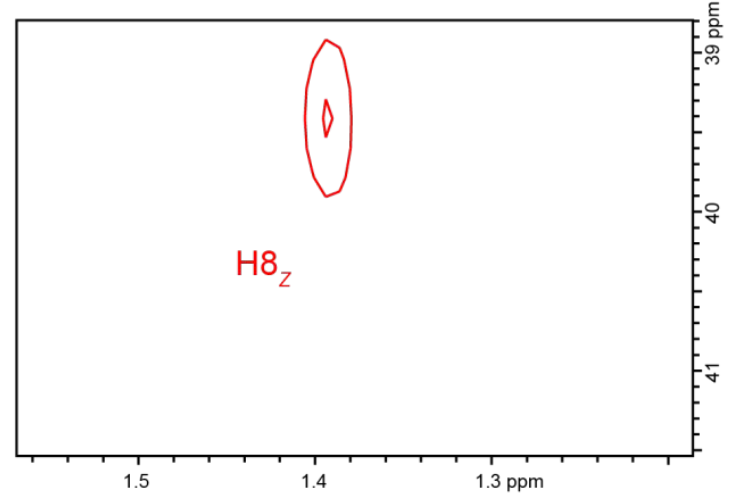

C) $\mathrm{H}={ }^{2} \mathrm{H}$

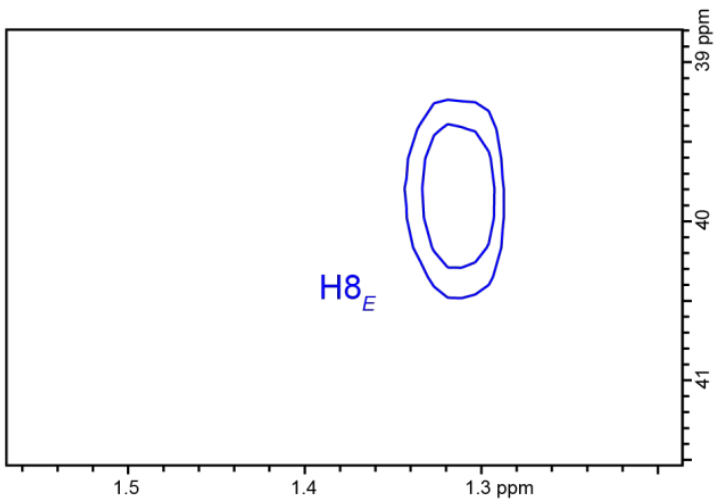

$(-)-2$
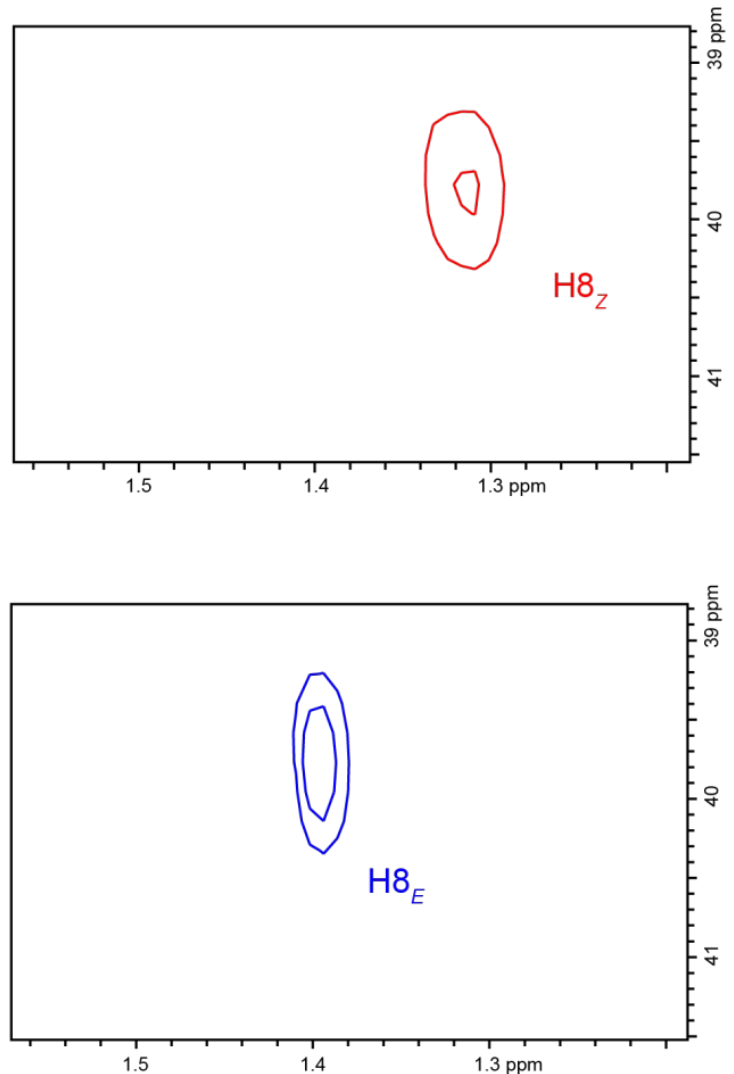

Figure S42. HSQC spectra of Cope rearrangement products of A) $\left.\left(8-{ }^{13} \mathrm{C}\right)-1, \mathrm{~B}\right)(4 S, 8 S, 10 S)$ $\left(4,8-{ }^{13} \mathrm{C}_{2}, 4,8-{ }^{2} \mathrm{H}_{2}\right)-1$ obtained from $(E)-\left(4-{ }^{13} \mathrm{C}, 4-{ }^{2} \mathrm{H}\right) \mathrm{IPP}$ with $\mathrm{HcS}$ (left) and $(4 S, 8 S, 10 R)-(4,8-$ $\left.{ }^{13} \mathrm{C}_{2}, 4,8-{ }^{2} \mathrm{H}_{2}\right)-1$ obtained from $(E)-\left(4-{ }^{13} \mathrm{C}, 4-{ }^{2} \mathrm{H}\right)$ IPP with PtTPS5-C403A (right), and $\mathrm{C}$ ) $(4 R, 8 R, 10 S)-\left(4,8-{ }^{13} \mathrm{C}_{2}, 4,8-{ }^{2} \mathrm{H}_{2}\right)-1$ obtained from (Z)- $\left(4-{ }^{13} \mathrm{C}, 4-{ }^{2} \mathrm{H}\right)$ IPP with HcS (left) and $(4 R, 8 R, 10 R)-\left(4,8-{ }^{13} \mathrm{C}_{2}, 4,8-{ }^{2} \mathrm{H}_{2}\right)-1$ obtained from (Z)-(4-13 $\left.\mathrm{C}, 4-{ }^{2} \mathrm{H}\right)$ IPP with PtTPS5-C403A (right). Black dots represent ${ }^{13} \mathrm{C}$-labeled carbons. Crosspeaks of deuterated carbons are slightly upfield shifted in both dimensions. 


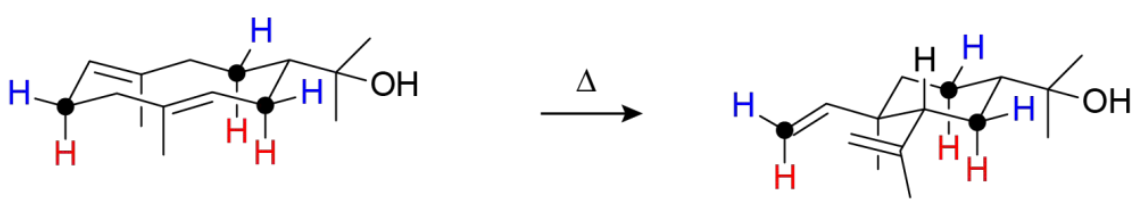

$(S)-1$

$(+)-2$

A)

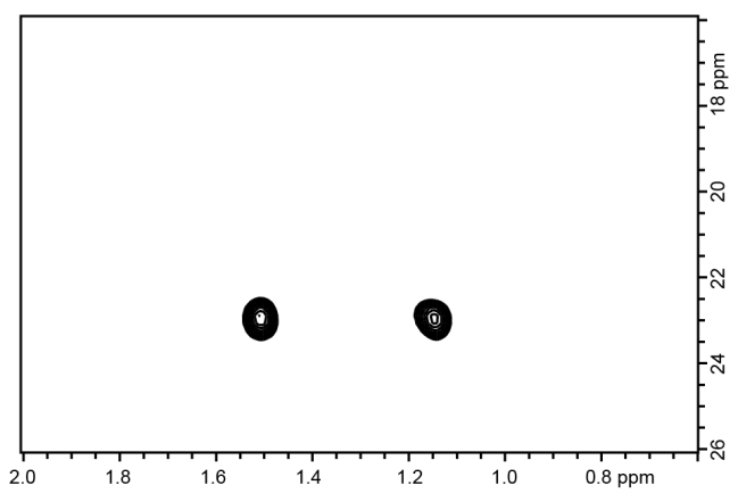

B) $\mathrm{H}={ }^{2} \mathrm{H}$

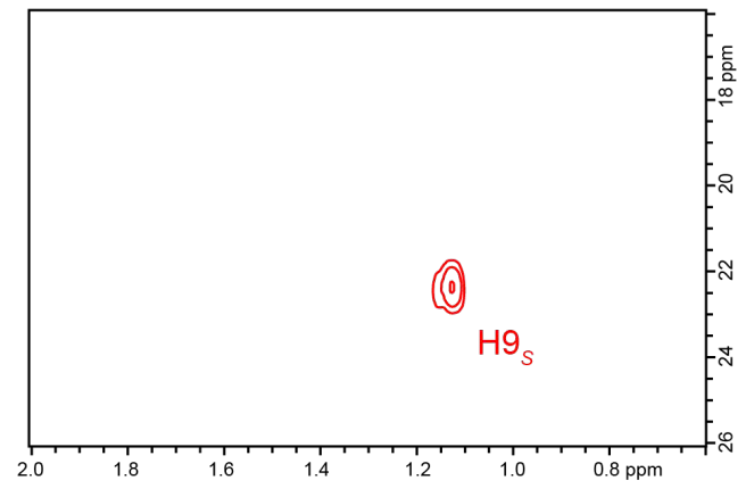

$(-)-2$

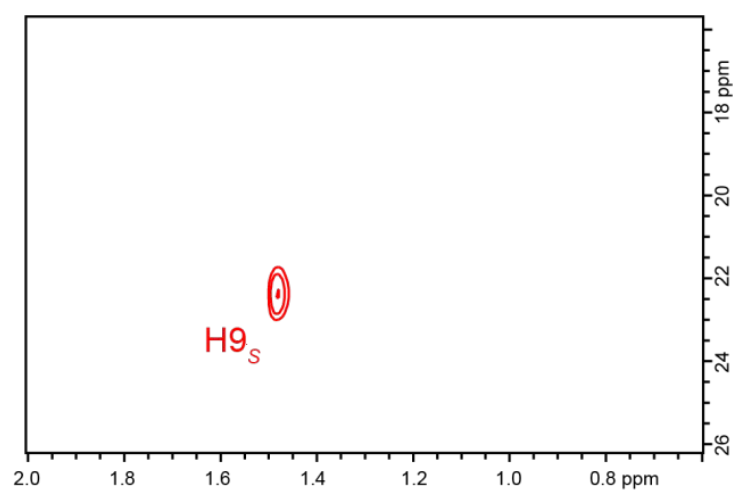

C) $\mathrm{H}={ }^{2} \mathrm{H}$
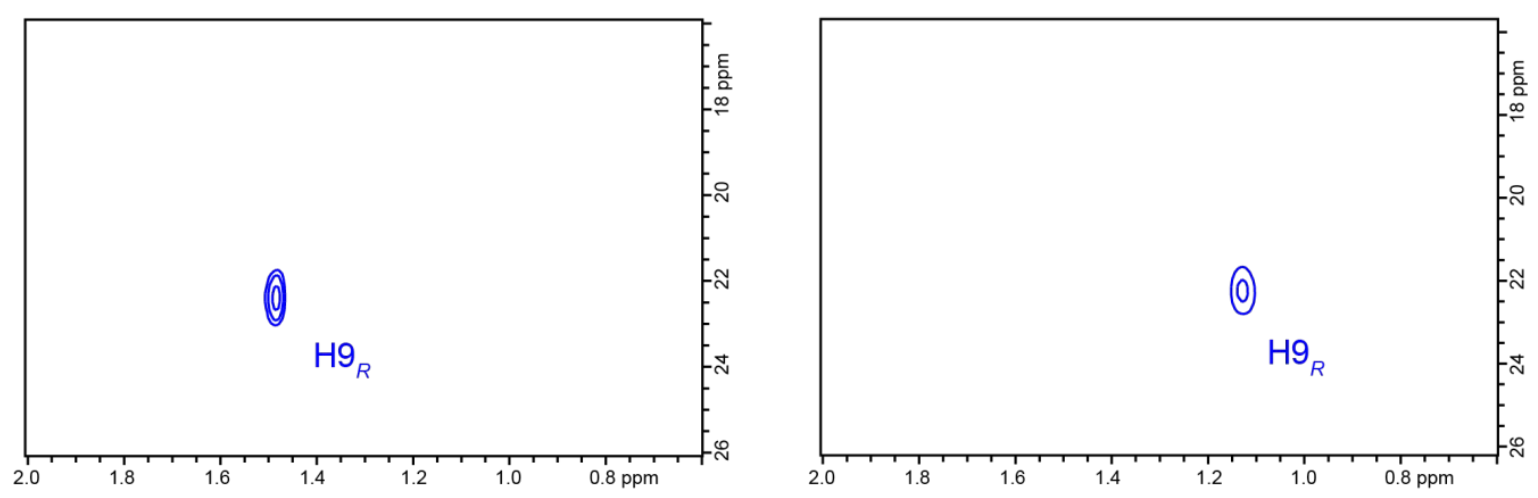

Figure S43. HSQC spectra of Cope rearrangement products of A) $\left(9-{ }^{13} \mathrm{C}\right)-1$, B) $(1 \mathrm{~S}, 5 R, 9 R, 10 S)-\left(1,5,9-{ }^{13} \mathrm{C}_{3}, 1,5,9-{ }^{2} \mathrm{H}_{3}\right)-1$ obtained from $(R)-\left(1-{ }^{13} \mathrm{C}, 1-{ }^{2} \mathrm{H}\right)$ IPP with $\mathrm{HcS}$ (left) and $(1 S, 5 R, 9 R, 10 R)-\left(1,5,9-{ }^{13} \mathrm{C}_{3}, 1,5,9-{ }^{2} \mathrm{H}_{3}\right)-1$ obtained from $(R)-\left(1-{ }^{13} \mathrm{C}, 1-{ }^{2} \mathrm{H}\right)$ IPP with PtTPS5C403A (right), and C) $(1 R, 5 S, 9 S, 10 S)-\left(1,5,9-{ }^{13} \mathrm{C}_{3}, 1,5,9-{ }^{2} \mathrm{H}_{3}\right)-1$ obtained from $(S)-\left(1-{ }^{13} \mathrm{C}, 1-\right.$ $\left.{ }^{2} \mathrm{H}\right) \mathrm{IPP}$ with $\mathrm{HcS}$ (left) and $(1 R, 5 S, 9 S, 10 R)-\left(1,5,9-{ }^{13} \mathrm{C}_{3}, 1,5,9-{ }^{2} \mathrm{H}_{3}\right)-1$ obtained from $(S)-\left(1-{ }^{13} \mathrm{C}, 1-\right.$ $\left.{ }^{2} \mathrm{H}\right)$ IPP with PtTPS5-C403A (right). Black dots represent ${ }^{13} \mathrm{C}$-labeled carbons. Crosspeaks of deuterated carbons are slightly upfield shifted in both dimensions. 


\section{References}

[1] Fulmer, G. R.; Miller, A. J. M.; Sherden, N. H.; Gottlieb, H. E.; Nudelman, A.; Stoltz, B. M.; Bercaw, J. E.; Goldberg, K. I. Organometallics 2010, 29, 2176-2179.

[2] Rabe, P.; Barra, L.; Rinkel, J.; Riclea, R.; Citron, C. A., Klapschinski, T. A.; Janusko, A.; Dickschat, J. S. Angew. Chem. Int. Ed. 2015, 54, 13448-13451.

[3] Baer, P.; Rabe, P.; Citron, C. A.; de Oliveira Mann, C. C.; Kaufmann, N.; Groll, M.; Dickschat, J. S. ChemBioChem 2014, 15, 213-216.

[4] Bian, G.; Rinkel, J.; Wang, Z.; Lauterbach, L.; Hou, A.; Yuan, Y.; Deng, Z.; Liu, T.; Dickschat, J. S. Angew. Chem. Int. Ed. 2018, 57, 15887-15890.

[5] Rabe, P.; Rinkel, J.; Nubbemeyer, B.; Köllner, T. G.; Chen, F.; Dickschat, J. S. Angew. Chem. Int. Ed. 2016, 55, 15420-15423.

[6] Rinkel, J.; Dickschat, J. S. Org. Lett. 2019, 21, 2426-2429.

[7] Hahn, F. M.; Hurlburt, A. P.; Poulter, C. D. J. Bacteriol. 1999, 181, 4499-4504.

[8] Lauterbach, L.; Rinkel, J.; Dickschat, J. S. Angew. Chem. Int. Ed. 2018, 57, 8280-8283. 